\title{
Trypanosomatids: Odd Organisms, Devastating Diseases
}

\author{
Angela H. Lopes*,1, Thaïs Souto-Padrón ${ }^{1}$, Felipe A. Dias ${ }^{2}$, Marta T. Gomes ${ }^{2}$, Giseli C. Rodrigues ${ }^{1}$, \\ Luciana T. Zimmermann ${ }^{1}$, Thiago L. Alves e Silva ${ }^{1}$ and Alane B. Vermelho ${ }^{1}$
}

\author{
${ }^{I}$ Instituto de Microbiologia Prof. Paulo de Góes, UFRJ; Cidade Universitária, Ilha do Fundão, Rio de Janeiro, R.J. \\ 21941-590, Brasil \\ ${ }^{2}$ Instituto de Bioquímica Médica, UFRJ; Cidade Universitária, Ilha do Fundão, Rio de Janeiro, R.J. 21941-590, Brasil
}

\begin{abstract}
Trypanosomatids cause many diseases in and on animals (including humans) and plants. Altogether, about 37 million people are infected with Trypanosoma brucei (African sleeping sickness), Trypanosoma cruzi (Chagas disease) and Leishmania species (distinct forms of leishmaniasis worldwide). The class Kinetoplastea is divided into the subclasses Prokinetoplastina (order Prokinetoplastida) and Metakinetoplastina (orders Eubodonida, Parabodonida, Neobodonida and Trypanosomatida) [1,2]. The Prokinetoplastida, Eubodonida, Parabodonida and Neobodonida can be free-living, commensalic or parasitic; however, all members of theTrypanosomatida are parasitic. Although they seem like typical protists under the microscope the kinetoplastids have some unique features. In this review we will give an overview of the family Trypanosomatidae, with particular emphasis on some of its "peculiarities" (a single ramified mitochondrion; unusual mitochondrial DNA, the kinetoplast; a complex form of mitochondrial RNA editing; transcription of all protein-encoding genes polycistronically; trans-splicing of all mRNA transcripts; the glycolytic pathway within glycosomes; T. brucei variable surface glycoproteins and T. cruzi ability to escape from the phagocytic vacuoles), as well as the major diseases caused by members of this family. However, the present review does not cover all trypanosomatids; for example, the insect trypanosomatids are underrepresented here. On the other hand, reviews on this particular group of parasites have been written by experts in the field [3-12].
\end{abstract}

Keywords: Trypanosomatids, Trypanosoma, Leishmania, Phytomonas, Herpetomonas.

\section{INTRODUCTION}

Trypanosomatids are evolutionarily extremely successful, not only because they are found over nearly the entire planet and parasitize all groups of vertebrates, several species of invertebrates (including many insects) and even plants [1316], but also because there is sound evidence that their ancestors date back to about 100 million years ago $[2,17,18]$. Although there are roughly a thousand described monoxenous trypanosomatids from insects, it is expected that hundreds of thousands of insect trypanosomatids will eventually be described, especially because new lines of evidence indicate that insects are the ancestral hosts for these parasites $[2,5,15,19,20]$.

The nine genera of trypanosomatids recognized to date (the monoxenous Crithidia, Blastocrithidia, Herpetomonas, Wallaceina and Leptomonas, as well as the heteroxenous Trypanosoma, Leishmania, Endotrypanum and Phytomonas) were classified mostly by morphological features in conjunction with host relationships. The morphotypes that characterize individual genera are cell shape, dimensions and the position of the complex kinetoplast-flagellar pocket relative to the nucleus $[15,21]$ (Fig. 1). These morphotypes can be altered considerably by the environment, in vitro cultivation or the addition of drugs [15,19,22-24].

*Address correspondence to this author at the Instituto de Microbiologia Prof. Paulo de Góes, UFRJ, Cidade Universitária, Ilha do Fundão, Rio de Janeiro, R.J. 21941-590, Brazil; Tel: 55-21-2562-6740; Fax: 55-21-25608344; E-mail: angela.lopes@micro.ufrj.br

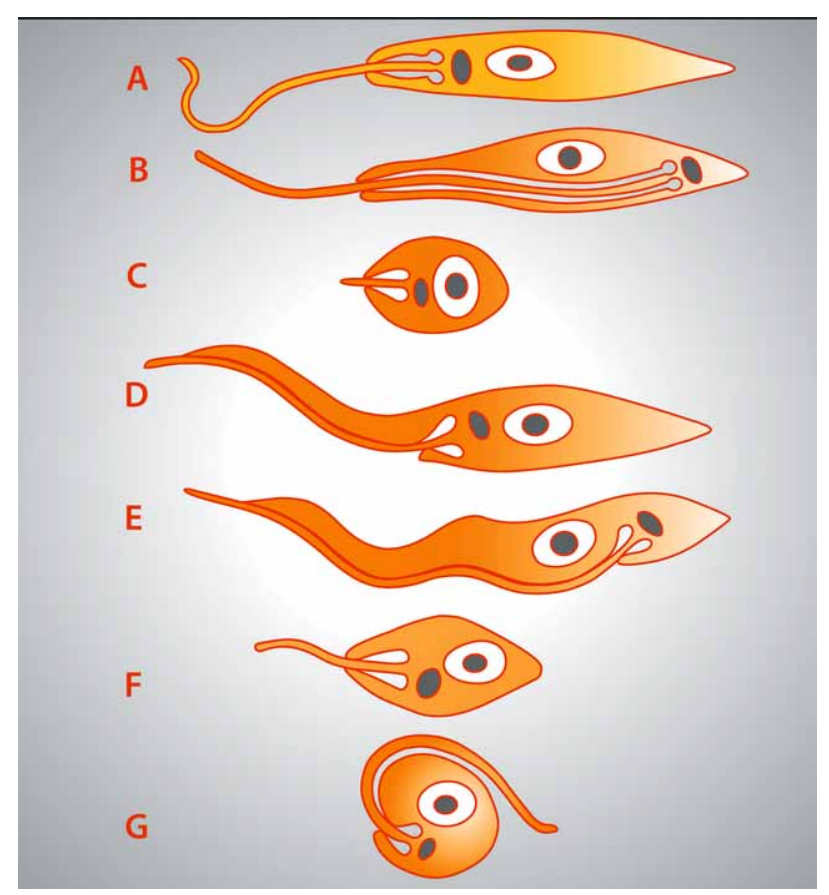

Fig. (1). The most common morphotypes of trypanosomatids. A: promastigote; B: opisthomastigote; C: amastigote; D: epimastigote; E: trypomastigote; F: choanomastigote; G: spheromastigote. Diagram based on Hoare and Wallace [21]. 
Biochemical, nutritional and ultrastructural characteristics were added to the classical morphological traits to distinguish trypanosomatid species [25]. Such biochemical features include the complement of cell surface polysaccharides, sialidases and proteolytic enzymes and the content and number of acidocalcisomes. These characteristics, either alone or in combination, are sufficient to distinguish between strains and species, but they usually fail to distinguish between genera [15,26-29]. However, molecular markers involving highly conserved gene sequences (such as small subunit rRNA, 5S rRNA, spliced-leader RNA or a few protein-coding genes) are especially useful for distinguishing between genera [2,15,20,30-32].

Some developmental stages of trypanosomatid protozoan parasites are well suited to cultivation in vitro; one such stage is the proliferative stage found in the gut of invertebrate hosts [33]. The most common of these stages is the promastigote, which is the insect stage of Leishmania species and the insect trypanosomatid morphotype that grows best in vitro (Fig. 1A). An exception is Crithidia spp., whose most commonly observed stage is the choanomastigote (Fig. 1F) [34]. With respect to African trypanosomes, the slender stage (proliferative in the bloodstream of mammalian hosts) and the procyclic form (proliferative in the fly midgut) grow well in vitro and have a trypomastigote shape (Fig. 1E) [35]. Most studies of $T$. cruzi were performed using the epimastigote form (Fig. 1D), which is the proliferative stage in the insect host [36]. The life cycles of $T$. cruzi, T. brucei, Leishmania spp. and Phytomonas spp. are discussed later in this review.

The most significant morphological and physiological aspects of trypanosomatids are briefly described here. We divide these aspects into two groups: "common" characteristics, which are traits that are present in other groups of organisms yet are somewhat unique; and "peculiar" features, which are characteristics that thus far have been found only among the kinetoplastids [37]. It is noteworthy that many "unique" biological phenomena first discovered in trypanosomes are in fact more widespread, but cryptic, in other eukaryotes. Examples of this include trans-splicing of nuclear RNAs, glycosylphosphatidylinositol (GPI)-anchored membrane proteins and RNA editing. All were first described in trypanosomatids but were subsequently shown to be general traits of eukaryotes [38]. Unless otherwise noted, all of these features will be described herein using $T$. cruzi as a model, as shown in the diagram of the fine structure of the epimastigote form (Fig. 2) [39].

\section{THE “COMMON” CHARACTERISTICS}

\section{Cell Surface}

The cytoplasmic membrane with its constituents is the interface between protozoa and their environment. The cell membrane of all examined trypanosomatids is similar to that of other eukaryotes, except for the fact that there are subpellicular microtubules firmly attached to the inner surface of the membrane. The cell surfaces of all trypanosomatids are coated with GPI-anchored proteins and/or free GPI glycolipids, both of which form protective surface layers and/or mediate crucial host-parasite interactions [40,41]. Intracellular trypanosomatids, such as T. cruzi and Leishmania, initially interact with cell surfaces in vertebrate hosts and then with the membrane of the parasitophorous vacuole. Trypanosomatids also interact with the epithelial intestinal cells of invertebrate hosts [42-44].

\section{Membrane Transporters}

Membrane transporters are proteins that possess many alpha helical transmembrane segments and mediate the translocation of various compounds through biological membranes. Some molecules that are small and relatively non-

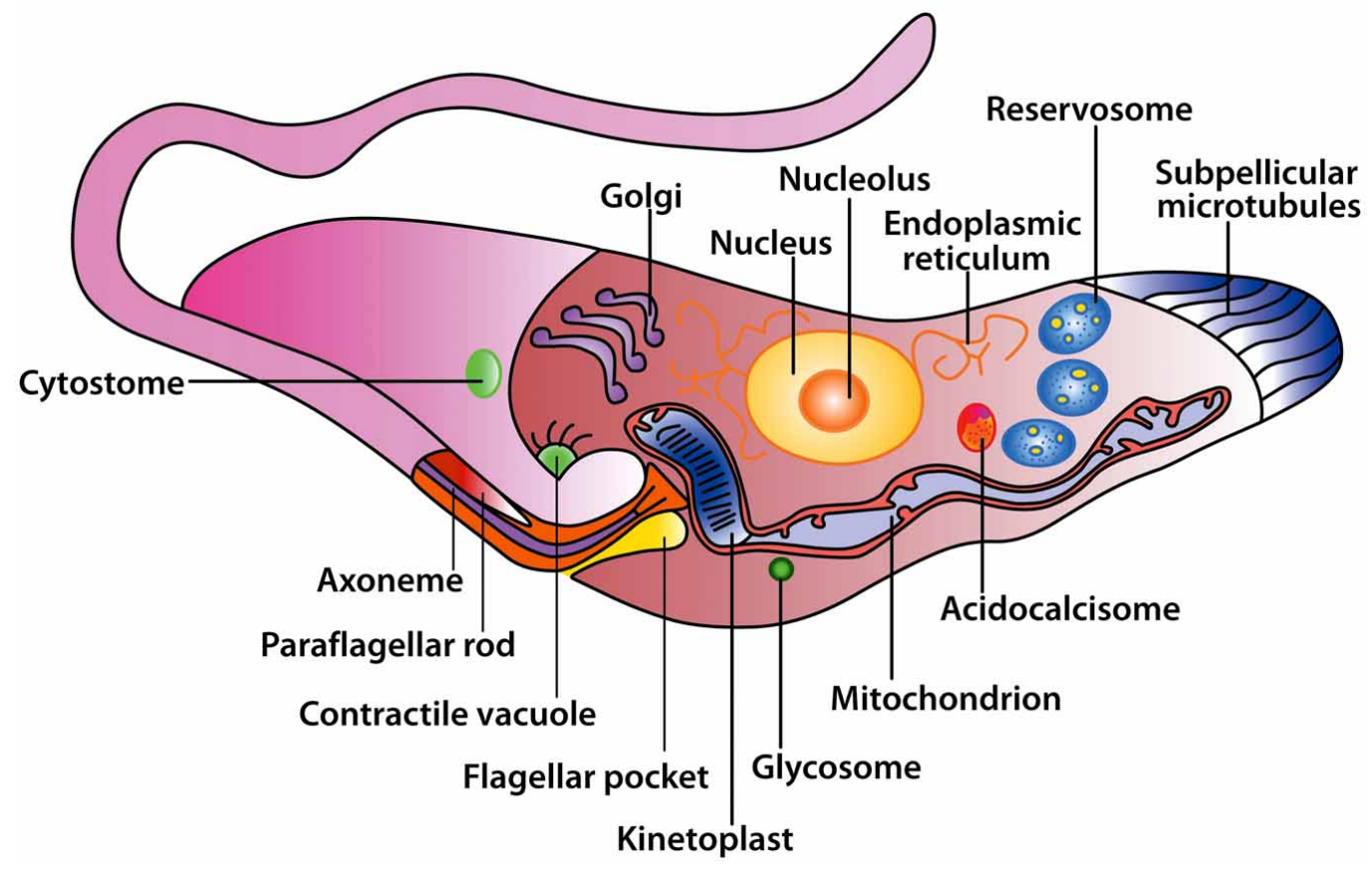

Fig. (2). Main structures and organelles found in the epimastigote form of Trypanosoma cruzi. The structures and organelles are depicted as detected in thin sections by transmission electron microscopy. Diagram adapted from De Souza [39] with permission from the author. 
polar, such as oxygen, nitrogen and carbon dioxide, can pass through lipid bilayers. All other molecules are too large and/or hydrophilic to diffuse across membranes, so they need transporters to facilitate their passage [45].

Membrane transporters perform a large number of tasks, such as taking up nutrients, expelling metabolites, establishing ion gradients, translocating compounds from one intracellular compartment to another and taking up or exporting drugs $[46,47]$. Not surprisingly, about 2 to $2.5 \%$ of the proteins encoded by the genome of trypanosomatids have been annotated as membrane transporters; some of those are developmentally regulated so that the parasites can cope with severe changes in their environment during the course of their life cycle $[45,48,49]$.

\section{Flagellum}

The flagellum is a motility organelle that moves the parasite forward by wave-like beats of the microtubule-based flagellar axoneme [50,51]. All of the stages of trypanosomatids possess one flagellum per cell, even the amastigote form. The flagellum emerges from a basal body in the cytoplasm through a prominent invagination of the plasma membrane called the flagellar pocket [50,51]. Along the length of the cell, the flagellum and cell body are held in close apposition by a network of cytoskeletal and membranous connections that collectively make up the flagellum attachment zone (FAZ) [52]. The flagellum has a typical array of one central microtubule pair and nine peripherally arranged microtubule doublets [53]. A fibrillar structure within the flagellum known as a paraflagellar or paraxial rod is a peculiar structure in the flagellum of trypanosomatids; this rod is made of a complex matrix of filaments connected to the axoneme and is essential for the parasite's survival [53-57]. The flagellar membrane, the flagellar pocket and the pellicular plasma membrane are morphologically, chemically and functionally distinct and have highly diverse biological functions; nonetheless, these three membranes are physically connected and all comprise part of the plasma membrane [50].

In addition to the importance of the flagellum for parasite motility, it is also involved in host-parasite interactions, cell morphogenesis, cell division and evasion from the hostimmune system [52]. Pathogenic features of sleeping sickness, Chagas disease and leishmaniasis are directly linked to the migration and binding of the parasites to specific host tissues, which is decisive for disease progression [52,58-60]. Moreover, the flagellum is essential for these parasites to complete each respective life cycle within the insect host, both for traveling and attaching to target tissues $[52,61,62]$.

Intercellular signaling cross-talk between trypanosomatids and their hosts directs the movements and developmental transformations of the parasite within specific host compartments [52], both in mammalian [57,63,64] and insect hosts [52,65-67]. Recent studies have localized cyclic nucleotide and calcium signaling pathways to the flagellum [52,68-71], suggesting that the flagellum provides a signaling platform for environmental sensing [52]. Intracellular signaling cross-talk between the flagellum and several organelles and the structures to which it is connected, e.g., the FAZ, the flagellar pocket, the kinetoplast and the mitochon- drion, directs their arrangement and organizes them for segregation during cytokinesis [72].

The flagellar pocket is the exclusive site of endocytosis and secretion in trypanosomatids [73] and it has long been speculated that flagellar beating influences entry into the flagellar pocket [52]. Flagellar motility mutants of bloodstream-form $T$. brucei are not able to engulf VSG complexed with immunoglobulin (Ig) [74]. As clearance of VSG-Ig protein complexes from the parasite surface is crucial for avoiding destruction by the host immune system, this result strongly suggests that flagellar motility contributes to immune evasion and persistent infection [74].

\section{Cytoskeleton}

In all trypanosomatids, subpellicular microtubules are distributed throughout the protozoan body, except in the flagellar pocket region. The subpellicular corset consists of microtubules that are connected to one another and to the plasma membrane. The microtubules form a helical pattern along the axis of the cell underlying the plasma membrane together with a regularly spaced intermicrotubule $[39,75,76]$.

Microfilaments have never been observed in the cytoplasm of T. cruzi. On the other hand, biochemical and genomic analyses identified a potential role for an actin-myosin system in $T$. cruzi, as this protozoan possesses an expanded myosin family and a CapZ F-actin capping complex in addition to an actin gene [77-79].

\section{Acidocalcisomes}

Acidocalcisomes are acidic calcium-storage organelles that were first described in T. brucei and T.cruzi $[80,81]$. Later, acidocalcisomes were also described in the protozoan parasites Toxoplasma gondii [82] and Plasmodium spp. [83], in the green alga Chlamydomonas reiinhardtii [84], in the slime mold Dictyostelium discoideum [85], in bacteria [86,87] and in human platelets [88]. Acidocalcisomes were morphologically identified by light microscopy more than one hundred years ago as a different kind of granule [89]. These organelles are observed in Giemsa-stained preparations and with the use of dyes that accumulate in acidic compartments [84-88,90].

The morphology and the number of acidocalcisomes vary from species to species and among the developmental stages of the same species [90,91]. By transmission electron microscopy (TEM), T. cruzi acidocalcisomes appear as round electron-dense structures with an average diameter of $0.2 \mu \mathrm{m}$ and their distribution varies among the three developmental stages of the parasite. X-ray microanalysis, ${ }^{31} \mathrm{P}-\mathrm{NMR}$ and biochemical techniques indicate the presence of $\mathrm{Na}, \mathrm{Mg}, \mathrm{S}$, $\mathrm{Cl}, \mathrm{K}, \mathrm{Ca}, \mathrm{Zn}, \mathrm{O}, \mathrm{Fe}$ and $\mathrm{P}$ (the latter concentrated in the form of inorganic phosphate and as short-chain polyphosphate (poly P)) [92]; amino acids [93]; and various enzymes [84,94]. The membrane of $T$. cruzi acidocalcisomes contains a specific glycoinositolphospholipid (GIPL) and low concentrations of $3 \beta$-hydroxyesterol and as observed in other organisms, a vacuolar ATPase (V-H $\mathrm{H}^{+}$ATPase) and a vacuolar pyrophosphatase (V-H $\left.\mathrm{H}^{+} \mathrm{PPase}\right)$ that establish the $\mathrm{H}^{+}$gradient; transporters (for basic amino acids, phosphate (Pi), pyrophosphate (PPi) and ions such as $\mathrm{Ca}\left(\mathrm{Ca}^{2+}\right.$-ATPase), $\mathrm{Mg}, \mathrm{Zn}$ and $\mathrm{Fe})$; exchangers $\left(\mathrm{Na}^{+}-\mathrm{H}^{+}\right.$-exchanger; $\mathrm{Ca}^{2+}-\mathrm{H}^{+}-$ 
exchanger); and channels (a $\mathrm{Cl}^{-}$channel and a water channel or aquaporin) [95].

The different functions attributed to acidocalcisomes include: phosphorous storage (which may be involved in environmental stress response, differentiation [96] and/or osmoregulation $[88,97,98]$ ); the storage of cations (mainly calcium, which is related to the host cell invasion process $[99,100])$; and $\mathrm{pH}$ homeostasis due to the generation of $\mathrm{H}^{+}$ from the hydrolysis of polyphosphate. Due to the importance of acidocalcisomes in trypanosomatid metabolism and their unique features observed in different organisms, this organelle is considered an important target for the development of new drugs [101,102].

\section{Nucleus}

The nucleus is enveloped by a typical porous membrane, which encloses a nucleolus and condensed chromatin dispersed throughout the nucleoplasm [103-105]. During the division process, the nuclear membrane remains intact, intranuclear microtubules appear, the chromatin disperses and dense plates appear, whose number varies depending on the trypanosomatid species [104]. Still, there is no evidence that these plates correspond to chromosomes, which have thus far been detected only using biochemical/molecular biological approaches [106].

A combination of scaffolds, synteny maps and end sequences from $T$. cruzi bacterial artificial chromosome (BAC) libraries was used to organize the majority of $T$. cruzi contigs into chromosome-size assemblies [107,108]. Additionally, a set of chromosomes was validated experimentally via Southern blot analysis using individual genes as probes to confirm the predicted organization of each chromosome. Using this approach, 41 pairs of chromosomes were assembled; this number is in agreement with the predicted chromosome number based upon pulse-field gel analysis [108].

\section{Endosymbionts}

Bacterial endosymbionts live in various plants, animals and protozoa and are especially relevant because they likely represent a transitional stage between bacteria and organelles such as mitochondria and chloroplasts [109]. Bacterial endosymbionts have been observed in some insect trypanosomatids of the genera Crithidia, Blastocrithidia and Herpetomonas [109].

Trypanosomatid endosymbionts possess two membranes; one corresponds to the plasma membrane, which is in contact with the bacterial matrix and the other is an outer membrane that faces the host protozoan cytoplasm [3]. The symbiont matrix contains ribosomes, filamentous genetic material, proteins, enzymes and metabolic intermediates that supplement essential biosynthetic pathways of the host protozoan, such as heme, purines, numerous amino acids and vitamins [11,109]. Recently, Motta et al. [110] found that during Crithidia deanei cell division the endosymbiont replicates before the basal body and kinetoplast segregations and that the nucleus is the last organelle to divide, before cytokinesis. Taking into consideration that the endosymbiosis in trypanosomatids is a mutualistic relationship, which resembles organelle acquisition during evolution, these findings can be considered an excellent model for the understanding of mechanisms related to the establishment of organelles in eukaryotic cells [110].

\section{THE "PECULIAR" FEATURES}

\section{Glycosomes}

Trypanosomatids harbor numerous genes sharing apparent common ancestry with plants and/or bacteria [111,112]. Many products of these horizontally acquired genes now function in glycosomes, which are found only in members of the class Kinetoplastea. Glycosomes are spherical structures with a protein-dense matrix surrounded by a single phospholipid bilayer and containing no DNA [114,115]. Although glycosomes are evolutionarily related to the peroxisomes of higher eukaryotes and the glyoxysomes of plants [114,115], glycosomes are distinct from peroxisomes because they harbor the glycolytic pathway, which is the mechanism that allows the conversion of glucose into pyruvate, which in trypanosomatids is more efficient than in most other eukaryotes [14]. Ardelli et al. [113] have also identified glycosomes and the glycolytic enzymes hexokinase, fructose-1,6-biphosphate aldolase, triosephosphate isomerase, glucosephosphate isomerase and glyceraldehyde-3phosphate-dehydrogenase associated with this organelle in pathogenic and nonpathogenic strains of the bodonid Cryptobia salmositica. The trypanosomatid glycosomal proteome of L. major, T. brucei and T. cruzi confirmed that glycosomes contain most of the glycolytic enzymes [116-118]. The other divergent feature of trypanosomatid glycosomes is the absence of catalase, a characteristic peroxisomal enzyme [119]. In the pathogenic haemoflagellate bodonid $C$. salmositica, however, catalase is found in the glycosomes [113]. On the other hand, the presence of the enzymes necessary for the initial steps in the production of phosphoglycerate from glucose or glycerol in the glycosomes is shared among trypanosomatids [91,115,119,120] and the bodonid C. salmositica [113], which contrasts with other eukaryotes, in which this pathway occurs in the cytoplasm.

Glycosomes, the cytosol and the mitochondrion cooperate in the energy metabolism of kinetoplastids. The insect stages of all human-pathogenic trypanosomatids ( $T$. brucei, T. cruzi and Leishmania spp.) seem to be capable of metabolizing both amino acids and sugars for their free energy supply; they have a large repertoire of enzymes for carbohydrate metabolism, including the glycolytic pathway and a welldeveloped mitochondrion with a respiratory chain-linked system for oxidative phosphorylation [121-124]. Glycosomes also have other functions related to the biosynthesis of pyrimidines, purine salvage pathways and the synthesis of ether lipids and $\beta$-oxidation of fatty acids [14,119,125]. Amastigote forms of Leishmania spp. and T. cruzi, as well as insect-stage parasites (called the procyclic form in T. brucei, the epimastigote form in $T$. cruzi and the promastigote form in Leishmania), have a more elaborate energy- and carbohydrate-metabolic network. In these cells, other ATPdependent kinases (e.g., phosphoenolpyruvate carboxykinase and pyruvate phosphate dikinase) may be found in the glycosomes, whereas phosphoglycerate kinase (PGK) is relocated to the cytosol [125]. Glycosomes seem to be crucial organelles for the bloodstream form of Trypanosoma brucei, as this form of the parasite is exclusively dependent on glycolysis for ATP generation [124]. 
Because of the absence of DNA and protein translational machinery in glycosomes, glycosomal proteins are encoded in the nucleus, synthesized by cytosolic ribosomes and then imported into glycosomes [120]. Thus, glycosomal proteins need to be tagged by post-translational modifications in order to reach and bind to their target glycosomal receptors [126].

\section{Mitochondria}

Mitochondria harbor systems for energy production through oxidative phosphorylation, synthesize key metabolites and iron-sulfur clusters and can be the reservoir for factors that amplify signals for programmed cell death $[39,106]$. It is worth mentioning that in order to synthesize mitochondrial proteins, all the mitochondrial tRNAs of trypanosomatids are imported from the cytoplasm [127-129]. In cells of multicellular organisms, the number of mitochondria is variable but often quite large. The ultrastructure of mitochondria in protists is usually peculiar. In addition to particularities in the density of the matrix and the number of cristae, individuals in the phylum Apicomplexa and in the order Trypanosomatida have a single ramified mitochondrion $[9,39,130]$ (Fig. 2). In trypanosomatids, separation of the replicated mitochondrial DNA is directly linked to the segregation of the flagellar basal body and mitochondrial division seems to be a checkpoint for cytokinesis [38,131].

In the order Trypanosomatida, the mitochondria are distributed in branches under the subpellicular microtubules and are dilated at regions in which kinetoplast DNA (kDNA) is present. The volume of each mitochondrion depends on environmental and nutritional resources [132,133]. In Trypanosoma brucei, mitochondrial volume and activity are higher in parasites in the midgut and proventriculus where glucose levels are low but are lower in metacyclic salivary gland forms. They reach their lowest values in slender forms from blood, where glucose levels are high and thus favor direct glycolysis $[134,135]$. In contrast, the relative volume occupied by glycosomes varies in the opposite manner. This volumetric counterbalance has been observed in all genera analyzed so far $[136,137]$.

There are two terminal oxidases in the mitochondrial electron transport chain. One is the usual cytochrome oxidase, which is a cyanide-sensitive oxidase and the other is a cytochrome-independent, salicylhydroxamic acid-sensitive alternative oxidase $[9,138-140]$. The bloodstream form of $T$. brucei uses glucose as its energy source and suppresses many mitochondrial activities. The bloodstream-form mitochondria lack cytochromes, so that respiration in this form is exclusively dependent on the cytochrome-independent trypanosome alternative oxidase (TAO) $[138,141]$. On the other hand, the procyclic form that lives in the insect's midgut have a well-developed mitochondrion with a fully functional cytochrome-dependent respiratory system and a reduced level of TAO. The procyclic-form mitochondria produce ATP by both oxidative and substrate-level phosphorylation $[138,142]$. On the other hand, bloodstream-form mitochondria do not produce ATP but hydrolyze ATP to maintain the inner membrane potential, analogous to the reactions that happen in the plant mitochondrial system [138,143-146].

In higher eukaryotes, the electron-transfer chain is a functional sequence of four major multi-subunit complexes that are randomly dispersed in the inner mitochondrial membrane and designated NADH-coenzyme Q reductase (complex I), succinate-CoQ reductase (complex II), ubiquinolcytochrome $c$ reductase (complex III) and cytochrome $c$ oxidase (complex IV). The enzyme complexes are connected by two mobile redox-active molecules: ubiquinone and cytochrome $c[147,148]$. In $T$. brucei procyclic forms, ubiquinone can carry electrons from succinate dehydrogenase (complex II) either to the cytochrome-mediated respiratory chain (involving cytochrome $c$ reductase (complex III), cytochrome $c$ and cytochrome $c$ oxidase (complex IV)) or to TAO $[142,148]$. On the other hand, ubiquinone can potentially carry electrons from NADH:ubiquinone oxidoreductase (complex I) and alternative NADH dehydrogenases either to complex III, complex IV or TAO [149-151]. Although a multisubunit complex I has recently been characterized in Phytomonas serpens, the presence of a typical complex I in T. brucei is controversial [149]. Hypothetically, complex I may be smaller and highly divergent from its equivalents in higher eukaryotes, or T. brucei may have bypassed the need for complex I by using an NADH-fumarate reductase to oxidize mitochondrial NADH, thereby producing succinate as a substrate for complex II [149,152].

Most of the trypanosomatid mitochondrial proteins are synthesized in free cytoplasmic ribosomes and then imported into the organelle [38]. Many other proteins are synthesized within the mitochondria, but as trypanosomatid mitochondrial genomes have lost all tRNA genes, they need to import the entire set of mitochondrial tRNAs [127]. All mitochondrial tRNAs in trypanosomatids derive from eukaryotic-type cytosolic tRNAs that need to function in the context of the bacterial-type translation system of mitochondria [127-129]. In Leishmania tropica, the RNA import complex (RIC) induces the transport of tRNAs across natural and artificial membranes [153]. RIC is a multi-subunit protein complex from the mitochondria that can also act as an efficient delivery vehicle for tRNA and other small RNAs into mitochondria within intact mammalian cells [153].

In trypanosomatids, mitochondrial tRNAs and their cytosolic correspondents originate from the same nuclear genes. However, due to compartment-specific post-transcriptional nucleotide modifications, cytosolic and imported mitochondrial tRNAs are often physically different [127]. The tRNAs of trypanosomatids are subject to extensive mitochondrionspecific modifications, which include methylation, thiolation and $\mathrm{C}$ to $\mathrm{U}$ editing $[31,127,154,155]$. Using inducible expression of a tagged tRNA ${ }^{\text {Glu }}$, Bruske et al. [127] showed that it is mainly the thiolated form that is imported to the mitochondrion in vivo. Unexpectedly, the imported tRNA becomes dethiolated after import, which explains why the non-thiolated form is enriched in mitochondria [127].

\section{Unusual Mitochondrial DNA: The Kinetoplast}

In the majority of trypanosomatids, the kinetoplast forms a disk-like structure; in contrast, trypomastigotes of $T$. cruzi and endosymbiont-bearing trypanosomatids possess a more rounded kinetoplast [39].

Kinetoplast DNA (kDNA) differs from nuclear DNA in its buoyant density, base ratio and degree of renaturation. Moreover, unlike any other DNA in nature, the kDNA of 
trypanosomatids is composed of circular molecules that are topologically relaxed and interlocked to form a single network. There are two types of DNA rings, minicircles and the maxicircles. There are several thousand minicircles, which range in size from about 0.5 to $10.0 \mathrm{~kb}$ and a few dozen maxicircles, which usually vary between 20 and $40 \mathrm{~kb}$ [156158]. The maxicircles are analogous to the mitochondrial DNA of higher eukaryotes and they encode two rRNAs and several subunits of the respiratory complexes as well as some guide RNAs (gRNAs). The minicircles encode gRNAs that modify maxicircle transcripts by extensive uridylate insertion or deletion in a process known as RNA editing $[9,158]$.

\section{Kinetoplastid RNA Editing}

Two different RNA editing systems have been described in the kinetoplast-mitochondrion of trypanosomatid protists. The first is a unique form of post-transcriptional RNA processing that occurs only in the mitochondria of kinetoplastid protists. This editing system involves the precise insertion and deletion of uridine residues mostly within the coding regions of maxicircle-encoded mRNAs to produce recognizable open reading frames (ORFs). This editing system is mediated by short overlapping complementary gRNAs that provide the information for $U$ insertion and deletion on the edited mRNA [159,160] through a series of enzymatic cleavage-ligation steps $[9,161]$.

The second RNA editing system is based upon another derived feature of the kinetoplastid mitochondrial genome, which is the complete lack of tRNA genes and the importation of all mitochondrial tRNAs from the cytosol [4]. Thus, the second system involves editing by a C34-to-U34 modification within the anticodon of imported tRNATrp, thereby permitting UGA stop codons to be read as tryptophan [9].

\section{Trans-Splicing of all mRNA Transcripts}

Unlike the majority of eukaryotic organisms, trypanosomatids transcribe all protein-encoding genes polycistronically [162-164]. Most trypanosomatid chromosomes contain at least two polycistronic gene clusters (PGCs), which can be transcribed towards the telomeres or away from the telomeres. Genes from a polycistronic unit in trypanosomatids usually do not code for functionally related proteins [165], which is completely different from how operons function in bacteria and nematodes [162].

Trypanosomatid parasites utilize RNA splicing for the maturation of nuclear pre-mRNA in two distinct ways: cissplicing and trans-splicing. Although cis-splicing has been observed in T. brucei [166], intron removal appears to be a rare event in trypanosomatids, as the trypanosomatid genome sequences have identified only three putative introncontaining genes [167]. Trans-splicing proceeds through a two-step transesterification reaction, analogous to cissplicing but forming a Y-shaped structure instead of a lariat intermediate $[168,169]$. Maturation to translatable monocistronic units in trypanosomatids requires resolution of each coding region by trans splicing of a 39-nucleotide (nt) spliced leader (SL) exon and 3'-end polyadenylation [168170]. The source of the SL sequence was found to be a small capped RNA, the SL RNA [169,171,172]. Thus, the addition of the SL sequence serves two purposes: it functions together with polyadenylation to dismember the polycistronic transcripts and it provides a cap for the mRNA [169]. The SL RNA is involved in the maturation of each and every nuclear mRNA, accounting for approximately $7 \%$ of total RNA synthesis $[170,173,174]$. Rapid substrate SL consumption suggests a dynamic processing mechanism [170]. Substrate SL RNA is modified by eight methylations of the 5-nt cap structure and pseudouridylation at nt $28\left(\psi_{28}\right)$ [170]. Along with those of the $\mathrm{m}^{7} \mathrm{G}$ (cap 0 ), the methylations of the kinetoplastid cap 4 are the most extensive, with 2'- $O$-ribose methylation of the first four nucleotides and additional base methylations on the first $\left(\mathrm{m}_{2}{ }^{6} \mathrm{~A}\right)$ and fourth $\left(\mathrm{m}^{3} \mathrm{U}\right)$ positions [170,175-177]. The SL cap 4, the primary exon sequence and/or pseudouridylation have all been implicated in kinetoplastid trans splicing [170,178-181] and polysome association $[170,182]$.

RNA splicing is carried out by the spliceosome, which consists of five small spliceosome nuclear ribonucleoprotein particles (snRNPs) (U1, U2, U4, U5 and U6) as well as nonsnRNP proteins. In the human system, there are approximately 45 distinct spliceosomal snRNP proteins and up to 170 proteins were found to be associated with spliceosomal complexes. In trypanosomatids, all five spliceosomal $U$ snRNAs have been identified [169,183] and there are orthologs of all seven Sm proteins $[183,184]$ and of LSm2 to LSm8 [183,185].

\section{Reservosomes}

Reservosomes are endocytic organelles of parasites from the Schizotrypanum sub-genus, such as $T$. vespertilionis, $T$. dionisii and $T$. cruzi. In $T$. cruzi, reservosomes are round electron-dense compartments with a mean diameter of 500 $\mathrm{nm}$ mainly localized at the posterior region of epimastigote forms. Reservosomes, which were first described as multivesicular bodies [186], present a matrix made primarily of proteins where internal vesicles, membrane profiles, electronlucent inclusions of a lipid nature and rod-shaped electronlucent structures bound by a membrane monolayer can be observed [136,187]. Reservosomes are the main site for the storage of proteins and lipids that are ingested by endocytosis and for secretory proteins produced by the parasite [136,188,189]. Reservosomes contain lysosomal proteins (including two peptidase, cruzipain [190-192] and serine carboxypeptidase [193,194]) and an arylsulfatase activity detected by ultrastructural cytochemistry [195]. Due to the presence of peptidases, an acidic $\mathrm{pH}$ of 6.0 maintained by the action of two P-type $\mathrm{H}^{+}$-ATPase isoforms [196] and the presence of Tc Rab11, a homolog of mammalian Rab11 [197], the organelle is also considered the main site of protein degradation and recycling.

Because multiple studies have failed to identify a molecular marker for this organelle, some researchers decided to perform a subcellular proteomic analysis of a purified epimastigote reservosome fraction using several biochemical analysis, including mass spectrometry (LC-MS/MS) $[192,198]$. Those studies confirmed the presence of the previously described molecules and identified new proteins from different classes such as enzymes, proton pumps and transport proteins. Reservosomes have a complex role in the life cycle of $T$. cruzi directly related to cell differentiation [199]. The unique features of this organelle are potential 
targets for the development of chemotherapeutical drugs for Chagas disease.

\section{CHAGAS DISEASE: TRYPANOSOMA CRUZI}

The pathophysiological aspects of Chagas disease and its mechanism of transmission were first reported by Carlos Chagas in a series of studies published in 1909 [200-202]. After 100 years of research, American trypanosomiasis (or Chagas disease) is still a serious health problem in the Americas. Unfortunately, no vaccines are available and very few anti-parasitic drugs are effective at treating the acute phase of the disease. The most important mode of transmission is through the feces of several species of hematophagous triatomine insects. However, blood transfusion, organ transplantation, congenital transmission and food contamination are other important ways of transmitting the disease [203-205].

The most prominent pathologies associated with the chronic form of the disease are cardiomyopathy and digestive megasyndrome $[202,206]$. The cerebral form is an infrequent complication of the acute phase that was already mentioned by Carlos Chagas in the original description of the disease [202,206,207]. In addition, it has been shown that chronic Chagasic patients that become immunodeficient because of HIV infection or specific drug treatment may undergo disease reactivation in the central nervous system [206].

Intriguingly, in a series of very elegant experiments, Hecht et al. [208] showed the presence of $T$. cruzi DNA in the genomes of Chagas patients and their descendants. Five families with Chagas disease were studied, as confirmed by specific anti- $T$. cruzi antibodies and/or nuclear DNA (nDNA) signatures. The targeted primer-thermal asymmetric interlaced PCR (tpTAIL-PCR) technique was used to demonstrate the rate of lateral DNA transfer (LDT) and to understand the consequences of lateral kDNA transfer (LkDT) from T. cruzi to host cells in the families examined. tpTAILPCR based on kDNA and long interspersed nuclear element1 (LINE-1) retrotransposon sequences showed that $T$. cruzi minicircles integrated primarily into host genome transposable elements. Furthermore, the integrated minicircle fragments were inherited by Chagas disease patient progeny. Minicircle integrations into nearly all human chromosomes were detected, kDNA minicircle sequences were concentrated within LINEs and multiple integration events mobilized minicircles and thus moved them to other chromosomes, resulting in disruption of coding regions and gene loss [208]. The LkDT and vertical kDNA transfer (VkDT) events were largely independent, as parasitic kDNA integrations could occur via germline or congenital transmission. The authors claim that LkDT- and VkDT-induced genotypic and phenotypic alterations might explain the variability of some clinical manifestations of Chagas disease [208].

Endemic Chagas disease affects eight to ten million people worldwide and kills more than any other parasitic disease in Latin America [209]. Chagas disease extends through North, Central and South America, from Mexico in the north to Argentina and Chile in the south, affecting 21 countries [210] (Fig. 3). Chagas disease is becoming a global health

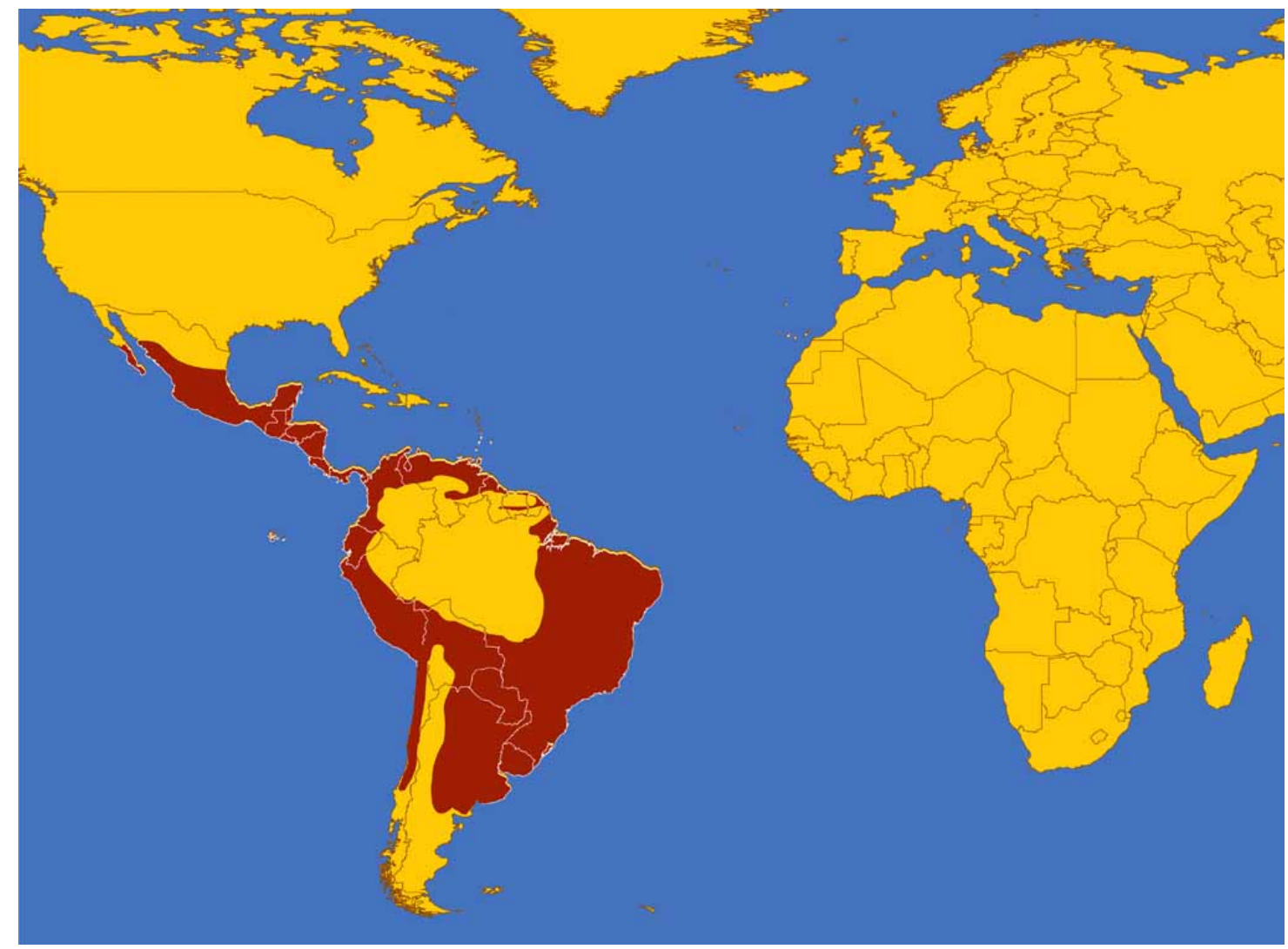

Fig. (3). Geographic distribution of endemic Chagas disease. Chagas disease and its vectors are distributed throughout the American continent and some Caribbean islands. The area with infected humans is shown in red (see text, [http://www.dpd.cdc.gov/]). 
problem because of the migration of Latin American people to other regions of the world [211]. Thousands of people infected with $T$. cruzi have been reported in the USA, Canada, several European countries, Australia and Japan. In the USA, it was estimated that in 2007, approximately 340,000 Latin American immigrants were potentially infected with $T$. cruzi. Of these, 65,000 may have or develop symptoms or signs of chronic Chagas disease [211].

The genome of $T$. cruzi was recently sequenced and it has been estimated that $50 \%$ of the genome is composed of repetitive sequences, consisting mostly of large gene families of surface proteins, retrotransposons and subtelomeric repeats [212]. T. cruzi exhibits extensive intraspecific genetic diversity [213] and its population structure has been separated into two major groups, T. cruzi I and T. cruzi II [214], based on several biological and molecular markers such as isoenzyme analysis, polymorphisms in the 24S $\alpha$ rDNA and mini-exon gene sequences. $T$. cruzi I strains, which contain zymodeme $\mathrm{Z1}$, are associated with the sylvatic cycle of transmission and arboreal mammals and show low parasitism in human Chagas patients.

In contrast, $T$. cruzi II strains, which contain zymodeme $\mathrm{Z} 2$, are associated with the domestic cycle of transmission and a terrestrial niche and cause human infection with high parasitemia in traditionally endemic areas [215]. Studies of the genetic composition and population structure of $T$. cruzi are still quite controversial. The biological properties of the parasite, including its geographical distribution, host specificity and clinical outcomes of infection, have been considered in the classification scheme. Some authors have suggested that $T$. cruzi I and II can occasionally form stable hybrids, sometimes polyploids, that are able to produce regular epidemiological samples in hybrid zone niches [216].

The life cycle of $T$. cruzi consists of two stages in the insect vector and two stages in the human host [202]. In the insect vector, epimastigote forms replicate in the midgut and are then transformed into infective metacyclic trypomastigotes. These forms can be expelled together in the insect's excreta during a blood meal and reach the host's bloodstream through the bite wound or exposed ocular or oral mucosa. In mammals, trypomastigotes are contained within a structure known as the parasitophorous vacuole from which they subsequently escape to differentiate into amastigotes and freely replicate in the cytosol [217]. After several binary divisions, amastigotes differentiate back into highly motile trypomastigotes, which are released upon host cell rupture. During blood feeding, a triatomine insect can acquire the parasite from an infected individual and continue the cycle [36] (Fig. 4).

Mesenchymal cells, especially macrophages and fibroblasts, are the first cells to be infected by metacyclic trypomastigotes at the site of primary infection [218]. Blood-

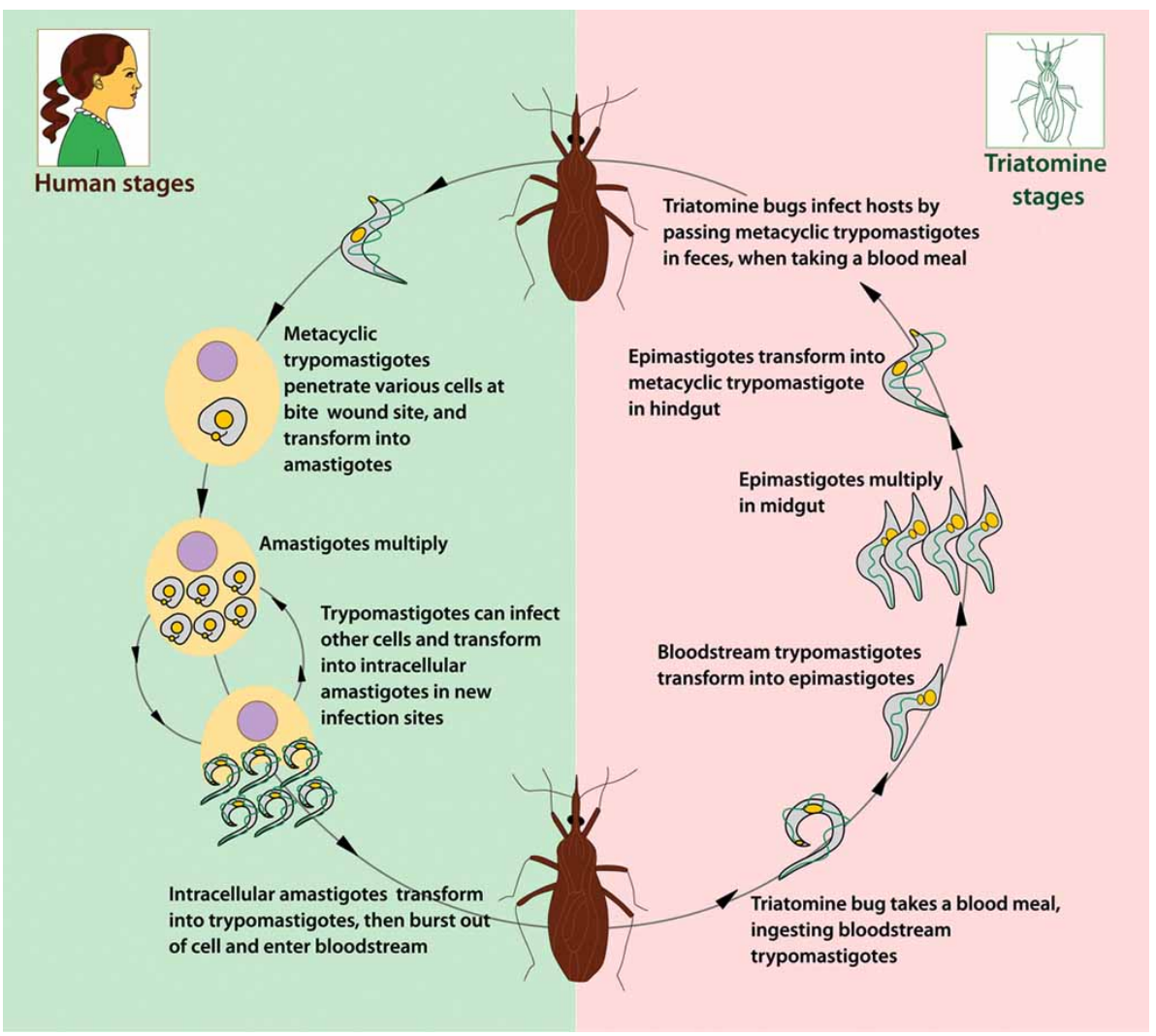

Fig. (4). Life cycle of Trypanosoma cruzi. Infection occurs when infected metacyclic trypomastigotes enter the body through wound openings or mucous membranes. The trypomatigotes enter various cells, differentiate into amastigotes and multiply intracellularly. The amastigotes differentiate into trypomastigotes which are then released back into the bloodstream. The life cycle is continued when a reduviid bug feeds on an infected person and ingests trypomastigotes in the blood meal (see text, [http://www.dpd.cdc.gov/]). Diagram based on Stuart et al. [217]. (Animated-life cycles of T. brucei, T. cruzi and Leishmania spp. can be seen at the following site: http://www.who.int/tdrold/ media/multimedia/lifecycle.htm). 
stream trypomastigotes can then infect several different types of cells farther from the wound site, but stable infection usually occurs in cardiac and skeletal muscle and enteric nerves [219]. Strain-dependent, tissue-specific tropism and genetically distinct strains and clones can be isolated both from animal models and patients with primary cardiac or gastrointestinal disease [220-224].

Prior to entry, parasites must survive, reach the cell surface and form stable attachments to host cells [224]. Interactions of parasites with host cells and the extracellular matrix occur through a diverse group of parasitic surface glycoproteins and peptidases [224]. These surface molecules perform important roles such as binding to host cells, cleaving receptors or ligands, digesting matrix constituents, assisting with immune evasion and triggering bidirectional signaling events in the parasite and host cells [41,204,224,225].

The major cell surface molecules expressed by kinetoplastids, including $T$. cruzi, are glycosylphosphatidylinositol (GPI)-anchored glycoconjugates. Nearly $50 \%$ of the $T$. cruzi genome is dedicated to encoding GPI-anchored proteins, which are expressed in all developmental stages and encoded by numerous members of multigene families, including the trans-sialidase (TS)/gp85 glycoprotein, mucin, mucinassociated surface protein (MASP) and metallopeptidase gp63 [41,212,226,227]. Enzymatic cleavage via GPI-specific phospholipase C (GPI-PLC) releases the head group and has been implicated in lipid and paracrine signaling, as well as signal termination [224,228,229]. Some GPI anchors and GPI-anchored molecules (e.g., TS/gp85 and mucins) in $T$. cruzi are robust proinflammatory molecules that are essential in the modulation of and escape from host immune responses [41,204,226,230-234]. These and several other T. cruzi molecules important for binding, entry and survival in host cells are listed in Table $\mathbf{1}$.

T. cruzi trypomastigotes directly invade both professional phagocytes and non-phagocytic cells. The cellular mechanisms of phagocytosis have been well-studied [324-327], showing that tissue resident macrophages are critical targets for early $T$. cruzi infection [224,328,329].

T. cruzi trypomastigotes exploit two distinct modes of host cell invasion by which they gain access to the intracellular environment of mammalian cells: a lysosome-dependent pathway and a lysosome-independent pathway [224,330]. In the first case, the parasite induces an increase in intracellular calcium $\left(\mathrm{Ca}^{2+}\right)$ when it interacts with the host cell, leading to actin polymerization and microtubule reorganization, as well as the fusion of preformed lysosomes with the plasma membrane [36,238,331,332]. The second pathway involves plasma membrane-mediated invagination and phosphoinositide 3 kinase (PI3K) signaling but is independent of actin polymerization [224,330,333,334].

Diverse molecules on the host cell surface interact with $T$. cruzi, including the mannose receptor, L-selectin and Toll-like receptors (TLRs) [335-338]. TLR2, TLR4 and TLR9 are all involved in the recognition of $T$. cruzi during invasion [231,335,339-341]. T. cruzi activates TLR2 and TLR4 via molecules rich in GPI or GIPL anchors and activates TLR9 via the parasite DNA, stimulating cytokine production by macrophages. TLR2 regulates the entry of $T$. cruzi into macrophages through the activation of PI3K [335,339,340].

Rab GTPases are small guanine phosphonucleotidebinding proteins and regulate the entry of $T$. cruzi into cells via the endocytic pathway, vesicle trafficking and different stages of phagosome maturation [335,342]. In their active form Rab proteins regulate the binding of other effector proteins and membrane-membrane fusion of vesicles to the developing phagosome [335,343,344]. Rab5 induces the fusion of early endosomes and Rab7 mediates fusion between late endosomes and lysosomes [335,345-347]. Rab5 binds to the membrane and serves as an anchor for the effector protein early endosomal antigen 1 (EEA1), which collaborates with Rab5 during membrane fusion [335,348].

Newly formed parasitophorous vacuoles containing trypomastigotes and amastigotes have an acidic $\mathrm{pH}$. After two hours of infection, $70 \%$ of the parasites can be found within partially destroyed vacuoles or free in the cytoplasm. When the $\mathrm{pH}$ of the vacuole is elevated by incubation with a variety of drugs, however, the escape of the parasites is significantly inhibited [349-351]. T. cruzi trypomastigotes secrete the acid-stable hemolytic protein Tc-Tox within the acidic parasitophorous vacuole. Tc-Tox is then incorporated into the phagosome membrane, forming pores that aid in the destruction of this membrane and the consequent escape of parasites into the cytoplasm [299,352]. Recently, transsialidase (TS) has also been implicated in escape from lysosomes [224]. In fact, trypomastigotes derived from infected mammalian cells express and release 20 times more TS activity than axenic metacyclic trypomastigotes [353].

The most important integral membrane proteins in lysosomes are lysosome-associated membrane protein 1 and 2 (LAMP1 and LAMP2) [354,355]. Both LAMPs are highly glycosylated and rich in sialic acid and they cover about $80 \%$ of the interior surface of the lysosome $[355,356]$. These two proteins are crucial in $T$. cruzi infection of host cells for both entry and intracellular development, as demonstrated by $T$. cruzi infection in LAMP1 and 2 double-knock-out (LAMP1/2\%) fibroblasts, probably because they are the major source of sialic acid for $T$. cruzi [354,356]. Infection studies with $T$. cruzi metacyclic trypomastigotes have supported this hypothesis, as trypomastigotes overexpressing trans-sialidase have shown that increased trans-sialidase activity is associated with faster parasite escape from vacuoles [353]. Intriguingly, unlike previous expectations [357], the insertion of TcTox seems to be more efficient in parasitophorous vacuoles lacking sialic acid [354].

Both innate immunity and systemic anti-parasite inflammatory responses are initiated by macrophages through epitope processing and presentation. Interestingly, macrophages play a dual role in $T$. cruzi infection by both harboring [358] and limiting the infection [224,359-361]. T. cruzi infection elicits intense innate and adaptive immune responses and focal areas of inflammation. T. cruzi can induce the production of cytokines that decrease the expression of molecules critical for T-cell stimulation such as major histocompatibility complex (MHC) class II and costimulatory molecules, possibly as a strategy for survival in the host [362,363]. On the other hand, exacerbated immune responses, although efficient in eliminating the pathogen, may lead to tissue 
Table 1. Some Molecules Synthesized by Trypanosoma cruzi Involved in Parasite Binding, Entry or Survival in Mammalian Host Cells

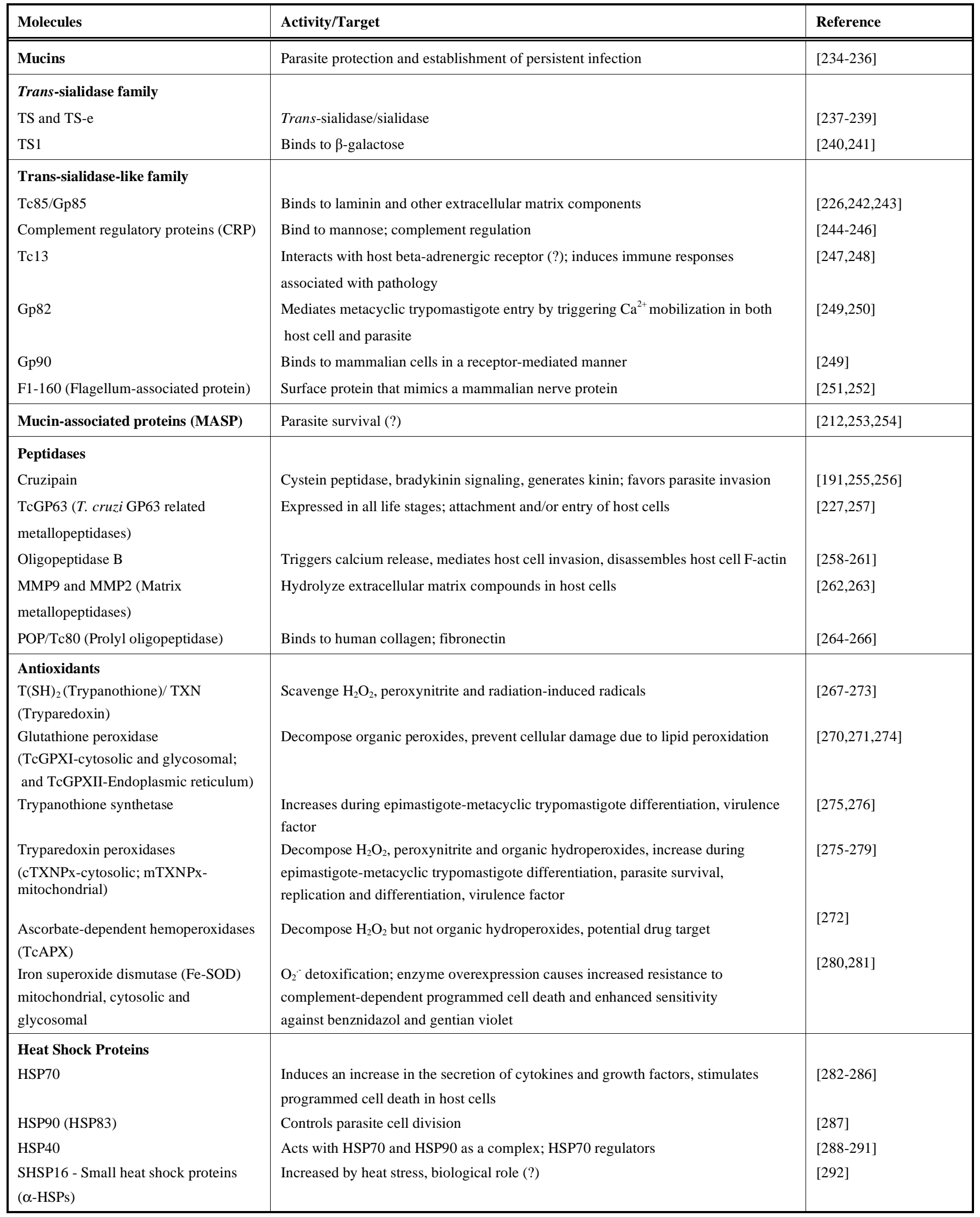


(Table 1). Contd.....

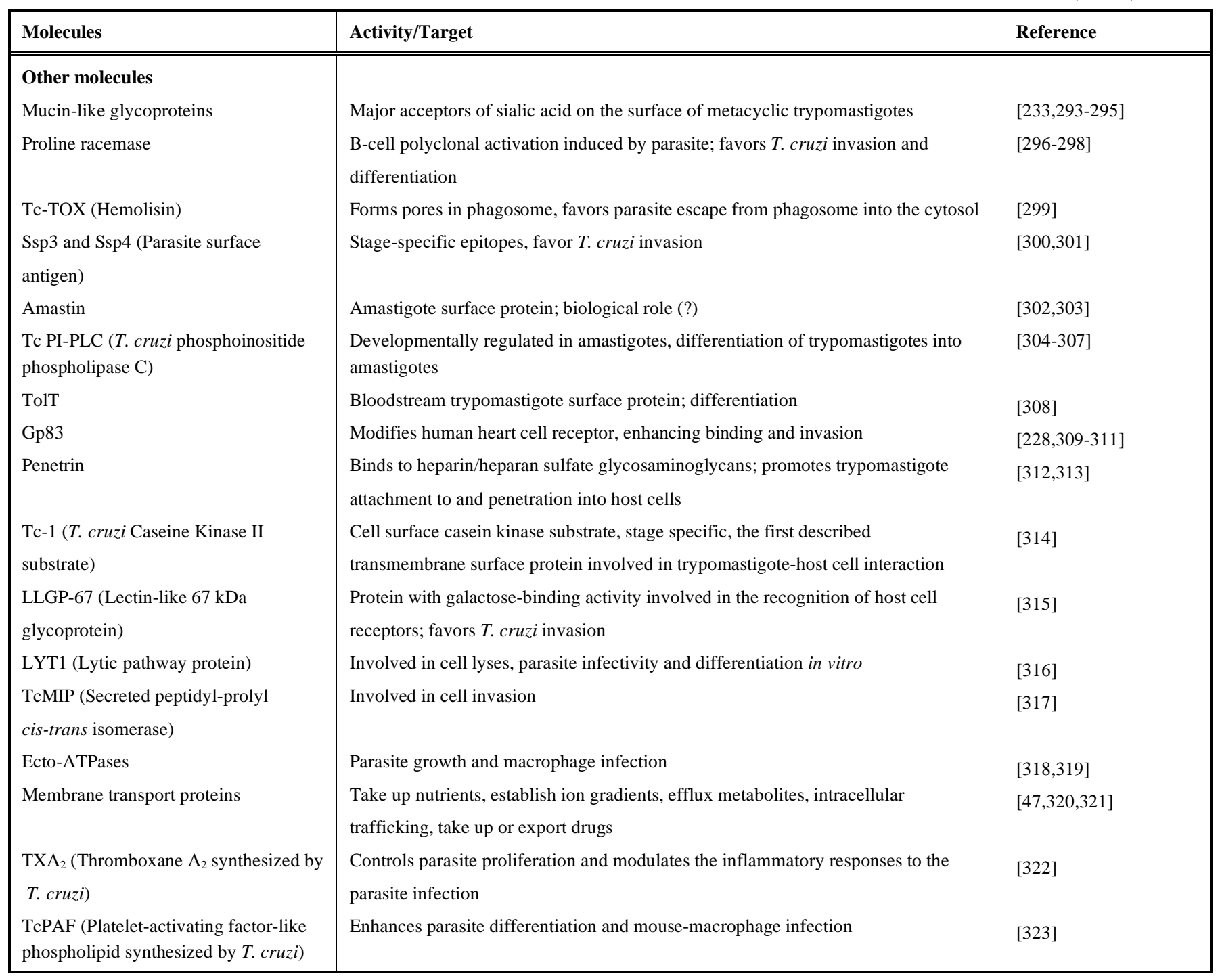

pathology [364]. According to Tarleton [365], there are two possible explanations for the delayed generation of protective immune responses: (a) a failure of prompt innate recognition of $T$. cruzi and (b) "immune confusion" generated by the presentation of a wide array of potential target epitopes to $\mathrm{CD} 8^{+} \mathrm{T}$ cells. The initial innate immune response against T. cruzi is mediated in part by TLRs [341]. Among the cytokines generated during this response, interleukin 12 (IL-12), interferon $\gamma$ (IFN- $\gamma$ ), tumor-necrosis factor $\alpha$ (TNF- $\alpha)$ and type I IFN participate in resistance to the parasite [365]. On the other hand, both TGF- $\beta$ and IL-10 prevent the protective action of IFN- $\gamma$ [366]. It was previously demonstrated that membrane components shed by $T$. cruzi increase tissue parasitism and inflammation by stimulation of IL-4 and IL-10 synthesis and this mechanism may play a central role in the pathogenesis of acute-phase Chagas disease [367].

The GPI anchors of mucins from cell-derived trypomastigotes (tGPI-mucins) induce production of the proinflammatory cytokines IL-12 and TNF by interacting with TLR2, TLR1 or TLR6 on the surface of macrophages [234]. Cruzipain is responsible for enhancing IL-4, IL-5 and IL-10 pro- duction while decreasing NO production by downregulating iNOS expression and generating endogenous kinins [368]. During infection of its mammalian host, $T$. cruzi secretes a proline racemase ( $T c$ PRAC) that contributes to parasite immune evasion by acting as a B-cell mitogen. Overexpression of $T c$ PRAC leads to an increase in parasite differentiation into infective forms and subsequent penetration into host cells [297]. In addition, other molecules released by $T$. cruzi have been shown to cause specific immunosuppression and could be present in vesicles. AgC10, a T. cruzi mucin-like protein present in amastigotes, blocks IL-2 synthesis at the transcriptional level by inhibiting tyrosine phosphorylation during T cell receptor-associated signal transduction [369].

Currently, there are no vaccines available for Chagas disease. T. cruzi antigens recognized by immune sera from infected humans or animals were the first disease antigens to be described. Characterization of these antigens allowed studies with recombinant proteins based on isolated, antigenspecific genes. Different antigens alone and mixtures of distinct adjuvants, plasmid DNA and, more recently, recombinant viruses and bacteria have been tested as $T$. cruzi vac- 
cines [370]. Various antigens delivered using distinct delivery systems have been able to induce protective immune responses in a mouse model of $T$. cruzi infection as measured by a reduction in acute-phase parasitemia, tissue parasitism and mortality [370]. In general, the diversity of the immunodominant response among strains presents a significant challenge for the development of vaccines. A vaccine would require a number of $\mathrm{CD}^{+}$epitopes that cover not only the different human MHC haplotypes but also the different parasite strains. Alternatively, the use of sub-dominant epitopes could favor protective immune responses without requiring as many epitopes [370].

The discovery that stem cells are capable of differentiating into specialized cell types has opened new avenues for the treatment of degenerative and traumatic disorders, including heart failure. For Chagas disease, in mice chronically infected with a myotropic Colombian $T$. cruzi strain that received bone marrow cells to repair the heart tissue, the transplanted cells showed a nearly $60 \%$ reduction in fibrosis two months after therapy [371]. Although the results of phase II and phase III clinical trials in patients with Chagas disease are encouraging, we are still in the beginning phases of development for a new therapy [372]. Interestingly, a case of chronic Chagas disease and systemic lupus erythematosus was recently described that required immunosuppression to control the autoimmune response. Interestingly, benznidazole induced a reduction, but not elimination, of circulating $T$. cruzi levels and subsequent treatment with posaconazole led to a successful outcome of the infection, even with the use of immunosuppressive therapy [373].

The drugs currently used to treat Chagas disease are nifurtimox, which is derived from nitrofuran and benznidazole, a nitroimidazole derivative. Nifurtimox and benznidazole are trypanocidal to all forms of the parasite [374]. They act through the formation of free radicals and/or electrophilic metabolites but can cause systemic toxicity.

Thus, studies are aimed at finding new therapeutic agents against $T$. cruzi such as inhibitors of certain cellular components, including (a) compounds that interfere with purine metabolism (e.g., allopurinol and purine analogs), (b) inhibitors of ergosterol synthesis, (c) compounds that act in the respiratory chain, (d) inhibitors of alkylphospholipid synthesis (e.g., miltefosine and phospholipid analogs), (e) inhibitors of enzymes involved in nucleotide synthesis, (f) inhibitors of the enzyme trypanothione reductase (e.g., nitrofuran, naphiloquinone and phenothiazine derivatives), (g) inhibitors of cruzipain, (h) inhibitors of glyceraldehyde-3-phosphate dehydrogenase and (i) inhibitors of protein kinases of $T$. cruzi [375]. Recently, K777 ( $N$-methyl-piperazine-urea-FhFvinyl-sulfone-phenyl), a cruzipain inhibitor in preclinical development, has shown good efficacy against different organisms, including T. cruzi [376].

Natural compounds with potential antichagasic activity have also been described, including (a) the antioxidative flavanols catechin, epicatechin, gallocatechin, epigallocatechin and some of their gallates; (b) xanthones; (c) tetracyclic triperpenes; and (d) naphthylisoquinoline alkaloids [375]. Further studies are required, however, to better understand these compounds.
Recently, successful elimination of $T$. cruzi transmission by Triatoma infestans was reported in Brazil, Uruguay, Chile and parts of Argentina, Bolivia and Paraguay. Still, we should not consider the problem solved because other countries have not implemented a national program for the control of $T$. cruzi transmission and possible re-infestation of treated areas and eventual spread to neighboring regions may take place [377]. Moreover, insecticide control has not been a complete success, especially because strains resistant to pyrethroids have been found in Rhodnius prolixus from Venezuela and in Triatoma infestans from Brazil [378,379]. Furthermore, in the last decade, different levels of pyrethroid resistance have been detected in an area ranging from northern Argentina to central Bolivia [378-380].

In this scenario, efforts and methodologies need to be combined to reach the prevention of and a cure for Chagas disease, which unfortunately still seems to be a long distance away.

\section{AFRICAN TRYPANOSOMIASIS: TRYPANOSOMA BRUCEI}

African trypanosomiasis (AT) is caused by protozoan parasites of the genus Trypanosoma. It is transmitted by tsetse flies (genus Glossina) and is known to be invariably fatal if untreated [381]. African animal trypanosomiasis (AAT) threatens about 50 million head of cattle per year, causing about 3 million deaths, which has a severe impact on cattle production in sub-Saharan Africa [382]. According to the World Health Organization (WHO), 60 million people in 36 countries are at risk of contracting human African trypanosomiasis (HAT, also known as sleeping sickness) and there are about 500,000 people infected with the disease, with at least 70,000 new cases per year [210].

AAT is caused by a large number of species: Trypanosoma congolense, T. vivax, T. evansi and T. brucei brucei cause "nagana" in cattle and T. equiperdum causes "dura" in horses. Representative strains of $T$. equiperdum and $T$. evansi have been characterized by numerous molecular and classical parasitological approaches and actually shown to be strains of $T$. brucei. Interestingly, these trypanosomes lost part (dyskinetoplastidy - Dk) or all (akinetoplastidy - Ak) of their kDNA [383]) and should therefore be considered two subspecies, T. brucei equiperdum and T. brucei evansi, respectively, that recently arose spontaneously [383].

Since the discovery of AAT (1894) and HAT (1910), peaks of epidemics have devastated the African continent [384]. Although a noticeable decrease in the incidence of AT was observed between 1949 and 1965, the disease has reemerged over the past few decades to become one of the major causes of morbidity and mortality in humans and cattle [385]. Thus, AT represents an obstacle to human welfare and cattle rearing, affecting approximately one-third of Africa's total land area (Fig. 5).

HAT transmission occurs through injection of the infective form of the parasite, metacyclic trypomastigotes (Mts), into the host's skin by the bite of a tsetse fly. A local skin lesion known as a "chancre" may develop 5-15 days later. After this period, Mts transform into bloodstream trypomastigotes and are carried to other sites throughout the body where they reach other blood fluids and continue replication 


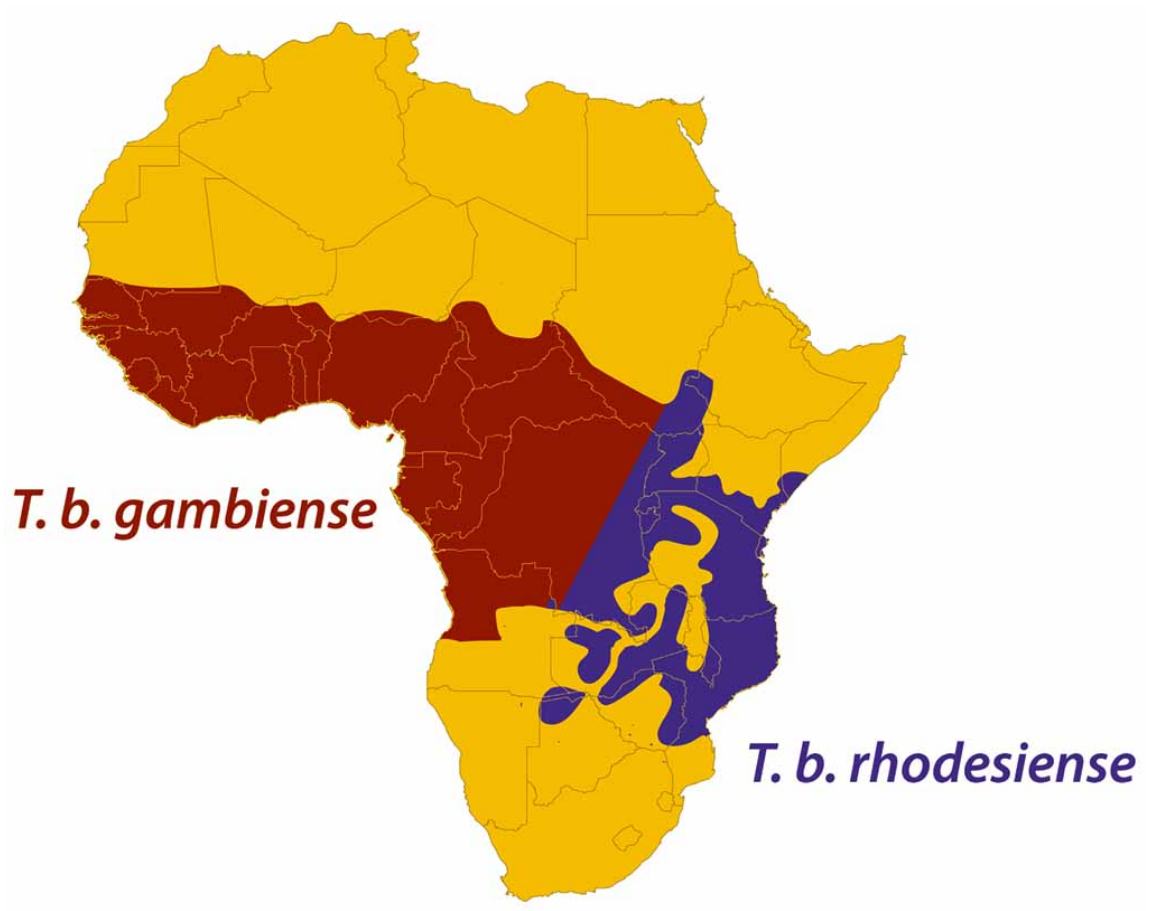

Fig. (5). Geographic distribution of the main subspecies of Trypanosoma brucei. Sleeping sickness occurs at a low level of transmission in the majority of countries in tropical Africa, with occasional epidemic outbreaks and at least 50 million people are at risk. Animal trypanosomiasis deters the breeding of domestic stock over large areas of the continent. The area with infected humans and animals is shown in red (see text, [http://www.dpd.cdc.gov/]).

by binary fission. These parasites can cross the blood-brain barrier and invade the central nervous system (CNS) in a few weeks. Tsetse flies are infected with bloodstream trypomastigotes when they suck the blood of an infected mammalian host. In the fly's midgut, parasites transform into procyclic trypomastigotes and multiply by binary fission. They then leave the midgut, transform into epimastigotes, reach the salivary glands, multiply by binary fission and transform into metacyclic trypomastigotes. This complete cycle in the fly takes approximately three weeks [217] (Fig. 6).

In the early stage of HAT, parasites are found in the bloodstream and lymphatic system (trypanosome proliferation) and symptoms include fever, chills, headache and lymphadenopathy. Immune activation is evident from lymph node enlargement, hepatomegaly and splenomegaly. Later, patients progress to the CNS stage, where the symptoms include severe headaches, insomnia, progressive mental deterioration, psychiatric manifestations and tremors. If left untreated, the disease finally culminates in seizures, somnolence, coma and death [217]. HAT is caused by infection with the morphologically indistinguishable subspecies $T$. brucei rhodesiense (in East and Southern Africa) and T. $b$. gambiense (in West and Central Africa). Over $90 \%$ of all reported cases of HAT are caused by T. brucei gambiense in which progression to late-stage disease may take several months or longer and late-stage CNS infection may last several years [386,387]. T. b. rhodesiense accounts for less than $10 \%$ of all reported cases of HAT but is responsible for the most virulent form of the disease with progression to latestage disease occurring in a matter of weeks and late-stage CNS infection usually leading to death within 3 months [381,388].
As all stages of African trypanosomes occur extracellularly, the parasites have evolved means to evade the host's innate and adaptive immune responses in the plasma mostly through antigenic variation involving variable surface glycoprotein (VSG) [389]. The surface of the parasite is covered with a dense layer of VSG homodimers (circa $10^{8}$ VSG molecules) attached to the trypanosome cell membrane via a GPI anchor [390]. T. brucei has about 1,000 VSG genes and pseudogenes and of these, only one is transcribed at a time from one of multiple telomeric VSG expression sites [391,392]. The mechanism of antigenic variation in trypanosomes consists of continuous random switching of VSG genes, enabling the parasite to maintain a state of chronic infection in the host that can last for years. The importance of this process is indicated by the fact that VSG genes occupy $10 \%$ of the trypanosome genome $[393,394]$.

VSG is involved in several mechanisms of escape from the host immune response such as the prevention of complement activation [389] and reduction of antibody titers against VSG, which occurs by the endocytosis of antibodyVSG complexes, followed by subsequent proteolysis of the antibody and recycling of the VSG back to the parasite surface [74]. VSG is an immunodominant antigen capable of eliciting both T-cell-dependent and -independent B-cell responses, depending on its conformation [395].

Mouse models of infection have shown that both host and parasite genetic factors may control the development of HAT. These factors interact in the immune response to infection, especially in the regulation of macrophage activation and inflammatory responses [396]. The first response of the host immune system consists of classically activated macrophages secreting pro-inflammatory molecules such as TNF, 


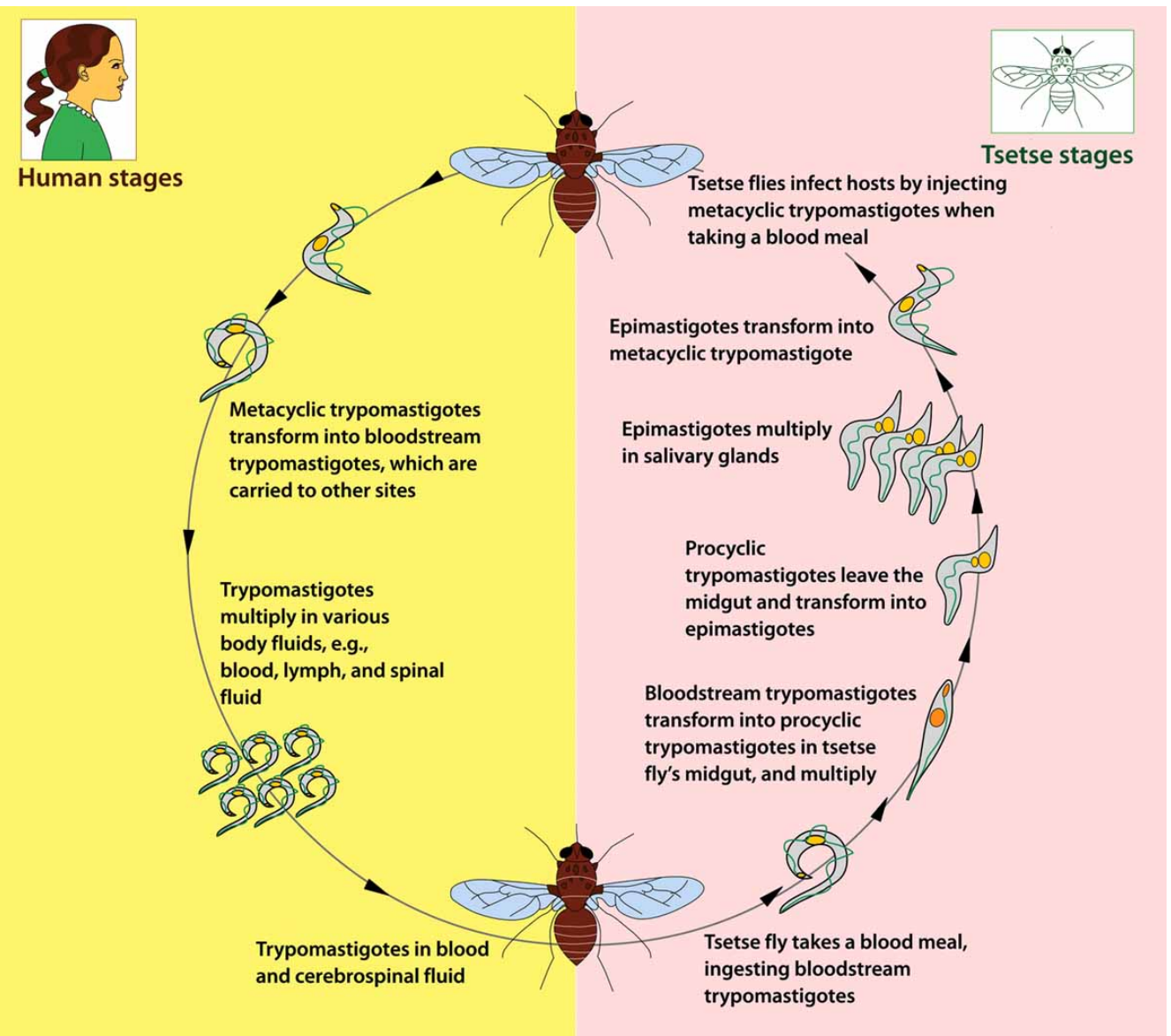

Fig. (6). Life cycle of Trypanosoma brucei. During a blood meal on the mammalian host, an infected tsetse fly (genus Glossina) injects metacyclic trypomastigotes into skin tissue. The parasites enter the lymphatic system and pass into the bloodstream. Inside the host, they transform into bloodstream trypomastigotes, are carried to other sites throughout the body, reach other blood fluids (e.g., lymph, spinal fluid) and continue the replication by binary fission. The entire life cycle of African Trypanosomes is represented by extracellular stages. The tsetse fly becomes infected with bloodstream trypomastigotes when taking a blood meal on an infected mammalian host. In the fly's midgut, the parasites transform into procyclic trypomastigotes, multiply by binary fission, leave the midgut and transform into epimastigotes. The epimastigotes reach the fly's salivary glands and continue multiplication by binary fission. The cycle in the fly takes approximately 3 weeks. Humans are the main reservoir for Trypanosoma brucei gambiense, but this species can also be found in animals. Wild animals are the main reservoir of $T$. $b$. rhodesiense (see text, [http://www.dpd.cdc.gov/]). Diagram based on Stuart et al. [217]. (Animated-life cycles T. brucei, T. cruzi and Leishmania spp. can be seen at the following site: http://www.who.int/tdrold/media/multimedia/lifecycle.htm).

IL-1, IL-6 and NO [397]. The GPI anchor of VSG also interacts with macrophages (via a presumed receptor) and induces the secretion of pro-inflammatory cytokines [390,398,399]. Interestingly, throughout both human and animal trypanosomiasis, TNF plays an important role in the control of parasitemia, as well as in the pathology resulting from infection (e.g., anemia, neurological disorders, fever and cachexia) $[397,400]$. VSG has been identified as the primary molecule inducing TNF in trypanosome-soluble extracts [397]. Apparently there are two modes of action for VSG: the glycosylinositolphosphate (GIP) fraction directly induces macrophage activation and the induction of TNF- $\alpha$ in macrophages following IFN- $\gamma$ stimulation, whereas the dimyristoylglycerol (DMG) component of the anchor is not able to induce TNF- $\alpha$ directly but is involved in macrophage priming [397].

A long, drawn-out inflammatory response can cause pathology; therefore, it is vital for the host to reduce inflammation by downregulating the classic activated macrophages and their pro-inflammatory cytokines. Longer survival of the host relies on the production of type II cytokines such as IL4, IL-10 and IL-13, which can induce macrophages to become more anti-inflammatory [401-404]. Comprehensive immune suppression affects both humoral (B cell) and cellular (T-cell and macrophage) immune functions [405], leading to trypanosome-induced immunopathology [406-408]. A frequent pathological trait is anemia, the degree of which is a sign of disease severity [409].

The main feature of HAT is a striking increase in immunoglobulin ( Ig) levels, particularly IgM, including both trypanosome-specific antibodies and non-specific Ig production induced by cytokine activation of B cells [410]. In African trypanosomiasis, the VSG-specific B cell responses can occur in a T-cell independent manner, although T-cells improve the B-cell response primarily by secreting cytokines that mediate antibody class switching [411]. From this perspective, increased IL-4 mRNA levels and a concomitant increase in IgG1 antibodies against VSG have been observed 
in trypanotolerant cattle infected with $T$. congolense, but not in trypanosusceptible cattle [404]. In animal trypanosomiasis, trypanotolerance involves the combination of a humoral response, which is necessary to control parasitemia, with the ability to oppress immunopathology [397]. Additionally, Bcells become suppressed or exhausted later in the infection, resulting in a total absence of IgG responses and a greatly reduced $\operatorname{IgM}$ response [397,412].

The humoral response to VSG has immunopathological consequences, e.g., the generation of auto-antibodies induced by molecular mimicry [413] and immune complex disease [414]. Furthermore, in the late CNS stage of infection, both trypanosome-specific IgG and IgM and polyclonal IgM responses have been detected in cerebrospinal fluid, which may be due to modified plasma cells in the white matter or plasma cells that form perivascular infiltrates in the brain [387,414].

In addition to antigenic variation, African trypanosomes cause a loss of various B cell populations, disable the host capacity to raise a long-lasting and specific protective antiparasite antibody response and abrogate vaccine-induced protective responses to non-related human pathogens [415].

Even more than 100 years since the discovery of African trypanosomes, only a few clinically useful drugs have been developed. These drugs are still considered unsatisfactory, however, mainly due to significant toxicity and severe side effects [217].

In the early stage of HAT, two drugs, pentamidine and suramin, are used against $T . b$. gambiense and $T$. b. rhodesiense, respectively. Pentamidine, an aromatic diamidine, has been used since the 1930s and acts by inducing changes in DNA topology and inhibiting topoisomerases, resulting in impaired DNA replication. Some adverse effects have been reported, however, such as nephrotoxicity and diabetes mellitus [416]. Suramin, a polysulfonated naphthalene derivative, was first used against sleeping sickness in 1922. The trypanocidal action of suramin is possibly due to inhibition of low density lipoprotein (LDL) uptake, affecting the parasite's supply of cholesterol and phospholipids. Unfortunately, this drug causes several side effects, mainly involving allergic reactions and renal complications [417].

For late-stage disease, the drugs of choice are melarsoprol (active against both $T$. $b$. gambiense and $T$. $b$. rhodesiense) and eflornithine (active only against $T$. b. gambiense). Melarsoprol, an arsenic derivative, has been used since 1949 and is the main drug of choice to date [418], although its mechanism of action remains unknown [419]. On the other hand, severe side effects have been observed with melarsoprol such as convulsions and other neurological sequelae that can precede coma and death in the reactive encephalopathy that afflicts $5-10 \%$ of treated patients [420] and is fatal in $10-70 \%$ of cases [421].

In contrast, eflornithine, an analog of the amino acid ornithine that acts by inhibiting the polyamine biosynthetic enzyme ornithine decarboxylase (ODC), is relatively safe. This drug has a similar affinity for both mammalian and trypanosomal ODCs, but it is degraded much more slowly in trypanosomes [418]. Recent clinical trials have shown that combinatorial therapy with eflornithine and nifurtimox is quite promising against the late/cerebral stage of $T . b . \mathrm{gam}$ biense infection [418,421].

The sequenced genome of $T$. brucei emphasized that generating a vaccine for AT is highly unlikely due to the alternate expression and recombination of a repertoire of approximately 1,000 genes encoding VSG [217,422]. On the other hand, characterization of invariable surface glycoproteins (ISGs) is an appealing alternative [394,423]. For instance, one of the ISG antigens has been used in DNA vaccine preparations against an experimental model of AT and shown to elicit humoral responses, achieve partial immune protection and preferentially induce Th1-like IgG2a anti- $T$. brucei antibodies. Furthermore, a DNA vaccine encoding a trans-sialidase gene induced partial immunoprotection against $T . b$. brucei in mice [424]. Preliminary data on vaccination with GPI in mice indicate that TNF-associated immunopathology is reduced in subsequently infected mice [390]. In other words, an understanding of the immunological components of this disease may offer new opportunities not only for vaccine development but also for therapeutic intervention [387].

\section{LEISHMANIASIS: LEISHMANIA SPP.}

Leishmaniasis is one of the major insect-borne diseases in developing countries. Leishmania species are found in most inter-tropical and temperate regions of the world. Transmission occurs through the bite of the insect vector, the phlebotomine sandfly. Leishmaniasis currently threatens 350 million people in 88 countries globally. Worldwide, 2 million new cases are estimated to occur annually and 12 million people are presently infected [210] (Fig. 7).

Leishmaniasis refers to a group of diseases that can be divided into cutaneous, diffuse cutaneous, mucocutaneous and visceral leishmaniasis; visceral leishmaniasis (VL) is lethal if untreated. Cutaneous leishmaniasis (CL) affects the skin, causing ulcers that usually heal after some weeks; the mucocutaneous form (MCL) causes ulceration, followed by the destruction of mucous membranes of the nasal, oral and throat cavities and surrounding tissues. The diffuse cutaneous form (DCL) produces disseminated and chronic skin lesions and it is more difficult to treat. Cases of DCL in Bolivia, Brazil and Peru account for $90 \%$ of all of the cases worldwide. The most dangerous form of leishmaniasis, however, is VL. It is characterized by high fever, weight loss, anemia and swelling of the liver and spleen [425]. Currently, another important aspect of the disease is co-infection with the human immunodeficiency virus (HIV); in these coinfection cases, the risk of development of VL increases by 100 to 1000 times [426].

The genus Leishmania was created in 1903 by Ross. Species of this genus are identified primarily by their clinical manifestation and geographic distribution. Other important criteria for classification include behavior of the parasite in sand fly and mammalian hosts [427], as well as biochemical and molecular characteristics [24,428-430]. More than twenty species have been described and allocated into two subgenera: Leishmania and Viannia [427,431]. The former contains species from both the Old World and the New World and the latter is composed only of species from the New World [432]. 


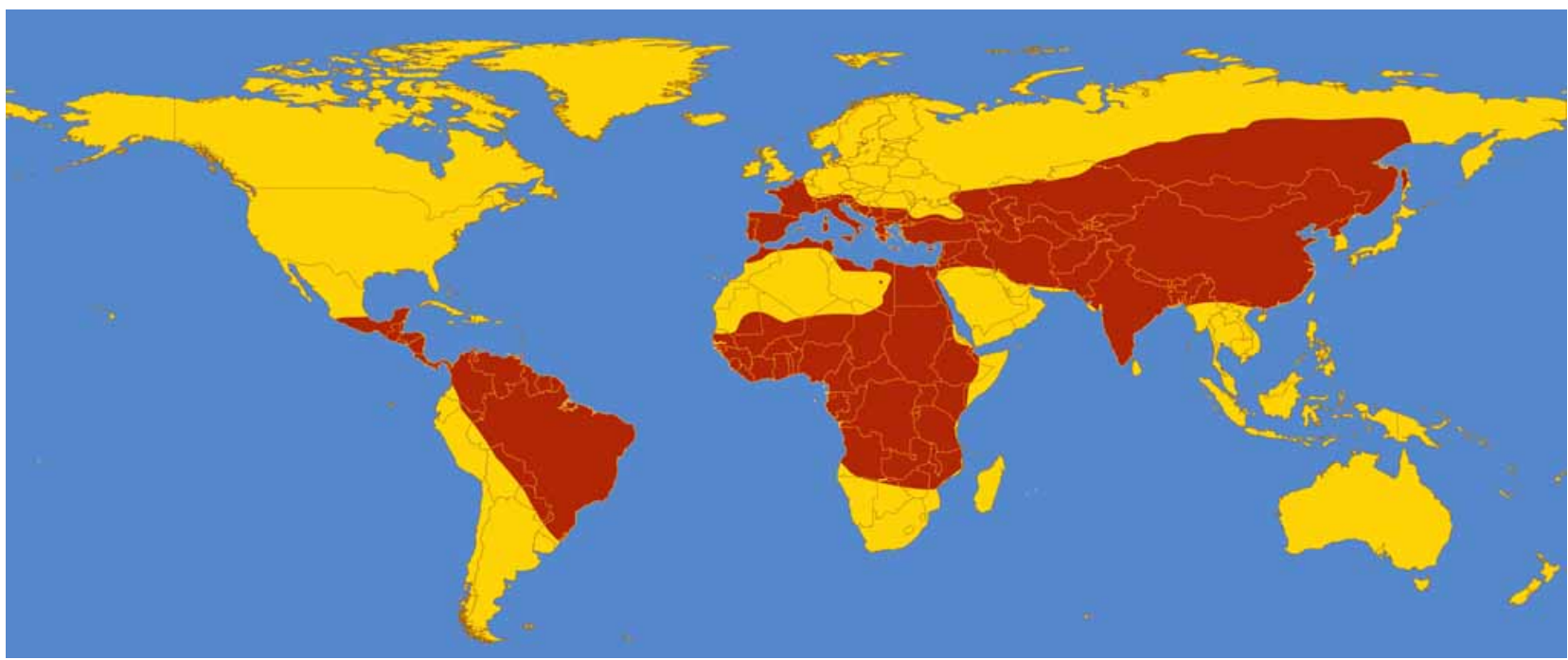

Fig. (7). Geographic distribution of endemic leishmaniasis. Leishmaniasis is found in parts of about 88 countries. Approximately 350 million people live in these areas. Most of the affected countries are in the tropics and subtropics. The settings in which leishmaniasis is found range from rain forests in Central and South America to deserts in West Asia. More than 90 percent of the world's cases of visceral leishmaniasis are in India, Bangladesh, Nepal, Sudan and Brazil. Leishmaniasis is found in Mexico, Central America and South America, from northern Argentina to Texas (not in Uruguay, Chile, or Canada), southern Europe (leishmaniasis is not common in travelers to southern Europe), Asia (not Southeast Asia), the Middle East and Africa (particularly East and North Africa, with some cases elsewhere). The areas with infected humans are shown in red (see text, [http://www.dpd.cdc.gov/]).

The life cycle of Leishmania involves three developmental forms: the amastigote, the procyclic promastigote (Fig. 1A) and the metacyclic promastigote [433]. The sandfly vector becomes infected when feeding on the blood of an infected individual or an animal reservoir host. In the sandfly, Leishmania parasites replicate as extracellular, actively motile, elongated (10-20 micrometers), flagellate procyclic promastigotes, which primarily inhabit the insect's alimentary tract. Procyclic promastigotes are multiplicative forms, not infective to mammalian hosts and found in the midgut. Metacyclic promastigotes are non-dividing forms, shorter than the procyclic promastigotes ( 7 to 10 micrometers), infective to mammalian hosts and found in the thoracic midgut and proboscis of the sandfly. When an infected sandfly feeds on a mammalian host, its proboscis pierces the skin and saliva-containing anti-coagulant is injected into the wound to prevent the blood from clotting; the metacyclic promastigotes are transferred to the host along with the saliva. Once in the host, the metacyclic promastigotes differentiate (after being phagocytosed by a macrophage) into the intracellular amastigote form (Fig. 1C). This form of the parasite, round and non-motile (3 to 7 micrometers in diameter), resides within the parasitophorous vacuole (a vacuole with lysosomal features), where it resists the microbiocidal action of the acid hydrolases from the lysozymes; the amastigote form survives and multiplies inside these vacuoles, eventually leading to lysis of the macrophages. The released amastigotes are taken up by additional macrophages, so the cycle continues. Ultimately, all the organs containing macrophages and phagocytes are infected, especially the spleen, liver and bone marrow [433] (Fig. 8).

The major components of the surface coat are free GPI glycolipids and/or bound to the cell surface via GPI. These components form protective layers that mediate host-parasite interactions; the constitution of this surface coat is precisely regulated during the course of the parasite life cycle [40]. Lipophosphoglycans are the most abundant macromolecules on the surface of Leishmania promastigotes and contain a structurally distinct GPI anchor [434]. Free GPIs constitute the major class of parasite molecules on the surface of amastigotes. However, amastigotes also acquire glycosphingolipids from the macrophage host; these glycosphingolipids appear to be incorporated into the exoplasm of the amastigote plasma membrane [40]. In fact, Leishmania species present many surface macromolecules, including GIPL and lipophosphoglycan (LPG), as well as the membrane proteins proteophosphoglycan (PPG), MSP/GP63 (major surface protein or $63-\mathrm{kDa}$ glycoprotein), PSA-2/GP46 (promastigote surface antigen-2 or 46-kDa glycoprotein) and amastin surface proteins (developmentally regulated amastigote proteins that are unique to the Trypanosomatidae). These glycoconjugates perform an important role in parasite adaptation and establishment in different hostile environments, such as the sandfly midgut and the macrophage phagolysosome $[257,435,436]$.

Neutrophils are short-lived leukocytes that are first recruited to inflamed tissues and thus play a crucial role in immunity to infection [437]. Neutrophils die by apoptosis, necrosis and NETosis [438], when they release fibrous traps of DNA, histones and granule proteins named neutrophil extracellular traps (NETs). These NETs attract and kill Leishmania efficiently, as previously described for fungi and bacteria [437].

To survive, Leishmania must evade activation of the mammalian host's immune responses. In the macrophages, the parasites undergo many rounds of replication and produce a great number of amastigotes [63]. During infection, upon activation, macrophages produce pro-inflammatory cytokines, such as interleukin 12 (IL-12), which induces the activation of Th-1 responses to combat intracellular parasites 


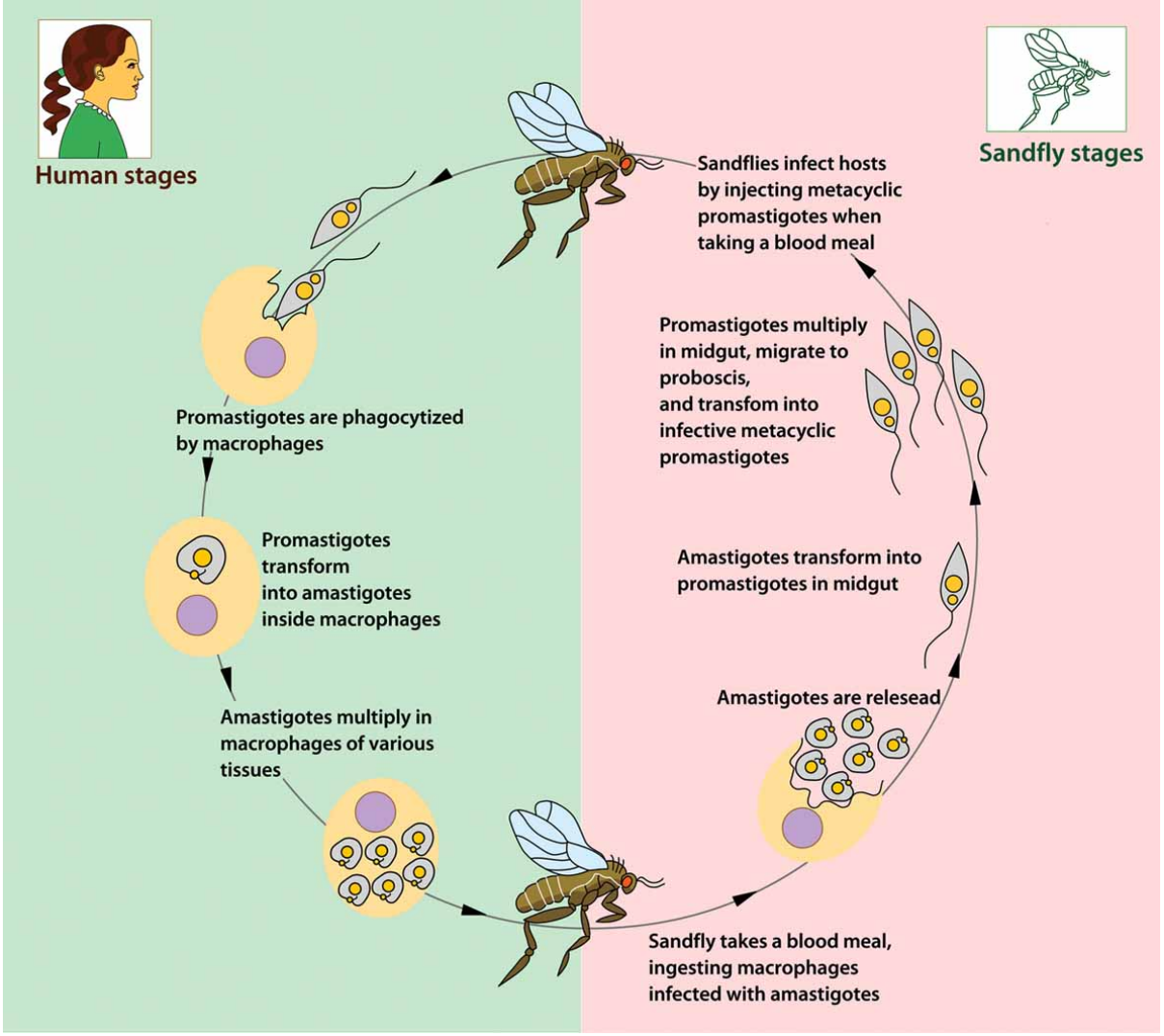

Fig. (8). Life-cycle of Leishmania spp. Leishmaniasis is transmitted by the bite of infected female phlebotomine sandflies. The sandflies inject the infective promastigotes from their proboscis during blood meals. Promastigotes that reach the wound are phagocytized by macrophages and other types of mononuclear phagocytic cells. Progmastigotes transform into amastigotes, which multiply by simple division and proceed to infect other mononuclear phagocytic cells. Parasite, host and other factors affect whether the infection becomes symptomatic and whether cutaneous or visceral leishmaniasis results. Sandflies become infected by ingesting infected cells during blood meals. In sandflies, amastigotes transform into promastigotes, develop in the gut and migrate to the proboscis (see text, [http://www.dpd.cdc.gov/]). Diagram based on Stuart et al. [217]. (Animated-life cycles T. brucei, T. cruzi and Leishmania spp. can be seen at the following site: http://www.who.int/tdrold/media/multimedia/lifecycle.htm).

[63]. Th-1 lymphocytes induce the activation of macrophages by secretion of INF- $\gamma$, which stimulates macrophages to produce nitric oxide, which is the major player in killing intracellular parasites [439]. The importance of TLR4 in the recognition of $L$. major promastigotes has been proposed [440]. Increased number of parasites in L. major-infected TLR $\%$ mice was shown to be associated with an overall increase in Th1- and Th2-like cytokine production in vitro [440]. On the other hand, a global decrease in both Th1- and Th2-like cytokines (IFN- $\gamma$ and IL-10) was observed in $L$. pifanoi-infected WT and TLR4\% mice [441].

There is still a need for innovative and alternative therapies against leishmaniasis. Despite decades of investigation, an efficacious vaccine against human leishmaniasis has not yet been developed, as attempts to confer significant protection against human leishmaniasis have ultimately failed $[217,426]$. On the other hand, the efficacy of a heterologous prime-boost vaccination using attenuated vaccinia virus and Leishmania DNA expressing an antigen homolog of receptors for activated $\mathrm{C}$ kinase has been shown [442]. Additionally, the first vaccine against canine leishmaniasis, Leishmune ${ }^{\circledR}$ vaccine, was recently licensed in Brazil. This vaccine presents around 76 to $80 \%$ effectiveness and has also been shown to be valuable in blocking transmission, causing a $79 \%$ reduction in the capacity for transmission by sandflies previously fed on serum of vaccinated dogs. In addition, this vaccine was also shown to effectively treat dogs infected with the parasite; at 22 months postvaccination, $90 \%$ of the animals were asymptomatic [443445].

The drugs currently used for the treatment of both VL and CL are the pentavalent antimonials, sodium stibogluconate and meglumine antimoniate. These drugs require longterm parenteral administration and are very toxic and almost obsolete. The antibiotic amphotericin B has been the drug of choice for the treatment of VL in India due to the emergence of drug-resistant parasites [217]. Miltefosine, a phospholipid derivative and the first oral treatment for VL, is effective against CL and was registered for treatment of both VL and CL in India and Colombia in 2002 and 2005, respectively. However, its use is limited because of potential teratogenicity $[217,446]$. Several groups of synthetic phospholipids have also shown activity against Leishmania and other protozoa $[217,447]$.

Molecular targets need to be validated as crucial for parasite growth or survival using gene knockout or knockdown technologies and/or using highly specific small molecule inhibitors. Current estimates suggest that about $10 \%$ of 
known genes are able to bind drug-like small molecules [217].

\section{PLANT INFECTIONS: PHYTOMONAS SPP.}

Phytophagous insects have generally been regarded as the primary vectors of Phytomonas spp. [448,449]. When a competent insect vector feeds on infected plant fluid, Phytomonas spp. reach the intestinal tract and, after migrating throughout the hemocele, reach the salivary glands. As the infected insect feeds on another plant, the flagellates are then transmitted via saliva [449-450]. Plant flagellates might also circulate between different insects, passing from one insect to another probably by coprophagy or during group feeding, common behaviors among insects [449,451] (Fig. 9).

After natural transmission in fruits and seeds, plant flagellates remain concentrated near the point of inoculation [448]. In lactiferous plants, the infection is generally limited and not all ducts are infected [452]. In contrast, flagellates that infect phloem vessels may disseminate throughout the vascular bundle [453]. Whereas the infection of fruits, seeds and latex tubes is not harmful, the infection of phloem sap is generally associated with lethal disease $[453,454]$. The pathology promoted by $P$. francai in Manihot palmata (esculenta), popularly known as cassava or manioc, results in chlorosis of the leaves and considerable atrophy of the roots, causing producers to incur major losses [449].

Little is known about the geographical distribution of species of the genus Phytomonas. Thus far, it has been recognized that the genus Phytomonas is endemic in South America, with most species isolated from Brazil; in a few
European countries, particularly in Spain and France; in Asia, particularly in India and China; and in Northwest Africa $[455,456]$ (Fig. 10). These findings suggest that the genus Phytomonas may be dispersed globally and strains from several other places in the world may be isolated within the next few years.

Vickerman and Preston [459] proposed that only trypanosomatids with a digenetic life cycle in plants and insects that retain the promastigote form throughout should be considered Phytomonas. On the other hand, a century after the first description of the genus, clear criteria to define plant isolates at the species level are still not available. A feature that is very common among Phytomonas promastigotes, but not commonly observed in insect trypanosomatids, is a corkscrew shape of the cellular body [460-462]. Another peculiar feature present in all Phytomonas species studied to date is extreme variation in shape and size depending on whether they grow in a host (plant or insect) or in axenic medium [463]. These changes in the form and shape of Phytomonas promastigotes may be the result of physiological changes that these trypanosomatids undergo in their hosts. All currently known plant trypanosomatids have been grouped in the genus Phytomonas, although they can differ greatly in terms of both their biological properties and their effects on the host [463].

When analyzed by electron microscopy, plant flagellates show the standard ultrastructure displayed by the majority of trypanosomatids. Perhaps the only unique trait of the cellular organization of plant flagellates is the pronounced quantity of glycosomes [106]. In all trypanosomatids, a large part of

\section{Phytophagous Insect}

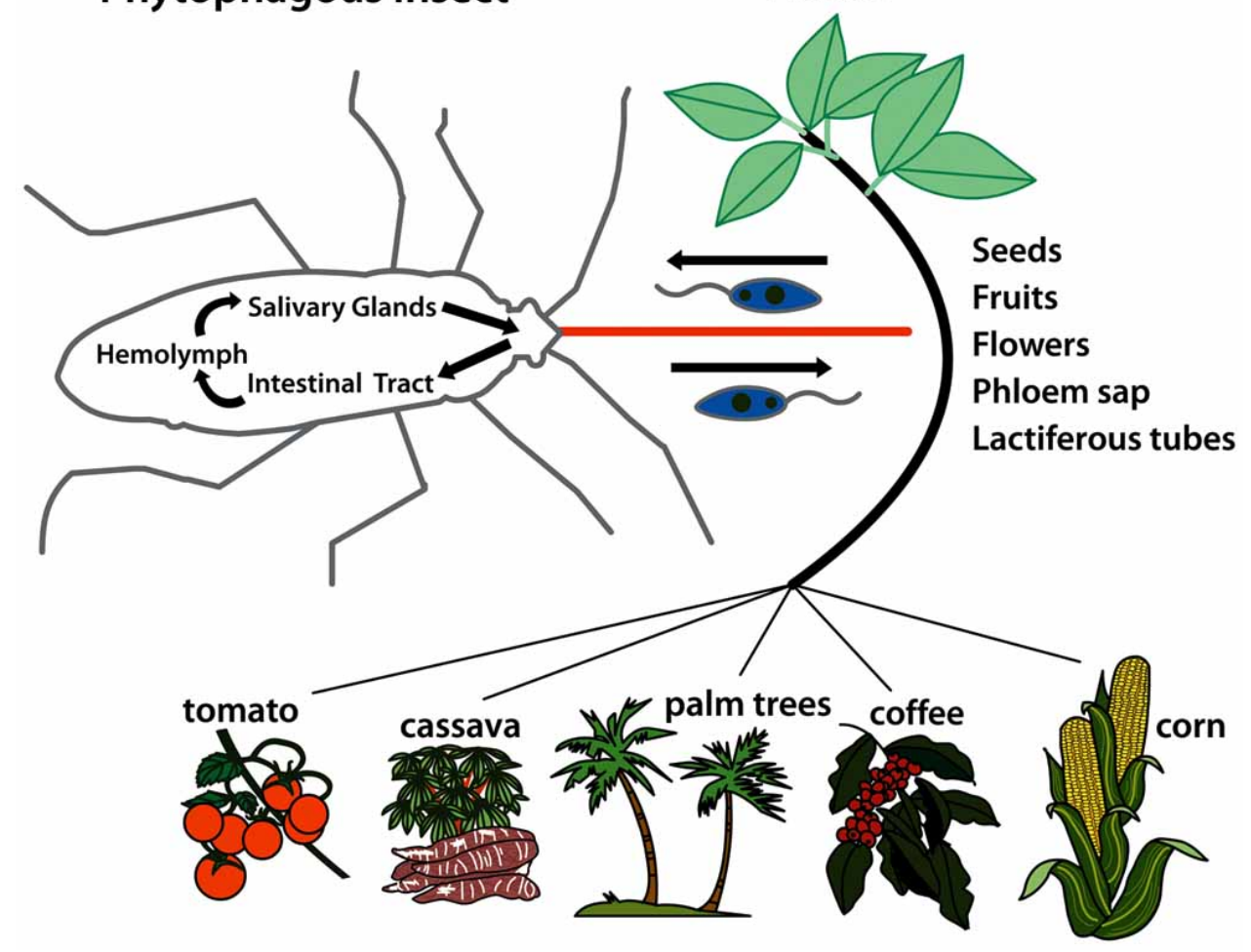

Fig. (9). Life cycle and transmission of Phytomonas spp. Parasites ingested by phytophagous insects reach the intestinal tract and pass through the hemocele, migrating through the hemolymph to infect the salivary glands. The infected insect transmits the parasites via saliva when it feeds on another plant. The major plant cultures affected by Phytomonas spp. are shown. 


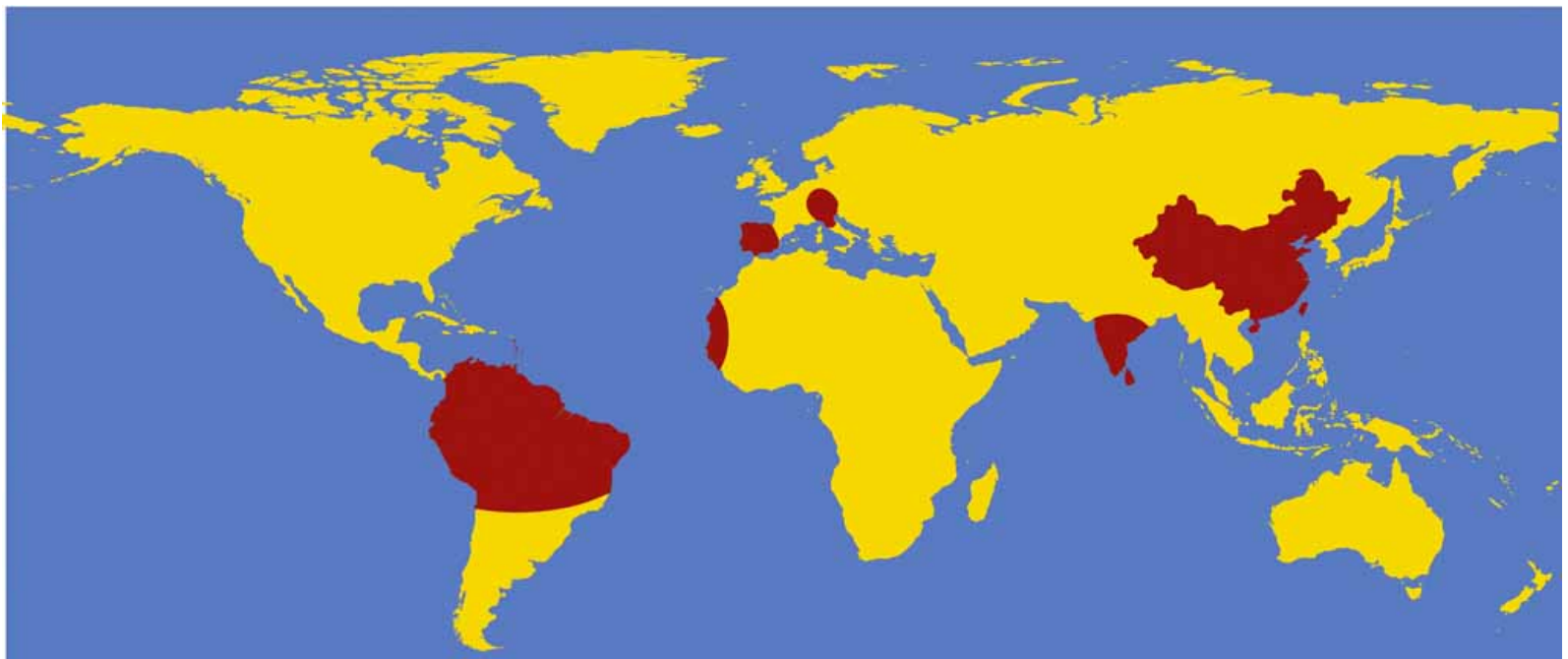

Fig. (10). Geographic distribution of Phytomonas spp. The map shows the distribution of Phytomonas spp-infected plants (in red) (see text [http://www.dpd.cdc.gov/]). Diagram based on Sturm et al. [456], Dollet et al. [457] and Votypka et al. [458].

glycolysis is performed in glycosomes [119]. The importance of these organelles for Phytomonas spp. is extremely pronounced once the plant stage is reached given that the mitochondria do not contain a functional Krebs cycle, cytochromes or the classical respiratory chain and the parasites are not able to catabolize amino acids; therefore, ATP production is based on glycolysis [464-466]. Respiration in these parasites is insensitive to inhibitors of ubiquinolcytochrome $c$ oxidoreductase (respiratory Complex III or $b c 1$ ) and cytochrome $c$ oxidase (respiratory Complex IV) [467]; however, respiration is entirely sensitive to salicylhydroxamic acid (SHAM), an inhibitor of cytochromeindependent trypanosome alternative oxidase (TAO) [138]. TAO performs a terminal oxidation step in a multicomponent pathway that serves to re-oxidize NADH produced during glycolysis [467]. This metabolic pattern is similar to that observed in a long, slender bloodstream form of Trypanosoma brucei, whereas in Phytomonas spp., it is observed in culture [467].

The plant stage of Phytomonas spp. involves the secretion of enzymes that the utilization of cellulose, starch, sucrose and xylulose, carbohydrates present in large quantities in the phloem, latex and fruits [12]. P. serpens possesses peptidases that share biochemical and biological functions with the metallopeptidase gp63 and cysteine peptidases, which are virulence factors present in Leishmania spp. and $T$. cruzi, respectively [257,468-471]. The importance of these peptidases in the interaction of Phytomonas species with the salivary glands of insect vectors has been demonstrated [468,472].

Recent studies have demonstrated immunological similarities between $P$. serpens and $T$. cruzi. For instance, serum samples from Chagas disease patients showed strong reactivity against $P$. serpens. In addition, the immunoprotective proprieties of $P$. serpens antigens were clearly demonstrated in mice previously immunized either orally or intraperitoneally with $P$. serpens that then showed reduced parasitemia and an increase in survival after being challenged with a known lethal inoculum of $T$. cruzi [473].
The genus Phytomonas has been considered a monophyletic group more closely related to insect trypanosomatids and Leishmania than to the genus Trypanosoma [2,24,474-476]. On the other hand, recent wide evolutionary divergence among members of the genus Phytomonas has been described and extremely different genomic organization between two Phytomonas groups has been observed $[477,478]$. Most notably, the chromosome number was found to be 7 in one Phytomonas group (with a genome size of 10 $\mathrm{Mb}$ ) versus 21 in another group (25 $\mathrm{Mb})$. These data demonstrate unsuspected genomic diversity among plant trypanosomatids that may justify further debate about their division into different genera [478].

\section{PERSPECTIVES}

The governments and pharmaceutical companies still regard parasitic diseases as neglected diseases. Considerable progress made by control programmes in some endemic localities contrasts with persisting difficulties in other vast geographic regions. Recent emergence of the diseases in non-endemic areas because of population migrations has become a problem. Drugs for treatment of these diseases are limited, poorly tolerated and not very effective, especially with raising numbers of drug resistance. On the other hand, the scientific community has grown to appreciate the importance of parasites as models for studying evolution, speciation and other questions of broader significance in biology. Molecular epidemiology and phylogeography, combined with insightful laboratory experiments, have transformed our understanding of the diseases caused by $T$. cruzi, T. bruce $i$ and Leishmania. Intriguing questions remain to be answered and new techniques, especially for developing better drugs, need to be improved.

\section{ACKNOWLEDGEMENTS}

We dedicate this review to Maria de Nazareth Silveira Leal de Meirelles, who has always been an outstanding adviser. We wish to express our gratitude to Mr. João Müller Haddad, who kindly made the diagrams depicted in this review. The studies performed in our laboratories were supported by the Brazilian financial agencies Conselho Nacional 
de Desenvolvimento Cientifico e Tecnológico (CNPq), Coordenação de Aperfeiçoamento de Pessoal de Nível Superior (CAPES), Fundação de Amparo a Pesquisa Carlos Chagas Filho (FAPERJ) and Instituto Nacional de Ciência e Tecnologia em Entomologia Molecular.

\section{REFERENCES}

[1] Moreira D, López-García P, Vickerman K. An updated view of kinetoplastid phylogeny using environmental sequences and a closer outgroup: proposal for a new classification of the class Kinetoplastea. Int J Syst Evol Microbiol 2004; 54: 1861-75.

[2] Simpson AG, Stevens J, Lukes J. The evolution and diversity of kinetoplastid flagellates. Trends Parasitol 2006; 22: 168-74.

[3] De Souza W, Motta MC. Endosymbiosis in protozoa of the Trypanosomatidae family. FEMS Microbiol Lett 1999; 173: 1-8.

[4] Simpson L, Thiemann OH, Savill NJ, Alfonzo JD, Maslov DA. Evolution of RNA editing in trypanosome mitochondria. Proc Natl Acad Sci USA 2000; 97: 6986-93.

[5] Podlipaev S. Insect trypanosomatids: the need to know more. Mem Inst Oswaldo Cruz 2000; 95: 517-22.

[6] Lukes J, Guilbride DL, Votýpka J, et al. Kinetoplast DNA network: evolution of an improbable structure. Eukaryot Cell 2002; 1: 495502 .

[7] Beverley SM. Protozomics: trypanosomatid parasite genetics comes of age. Nat Rev Genet 2003; 4: 11-9.

[8] Duncan RC, Salotra P, Goyal N, et al. The application of gene expression microarray technology to kinetoplastid research. Curr Mol Med 2004; 4: 611-21.

[9] Lukes J, Hashimi H, Zíková A. Unexplained complexity of the mitochondrial genome and transcriptome in kinetoplastid flagellates. Curr Genet 2005; 48: 277-99.

[10] Santos AL, Branquinha MH, D'Avila-Levy CM. The ubiquitous gp63-like metalloprotease from lower trypanosomatids: in the search for a function. An Acad Bras Cienc 2006; 78: 687-714.

[11] Motta MC. Endosymbiosis in protozoa of the Trypanosomatidae family. FEMS Microbiol Lett 1999; 173: 1-8.

[12] Tielens AG, Van Hellemond JJ. Surprising variety in energy metabolism within Trypanosomatidae. Trends Parasitol 2009; 25: 48290.

[13] Wallace FG. The trypanosomatids parasites of insects and arachnids. Exp Parasitol 1966; 18: 124-93.

[14] Vickerman K. The evolutionary expansion of the trypanosomatid flagellates. Int J Parasitol 1994; 24: 1317-31.

[15] Svobodová M, Zídková L, Cepicka I, et al. Sergeia podlipaevi gen. nov., sp. nov. (Trypanosomatidae, Kinetoplastida), a parasite of biting midges (Ceratopogonidae, Diptera). Int J Syst Evol Microbiol 2007; 57: 423-32.

[16] Vickerman K. "Not a very nice subject." Changing views of parasites and parasitology in the twentieth century. Parasitology 2009; 136: $1395-402$.

[17] Poinar G Jr, Poinar R. Evidence of vector-borne disease of early cretaceous reptiles. Vector Borne Zoonotic Dis 2004; 4: 281-4.

[18] Poinar G Jr, Poinar R. Fossil evidence of insect pathogens. J Invertebr Pathol 2005; 89: 243-50.

[19] Podlipaev S. The more insect trypanosomatids under study-the more diverse Trypanosomatidae appears. Int J Parasitol 2001; 31: 648-52.

[20] Stevens J, Noyes HA, Schofield CJ, Gibson W. The molecular evolution of Trypanosomatidae. Adv Parasitol 2001; 48: 1-56.

[21] Hoare CA, Wallace FG. Developmental stages of trypanosomatid flagellates: a new terminology. Nature 1966; 212: 1385-6.

[22] Lopes AH, Costa e Silva Filho F, Alviano CS, et al. Changes in cell surface anionogenic groups induced by propranolol in Herpetomonas muscarum muscarum. J Protozool 1989; 36: 231-7.

[23] Momen H. Some current problems in the systematics of Trypanosomatids. Int J Parasitol 2001; 31: 640-2.

[24] Yurchenko V, Lukes J, Xu X, Maslov DA. An integrated morphological and molecular approach to a new species description in the Trypanosomatidae: the case of Leptomonas podlipaevi n. sp., a parasite of Boisea rubrolineata (Hemiptera: Rhopalidae). J Eukaryot Microbiol 2006; 53: 103-11.

[25] Levine ND, Corliss JO, Cox FE, et al. A newly revised classification of the protozoa. J Protozool 1980; 27: 37-58.
[26] Abreu Filho BA, Dias Filho BP, Vermelho AB, et al. Surface component characterization as taxonomic tools for Phytomonas spp. Parasitol Res 2001; 87:138-44.

[27] D'Avila-Levy CM, Araújo FM, Vermelho AB, et al. Differential lectin recognition of glycoproteins in choanomastigote-shaped trypanosomatids: taxonomic implications. FEMS Microbiol Lett 2004; 231: 171-6.

[28] Miranda K, Docampo R, Grillo O, De Souza W. Acidocalcisomes of trypanosomatids have species-specific elemental composition. Protist 2004; 155: 395-405.

[29] Santos AL, Abreu CM, Alviano CS, Soares RM. Use of proteolytic enzymes as an additional tool for trypanosomatid identification. Parasitology 2005; 130: 79-88.

[30] Fernandes O, Santos SS, Cupolillo E, et al. A mini-exon multiplex polymerase chain reaction to distinguish the major groups of Try. panosoma cruzi and T. rangeli in the Brazilian Amazon. Trans $\mathrm{R}$ Soc Trop Med Hyg 2001; 95: 97-9.

[31] Crain PF, Alfonzo JD, Rozenski J, et al. Modification of the universally unmodified uridine- 33 in a mitochondria-imported edited tRNA and the role of the anticodon arm structure on editing efficiency. RNA 2002; 8: 752-61.

[32] Hamilton PB, Stevens JR, Gaunt MW, Gidley J, Gibson WC. Trypanosomes are monophyletic: evidence from genes for glyceraldehyde phosphate dehydrogenase and small subunit ribosomal RNA. Int J Parasitol 2004; 34: 1393-404.

[33] Schaub GA. Interactions of Trypanosomatids and Triatomines. In Advances in Insect Physiology; Stephen JS, Casas J. Eds. Elsevier Ltd, Academic Press 2009, 37: 177-242.

[34] Yurchenko VY, Lukes J, Tesarová M, Jirku M, Maslov DA. Morphological discordance of the new trypanosomatid species phylogenetically associated with the genus Crithidia. Protist 2008; 159: 99-114.

[35] Matthews KR. The developmental cell biology of Trypanosoma brucei. J Cell Sci 2005; 118: 283-90.

[36] Tyler KM, Engman DM. The life cycle of Trypanosoma cruzi revisited. Int J Parasitol 2001; 31: 472-81.

[37] Simpson L. Death of the "ologies". Protist 2006; 157: 361-2.

[38] Schneider A, Bursać D, Lithgow T. The direct route: a simplified pathway for protein import into the mitochondrion of trypanosomes. Trends Cell Biol 2008; 18: 12-8.

[39] De Souza W. An introduction to the structural organization of parasitic protozoa. Curr Pharm Des 2008; 14: 822-38.

[40] Ilgoutz SC, McConville MJ. Function and assembly of the Leishmania surface coat. Int J Parasitol 2001; 31: 899-908.

[41] Nakayasu ES, Yashunsky DV, Nohara LL, et al. GPIomics: global analysis of glycosylphosphatidylinositol-anchored molecules of Trypanosoma cruzi. Mol Syst Biol 2009; 5: 261-79.

[42] Vickerman K. On the surface coat and flagellar adhesion in trypanosomes. J Cell Sci 1969; 5: 163-93.

[43] De Souza W, Meyer H. An electron microscopic and cytochemical study of the cell coat of Trypanosoma cruzi in tissue cultures. Z Parasitenkd 1975; 46: 179-87.

[44] De Souza W, Arguello C, Martinez-Paloma A, et al. Surface charge of Trypanosoma cruzi. Binding of cationized ferritin and measurement of cellular electrophoretic mobility. J Protozool 1977; 24: 411-5.

[45] Landfear SM. Transporters for drug delivery and as drug targets in parasitic protozoa. Clin Pharmacol Ther 2010; 87: 122-5.

[46] Landfear SM, Ullman B, Carter NS, Sanchez MA. Nucleoside and nucleobase transporters in parasitic protozoa. Eukaryot Cell 2004; 3: 245-54.

[47] Landfear SM. Drugs and transporters in kinetoplastid protozoa. Adv Exp Med Biol 2008; 625: 22-32.

[48] Dean S, Marchetti R, Kirk K, Matthews KR. A surface transporter family conveys the trypanosome differentiation signal. Nature 2009; 459: 213-7.

[49] Gaur U, Showalter M, Hickerson S, et al. Leishmania donovani lacking the Golgi GDP-Man transporter LPG2 exhibit attenuated virulence in mammalian hosts. Exp Parasitol 2009; 122: 182-91.

[50] Landfear SM, Ignatushchenko M. The flagellum and flagellar pocket of trypanosomatids. Mol Biochem Parasitol 2001; 115: 117.

[51] Gull K. Host-parasite interactions and trypanosome morphogenesis: a flagellar pocketful of goodies. Curr Opin Microbiol 2003; 6: 365-70. 
[52] Ralston KS, Kabututu ZP, Melehani JH, Oberholzer M, Hill KL. The Trypanosoma brucei flagellum: moving parasites in new directions. Annu Rev Microbiol 2009; 63: 335-62.

[53] Portman N, Gull K. The paraflagellar rod of kinetoplastid parasites: from structure to components and function. Int J Parasitol 2010; 40: 135-48.

[54] Farina M, Attias M, Souto-Padron T, De Souza W. Further studies on the organization of the paraxial rod of trypanosomatids. J Protozool 1986; 33: 552-7.

[55] Bastin P, Gull K. Assembly and function of complex flagellar structures illustrated by the paraflagellar rod of trypanosomes. Protist 1999; 150: 113-23.

[56] Oberholzer M, Lopez MA, McLelland BT, Hill KL. Social motility in African trypanosomes. PLoS Pathog 2010; 6(1): e1000739.

[57] Hill KL. Parasites in motion: flagellum-driven cell motility in African trypanosomes. Curr Opin Microbiol 2010; 13: 459-65.

[58] Elias MC, da Cunha JP, de Faria FP, et al. Morphological events during the Trypanosoma cruzi cell cycle. Protist 2007; 158: 147-57.

[59] Vannier-Santos MA, Martiny A, de Souza W. Cell biology of Leishmania spp.: invading and evading. Curr Pharm Des 2002; 8: 297-318.

[60] Rittig MG, Bogdan C. Leishmania-host-cell interaction: complexities and alternative views. Parasitol Today 2000; 16: 292-7.

[61] Kollien AH, Schmidt J, Schaub GA. Modes of association of Trypanosoma cruzi with the intestinal tract of the vector Triatoma infestans. Acta Trop 1998; 70: 127-41.

[62] Cuvillier A, Miranda JC, Ambit A, Barral A, Merlin G. Abortive infection of Lutzomyia longipalpis insect vectors by aflagellated LdARL-3A-Q70L overexpressing Leishmania amazonensis parasites. Cell Microbiol 2003; 5: 717-28.

[63] Olivier M, Gregory DJ, Forget G. Subversion mechanisms by which Leishmania parasites can escape the host immune response: a signaling point of view. Clin Microbiol Rev 2005; 18: 293-305.

[64] Yoshida N, Cortez M. Trypanosoma cruzi: parasite and host cell signaling during the invasion process. Subcell Biochem 2008; 47: 82-91.

[65] Dillon RJ, Ivens AC, Churcher C, et al. Analysis of ESTs from Lutzomyia longipalpis sand flies and their contribution toward understanding the insect-parasite relationship. Genomics 2006; 88: 831-40.

[66] Whitten M, Sun F, Tew I, et al. Differential modulation of Rhodnius prolixus nitric oxide activities following challenge with Trypanosoma rangeli, T. cruzi and bacterial cell wall components. Insect Biochem Mol Biol 2007; 37: 440-52.

[67] Van Den Abbeele J, Claes Y, van Bockstaele D, Le Ray D, Coosemans M. Trypanosoma brucei spp. development in the tsetse fly: characterization of the postmesocyclic stages in the foregut and proboscis. Parasitology 1999; 118: 469-78.

[68] Portman N, Lacomble S, Thomas B, McKean PG, Gull K. Combining RNA interference mutants and comparative proteomics to identify protein components and dependencies in a eukaryotic flagellum. J Biol Chem 2008; 284: 5610-9.

[69] Paindavoine P, Rolin S, Van Assel S, et al. A gene from the variant surface glycoprotein expression site encodes one of several transmembrane adenylate cyclases located on the flagellum of Trypanosoma brucei. Mol Cell Biol 1992; 12: 1218-25.

[70] Oberholzer M, Bregy P, Marti G, et al. Trypanosomes and mammalian sperm: one of a kind? Trends Parasitol 2007; 23: 71-7.

[71] Oberholzer M, Marti G, Baresic M, et al. The Trypanosoma brucei cAMP phosphodiesterases TbrPDEB1 and TbrPDEB2: flagellar enzymes that are essential for parasite virulence. FASEB J 2007. 21: 720-31.

[72] Moreira-Leite FF, Sherwin T, Kohl L, Gull K. A trypanosome structure involved in transmitting cytoplasmic information during cell division. Science 2001; 294: 610-2.

[73] Webster P, Russell DG. The flagellar pocket of trypanosomatids. Parasitol Today 1993; 9: 201-6.

[74] Engstler M, Pfohl T, Herminghaus S, et al. Hydrodynamic flowmediated protein sorting on the cell surface of trypanosomes. Cell 2007; 131: 505-15.

[75] Gull K. The cytoskeleton of trypanosomatid parasites. Annu Rev Microbiol 1999; 53: 629-55.

[76] Sant'Anna C, Campanati L, Gadelha C, et al. Improvement on the visualization of cytoskeletal structures of protozoan parasites using high-resolution field emission scanning electron microscopy (FESEM). Histochem Cell Biol 2005; 124: 87-95.
[77] Corrêa JR, Atella GC, Menna-Barreto RS, Soares MJ. Clathrin in Trypanosoma cruzi: in silico gene identification, isolation and localization of protein expression sites. J Eukaryot Microbiol 2007; 54: 297-302.

[78] Corrêa JR, Atella GC, Batista MM, Soares MJ. Transferrin uptake in Trypanosoma cruzi is impaired by interference on cytostomeassociated cytoskeleton elements and stability of membrane cholesterol, but not by obstruction of clathrin-dependent endocytosis. Exp Parasitol 2008; 119: 58-66.

[79] De Melo LD, Sant'Anna C, Reis SA, et al. Evolutionary conservation of actin-binding proteins in Trypanosoma cruzi and unusual subcellular localization of the actin homologue. Parasitology 2008; 135: 955-65.

[80] Vercesi AE, Moreno SNJ, Docampo R. $\mathrm{Ca}^{2+} / \mathrm{H}^{+}$Exchange in acid vacuoles of Trypanosoma brucei. Biochem J 1994; 304: 227-33.

[81] Docampo R, Scott DA, Vercesi AE, Moreno SN. Intracellular $\mathrm{Ca}^{2+}$ storage in acidocalcisomes of Trypanosoma cruzi. Biochem J 1995; 310: 1005-12.

[82] Moreno SN, Zhong L. Acidocalcisomes in Toxoplasma gondii tachyzoites. Biochem J 1996; 313: 655-9.

[83] Marchesini N, Luo S, Rodrigues CO, Moreno SN, Docampo R. Acidocalcisomes and a vacuolar $\mathrm{H}^{+}$-pyrophosphatase in malaria parasites. Biochem J 2000; 347: 243-53.

[84] Ruiz FA, Marchesini N, Seufferheld M, Govindjee, Docampo R. The polyphosphate bodies of Clamydomonas reinhardtii possess a proton-pumping pyrophosphate and are similar to acidocalcisomes. J Biol Chem 2001; 276: 46196-203.

[85] Marchesini N, Ruiz FA, Vieira M, Docampo R. Acidocalcisomes are functionally linked to the contractile vacuole of Dictyostelium discoideum. J Biol Chem 2002; 277: 8146-53.

[86] Seufferheld M, Vieira MC, Ruiz FA, Rodrigues CO, Moreno SN, Docampo R. Identification of organelles in bacteria similar to acidocalcisomes of unicellular eukaryotes. J Biol Chem 2003; 278: 29971-78.

[87] Seufferheld M, Lea CR, Vieira M, Oldifield E, Docampo R. The $\mathrm{H}^{+}$-pyrophosphatase of Rhodospirillum rubrum is predominantly located in polyphosphate-rich acidocalcisomes. J Biol Chem 2004; 279: 51193-202.

[88] Ruiz FA, Lea CR, Oldfield E, Docampo R. Human platelet dense granules contain polyphosphate and are similar to acidocalcisomes of bacteria and unicellular eukaryotes. J Biol Chem 2004; 279: 44250-57.

[89] Moreno SN, Docampo R. The role of acidocalcisomes in parasitic protists. J Eukaryot Microbiol 2009; 56: 208-13.

[90] Miranda K, Benchimol M, Docampo R, de Souza W. The fine structure of acidocalcisomes in Trypanosoma cruzi. Parasitol Res 2000; 86: 373-84.

[91] Docampo R, De Souza W, Miranda K, Rohloff P, Moreno SN Acidocalcisomes - conserved from bacteria to man. Nat Rev Microbiol 2005; 3: 251-61.

[92] Moreno B, Urbina JA, Oldifield E, Bailey BN, rodrigues CO, Docampo R. ${ }^{31} \mathrm{P}$ NMR spectroscopy of Trypanosoma brucei, Trypanosoma cruzi and Leishmania major. Evidence for high levels of condensed inorganic phosphates. J Biol Chem 2000; 275: 2835662 .

[93] Rohloff P, Rodrigues CO, Docampo R. Regulatory volume decrease in Trypanosoma cruzi involves amino acid efflux and changes in intracellular calcium. Mol Biochem Parasitol 2003; 126: 219-30.

[94] Fang J, Ruiz FA, Docampo M, et al. Overexpression of a $\mathrm{Zn}^{2+}$ sensitive soluble exopolyphosphate from Trypanosoma cruzi depletes polyphosphate and affects osmoregulation. J Biol Chem 2007; 282: 32501-10.

[95] Docampo R, Ulrich P, Moreno SN. Evolution of acidocalcisomes and their role in polyphosphate storage and osmoregulation in eukaryotic microbes. Phil Trans R Soc B 2010; 365: 775-84.

[96] Ruiz FA, Rodrigues CO, Docampo R. Rapid changes in polyphosphate content within acidocalcisomes in response to cell growth, differentiation and environmental stress in Trypanosoma cruzi. J Biol Chem 2001; 276: 26114-21.

[97] Montalveti A, Rohloff P, Docampo R. A functional aquaporin colocalizes with the vacuolar proton pyrophosphatase to acidocalcisomes and the contractile vacuole complexo of Trypanosoma cruzi. J Biol Chem 2004; 279: 38673-82. 
[98] Rohloff P, Montalvetti A, Docampo R. Acidocalcisomes and the contractile vacuole complex are involved in osmoregulation in Trypanosoma cruzi. J Biol Chem 2004; 279: 52270-81

[99] Neira I, Ferreira AT, Yoshida N. Activation of distinct signal transduction pathways in Trypanosoma cruzi isolates with differential capacity to invade host cells. Intl J Parasitol 2002; 32: 405-14.

[100] Fernandes AB, Neira I, Ferreira AT, Mortara RA. Cell invasion by Trypanosoma cruzi amastigotes of distinct infectivities: studies on signaling pathway. Parasitol Res 2006; 100: 59-68.

[101] Menna-Barreto RF, Henriques-Pons A, Pinto AV, et al. Effect of a beta-lapachone-derived naphthoimidazole on Trypanosoma cruzi: identification of target organelles. J Antimicrob Chemother 2005; 56: 1034-41.

[102] Docampo R, Moreno SN. The acidocalcisome as a target for chemotharapeutic agents in protozoan parasites. Curr Pherm Des 2008; 14: 882-8.

[103] De Souza W, Meyer H. On the fine structure of the nucleus in Trypanosoma cruzi in tissue culture forms. Spindle fibers in the dividing nucleus. J Protozool 1974; 21: 48-52.

[104] Solari AJ. Mitosis and genome partition in trypanosomes. Biocell 1995; 19: 65-84.

[105] Elias MC, Marques-Porto R, Freymüller E, Schenkman S. Transcription rate modulation through the Trypanosoma cruzi life cycle occurs in parallel with changes in nuclear organisation. Mol Biochem Parasitol 2001; 112: 79-90.

[106] De Souza W. Structural organization of Trypanosoma cruzi. Mem Inst Oswaldo Cruz 2009; 104: 89-100.

[107] NIH BAC Resource Network (http://www.genome.gov/10001844)

[108] Weatherly DB, Boehlke C, Tarleton RL. Chromosome level assembly of the hybrid Trypanosoma cruzi genome. BMC Genomics 2009; 10: 255-68.

[109] Gray MW. The endosymbiont hypothesis revisited. Int Rev Cytol 1992; 141: 233-357.

[110] Motta MC, Catta-Preta CM, Schenkman S, et al. The bacterium endosymbiont of Crithidia deanei undergoes coordinated division with the host cell nucleus. PLoS One 2010; 5: e12415.

[111] Wilson RJ, Denny PW, Preiser PR, et al. Complete gene map of the plastid-like DNA of the malaria parasite. J Mol Biol 1996; 261: 155-72.

[112] Maldonado RA, Fairlamb AH. Cloning of a pyruvate phosphate dikinase from Trypanosoma cruzi. Mol Biochem Parasitol 2001; 112: 183-91.

[113] Ardelli BF, Witt JD, Woo PT. Identification of glycosomes and metabolic end products in pathogenic and nonpathogenic strains of Cryptobia salmositica (Kinetoplastida: Bodonidae). Dis Aquat Organ 2000; 42: 41-51.

[114] Michels PA, Moyersoen J, Krazy H, et al. Peroxisomes, glyoxysomes and glycosomes. Mol Membr Biol 2005; 22: 133-45.

[115] Opperdoes FR, Borst P. Localization of nine glycolytic enzymes in a microbody-like organelle in Trypanosoma brucei: the glycosome. FEBS Lett 1977; 80: 360-64.

[116] Waller RF, McConville MJ, McFadden GI. More plastids in human parasites? Trends Parasitol 2004; 20: 54-7.

[117] Opperdoes FR, Szikora JP. In silicon prediction of the glycosomal enzymes of Leishmania major and trypanosomes. Mol Biochem Parasitol 2006; 147: 193-206.

[118] Parsons M. Glycosomes: parasites and the divergence of peroxisomal purpose. Mol Microbiol 2004; 53: 717-24.

[119] Michels PA, Hannaert V, Bringaud F. Metabolic aspects of glycosomes in Trypanosomatidae - new data and views. Parasitol Today $2000 ; 16: 482-49$.

[120] Opperdoes FR. Compartmentation of carbohydrate metabolism in trypanosomes. Annu Rev Microbiol 1987; 41: 127-51.

[121] Hannaert V, Michels PA. Structure, function, and biogenesis of glycosomes in Kinetoplastida. J Bioenerg Biomembr 1994; 26 : 205-12.

[122] Tielens AGM, Van Hellemond JJ. Differences in energy metabolism between Trypanosomatidae. Parasitol Today 1998; 14: 26571.

[123] Tielens AGM, Van Hellemond JJ. Surprising variety in energy metabolism within Trypanosomatidae. Trends Parasitol 2009; 25: 482-90.

[124] Hannaert V, Bringaud F, Opperdoes FR, Michels, PA. Evolution of energy metabolism and its compartmentation in Kinetoplastida. Kinetoplast Biol Dis (BioMed Central) 2003; 2: 1-30.
[125] Moyersoen J, Choe J, Fan E, Hol WG, Michels PA. Biogenesis of peroxisomes and glycosomes: trypanosomatid glycosome assembly is a promising new drug target. FEMS Microbiol Rev 2004; 28 : 603-43.

[126] Pilar AV, Madrid KP, Jardim A. Interaction of Leishmania PTS2 receptor peroxin 7 with the glycosomal protein import machinery. Mol Biochem Parasitol 2008; 158: 72-81.

[127] Bruske EI, Sendfeld F, Schneider A. Thiolated tRNAs of Trypanosoma brucei are imported into mitochondria and dethiolated after import. J Biol Chem 2009; 284: 36491-9.

[128] Schneider A. Unique aspects of mitochondrial biogenesis in trypanosomatids. Int J Parasitol 2001; 31: 1403-15.

[129] Schneider A. Does the evolutionary history of aminoacyl-tRNA synthetases explain the loss of mitochondrial tRNA genes? Trends Genet 2001; 17: 557-9.

[130] Benard G, Rossignol R. Ultrastructure of the mitochondrion and its bearing on function and bioenergetics. Antioxid Redox Signal 2008; 10: 1313-42.

[131] Chanez AL, Hehl AB, Engstler M, Schneider A. Ablation of the single dynamin of $T$. brucei blocks mitochondrial fission and endocytosis and leads to a precise cytokinesis arrest. J Cell Sci 2006; 119: 2968-74.

[132] Brun R, Krassner SM. Quantitative ultrastructural investigations of mitochondrial development in Leishmania donovani during transformation. J Protozool 1976; 23: 493-7.

[133] Bunn CL, Wallace DC, Eisenstadt JM. Mitotic segregation of cytoplasmic determinants for chloramphenicol resistance in mammalian cells. I: Fusion with mouse cell lines. Somatic Cell Genet 1977; 3: 71-92.

[134] Steiger RF. On the ultrastructure of Trypanosoma (Trypanozoon) bruce $i$ in the course of its life cycle and some related aspects. Acta Trop 1973; 30: 64-168.

[135] Vickerman K. Polymorphism and mitochondrial activity in sleeping sickness trypanosomes. Nature 1965; 208: 762-6.

[136] Soares MJ, De Souza W. Cytoplasmic organelles of trypanosomatids: a cytochemical and stereological study. J Submicrosc Cytol Pathol 1988; 20: 349-61.

[137] Souto-Padrón T, de Souza W. Fine structure and cytochemistry of peroxisomes (microbodies) in Leptomonas samueli. Cell Tissue Res 1982; 222: 153-8.

[138] Chaudhuri M, Robert Daniel Ott RD, Hill GC. Trypanosome alternative oxidase: from molecule to function. Trends Parasitol 2006; 22: 484-91.

[139] Moore AL, Siedow JN. The regulation and nature of the cyanideresistant alternative oxidase of plant mitochondria. Biochim Biophys Acta 1991; 1059: 121-40.

[140] Vanlerberghe GC, McIntosh L. Alternative oxidase: from gene to function. Annu Rev Plant Physiol Plant Mol Biol 1997; 48: 703-34.

[141] Chaudhuri M, Ajayi W, Temple S, Hill GC. Identification and partial purification of a stage specific $33 \mathrm{kDa}$ mitochondrial protein as the alternative oxidase of Trypanosoma brucei brucei bloodstream trypanosomes. J Eukaryot Microbiol 1995; 42: 467-72.

[142] Hill GC. Electron transport systems in kinetoplastids. Biochim Biophys Acta 1976; 456: 149-93.

[143] Fairlamb AH, Bowman IB. The isolation and characterization of particulate sn-glycerol-3-phosphate oxidase from Trypanosoma brucei. Int J Biochem 1977; 6: 659-68.

[144] Berthold DA, Voevodskaya N, Stenmark P, Gräslund A, Nordlund P. EPR studies of the mitochondrial alternative oxidase: evidence for a diiron carboxylate center. J Biol Chem 2002; 277: 43608-14.

[145] Rhoads DM, Umbach AL, Sweet CR, et al. Regulation of the cyanide-resistant alternative oxidase of plant mitochondria. Identification of the cysteine residue involved in $\alpha$-keto acid stimulation and intersubunit disulfide bond formation. J Biol Chem 1998; 273: 30750-6.

[146] Vanlerberghe GC, Vanlerberghe AE, McIntosh L. Molecular genetic alteration of plant respiration (silencing and overexpression of alternative oxidase in transgenic tobacco). Plant Physiol 1994; 106: 1503-10.

[147] Green DE, Tzagoloff A. The mitochondrial electron transfer chain. Arch Biochem Biophys 1966; 116: 293-304.

[148] Lenaz G, Genova ML. Structure and organization of mitochondrial respiratory complexes: a new understanding of an old subject. Antioxid Redox Signal 2010; 12: 961-1008.

[149] Guler JL, Kriegova E, Smith TK, Lukes J, Englund PT. Mitochondrial fatty acid synthesis is required for normal mitochon- 
drial morphology and function in Trypanosoma brucei. Mol Microbiol 2008; 67: 1125-42.

[150] Fang J, Beattie DS. Novel FMN-containing rotenone-insensitive NADH dehydrogenase from Trypanosoma brucei mitochondria: isolation and characterization. Biochemistry 2002; 41: 3065-72.

[151] Fang J, Beattie DS. Identification of a gene encoding a $54 \mathrm{kDa}$ alternative NADH dehydrogenase in Trypanosoma brucei. Mol Biochem Parasitol 2003; 127: 73-7.

[152] Turrens JF. The role of succinate in the respiratory chain of Trypanosoma brucei procyclic trypomastigotes. Biochem J 1989; 259: 363-8.

[153] Adhya S. Leishmania mitochondrial tRNA importers. Int J Biochem Cell Biol 2008; 40: 2681-5.

[154] Alfonzo JD, Blanc V, Estévez AM, Rubio MA, Simpson L. C to U editing of the anticodon of imported mitochondrial tRNA(Trp) allows decoding of the UGA stop codon in Leishmania tarentolae. EMBO J 1999; 18: 7056-62.

[155] Charrière F, Helgadóttir S, Horn EK, Söll D, Schneider A. Dual targeting of a single tRNA(Trp) requires two different tryptophanyl-tRNA synthetases in Trypanosoma brucei. Proc Natl Acad Sci USA 2006; 103: 6847-52.

[156] Liu B, Liu Y, Motyka SA, Agbo EE, Englund PT. Fellowship of the rings: the replication of kinetoplast DNA. Trends Parasitol 2005; 21 : 363-9.

[157] Liu Y, Englund PT. The rotational dynamics of kinetoplast DNA replication. Mol Microbiol 2007; 64: 676-90.

[158] Stuart K, Panigrahi AK. RNA editing: complexity and complications. Mol Microbiol 2002; 45: 591-6.

[159] Blum B, Simpson L. Guide RNAs in kinetoplastid mitochondria have a nonencoded $3^{\prime}$ oligo(U) tail involved in recognition of the preedited region. Cell 1990; 62: 391-7.

[160] Blum B, Bakalara N, Simpson L. A model for RNA editing in kinetoplastid mitochondria: "guide" RNA molecules transcribed from maxicircle DNA provide the edited information. Cell 1990; 60: 189-98.

[161] Kable ML, Seiwert SD, Heidmann S, Stuart K. RNA Editing: A mechanism for gRNA-Specified Uridylate Insertion into Precursor mRNA. Science 1996: 273: 1189-95.

[162] Martinez-Calvillo S, Vizuet-de-Rueda JC, Florencio-Martinez et al. Gene expression in trypanosomatid parasites. J Biomed Biotechnol 2010; 2010: 525241 .

[163] Johnson PJ, Kooter JM, Borst P. Inactivation of transcription by UV irradiation of $T$. brucei provides evidence for a multicistronic transcription unit including a VSG gene. Cell 1987; 51: 273-81.

[164] Figueroa-Angulo E, Martínez-Calvillo S, López-Villaseñor I, Hernández R. Evidence supporting a major promoter in the Trypanosoma cruzi rRNA gene. FEMS Microbiol Lett 2003; 225: 221-25.

[165] Vanhamme L. Trypanosome RNA polymerases and transcription factors: sensible trypanocidal drug targets? Current Drug Targets 2008; 9: 979-96.

[166] Cordingley JS. Nucleotide sequence of the 5S ribosomal RNA gene repeat of Trypanosoma brucei. Mol Biochem Parasitol 1985; 17: 321-30.

[167] Stuart KD, Schnaufer A, Ernst NL, Panigrahi AK. Complex management: RNA editing in trypanosomes. Trends Biochem Sci 2005; 30: 97-105.

[168] Boothroyd JC, Cross GA. Transcripts coding for variant surface glycoproteins of Trypanosoma brucei have a short, identical exon at their 5' end. Gene 1982; 20: 281-9.

[169] Liang XH, Haritan A, Uliel S, Michaeli S. Trans and cis splicing in trypanosomatids: mechanism, factors, and regulation. Eukaryot Cell 2003; 2: 830-40.

[170] Zamudio JR, Mittra B, Chattopadhyay A, et al. Trypanosoma brucei spliced leader RNA maturation by the cap 1 2'-O-ribose methyltransferase and SLA1 H/ACA snoRNA pseudouridine synthase complex. Mol Cell Biol 2009; 29: 1202-11.

[171] Campbell DA, Thornton DA, Boothroyd JC. Apparent discontinuous transcription of Trypanosoma brucei variant surface antigen genes. Nature $1984 ; 311 ; 350-5$

[172] Milhausen M, Nelson RG, Sather S, Selkirk M, Agabian N. Identification of a small RNA containing the trypanosome spliced leader: a donor of shared 5' sequences of trypanosomatid mRNAs? Cell 1984; $38: 721-9$.

[173] Boothroyd J, Campbell D, Sutton R. Expression of surface antigen genes in Trypanosoma brucei involves a novel system of discon- tinuous transcription, pp. 61-6. In Lerner R, Channock R, Brown F. Eds. Vaccines 85: modern approaches to vaccines. Cold Spring Harbor Laboratory, Cold Spring Harbor, NY 1985.

[174] Haanstra JR, Stewart M, Luu VD, et al. Control and regulation of gene expression: quantitative analysis of the expression of phosphoglycerate kinase in bloodstream form Trypanosoma brucei. J Biol Chem 2008; 283: 2495-507.

[175] Bangs JD, Crain PF, Hashizume T, McCloskey JA, Boothroyd JC. Mass spectrometry of mRNA cap 4 from trypanosomatids reveals two novel nucleosides. J Biol Chem 1992; 267: 9805-15.

[176] Freistadt MS, Cross G, Robertson HD. Discontinuously synthesized mRNA from Trypanosoma brucei contains the highly methylated 5' cap structure, m7GpppA*A*C(2'-O)mU*A. J Biol Chem 1988; 263: 15071-5.

[177] Perry KL, Watkins KP, Agabian N. Trypanosome mRNAs have unusual "cap 4" structures acquired by addition of a spliced leader. Proc Natl Acad Sci USA 1987; 84: 8190-4.

[178] Barth S, Hury A, Liang XH, Michaeli S. Elucidating the role of H/ACA-like RNAs in trans-splicing and rRNA processing via RNA interference silencing of the Trypanosoma brucei CBF5 pseudouridine synthase. J Biol Chem 2005; 280: 34558-68.

[179] Mandelboim M, Estraño CL, Tschudi C, Ullu E, Michaeli S. On the role of exon and intron sequences in trans-splicing utilization and cap 4 modification of the trypanosomatid Leptomonas collosoma SL RNA. J Biol Chem 2002; 277: 35210-8.

[180] Sturm NR, Fleischmann J, Campbell DA. Efficient trans-splicing of mutated spliced leader exons in Leishmania tarentolae. J Biol Chem 1988; 273: 18689-92.

[181] Ullu E, Tschudi C. Trans splicing in trypanosomes requires methylation of the 5' end of the spliced leader RNA. Proc Nat Acad Sci USA $1991 ; 88$ : 10074-8

[182] Zeiner, GM, Sturm NR, Campbell DA. The Leishmania tarentolae spliced leader contains determinants for association with polysomes. J Biol Chem 2003; 278: 38269-75.

[183] Luz-Ambrósio D, Lee JH, Panigrahi AK, et al. Spliceosomal proteomics in Trypanosoma brucei reveal new RNA splicing factors. Eukaryot Cell 2009; 8: 990-1000.

[184] Palfi Z, Lucke S, Lahm HW, et al. The spliceosomal snRNP core complex of Trypanosoma brucei: cloning and functional analysis reveals seven Sm protein constituents. Proc Natl Acad Sci USA 2000; 97: 8967-72.

[185] Tkacz ID, Cohen S, Salmon-Divon M, Michaeli S. Identification of the heptameric Lsm complex that binds U6 snRNA in Trypanosoma brucei. Mol Biochem Parasitol 2008; 160: 22-31.

[186] De Souza W, Carvalho TU, Benchimol M. Trypanosoma cruzi: ultraestructural, cytochemical and freeze-fracture studies of protein uptake. Exp Parasitol 1978; 45: 101-15.

[187] Soares MJ, Souto-Padrón T, Bonaldo MC, Goldenberg S, De Souza W. A steriological study of the differentiation process in Trypanosoma cruzi. Parasitol Res 1989; 75: 522-7.

[188] Porto-Carreiro I, Attias M, Miranda K, De Souza W, Cunha-e-Silva N. Trypanosoma cruzi epimastigote endocytic pathway: cargo enters the cytostome and passes through na early endosomal network before storage in reservosomes. Eur J Cell Biol 2000; 79: 858-69.

[189] Cunha-e-Silva N, Sant'Anna C, Pereira MG, et al. Reservosomes: multipurpose organelles? Parasitol Res 2006; 99: 325-7.

[190] Soares MJ, Souto-Padrón T, De Souza W. Identification of a large pre-lysosomal compartment in the pathogenic protozoon Trypanosoma cruzi. J Cell Sci 1992; 102: 157-67.

[191] Souto-Padrón T, Campetella OE, Cazzulo JJ, de Souza W. Cysteine proteinase in Trypanosoma cruzi: immunocytochemical localization and involvement in parasite-host cell interaction. J Cell Sci 1990; 96: 485-90.

[192] Cunha-e-Silva NL, Atella GC, Porto-Carreiro IA, Morgado-Diaz JA, Pereira MG, De Souza W. Isolation and characterization of a reservosome fraction from Trypanosoma cruzi. FEMS Microbiol Lett 2002; 214: 7-12

[193] Sant'Anna C, Pereira MG, Lemgruber L, de Souza W, Cunha e Silva NL. New insights into the morphology of Trypanosoma cruzi reservosome. Microsc Res Tech 2008; 71: 599-605.

[194] Parussini F, García M, Mucci J, et al. Characterization of a lysosomal serine carboxypeptidase from Trypanosoma cruzi. Mol Biochem Parasitol 2003; 131: 11-23.

[195] Adade CM, de Castro SL, Soares MJ. Ultrastructural localization of Trypanosoma cruzi lysosomes by aryl sulphatase cytochemistry. Micron 2007; 38: 252-6. 
[196] Vieira M, Rohloff P, Luo S, et al. Role for a P-type $\mathrm{H}^{+}$-ATPase in the acidification of the endocytic pathway of Trypanosoma cruzi. Biochem J 2005; 392: 467-74.

[197] Mendonça SM, Da Silva JLN, Cunha-e-Silva NL, De Souza W, Lopes UG. Characterization of a Rab11 homologue in Trypanosoma cruzi. Gene 2000; 243: 179-85.

[198] Sant'Anna C, Nakayasu ES, Pereira MG, et al. Subcellular proteomics of Trypanosoma cruzi reservosomes. Proteomics 2009; 9: 1782-94.

[199] Sant'Anna C, De Souza W, Cunha-e-Silva N. Biogenesis of the reservosomes of Trypanosoma cruzi. Microsc Microanal 2004; 10: 637-46.

[200] Chagas C. Neue Trypanosomen: Vorlaufige mitteilung. Archiv fur Schiffs-und Tropen-Hygiene. 1909; 13: 120-2.

[201] Chagas C. Nouvelle espece de trypanosomiase humaine. Bull Soc Pathol Exotique 1909; 2: 304-7.

[202] Chagas C. Nova tripanozomiase humana: Estudos sobre a morfolojia e o ciclo evolutivo do Schizotrypanum cruzi n. Gen., n. Sp., ajente etiolojico de nova entidade mórbida do homem. Mem Inst Oswaldo Cruz 1909; 1: 159-218.

[203] Coura JR. Transmission of chagasic infection by oral route in the natural history of Chagas' disease. Rev Soc Bras Med Trop 2006; 39: 113-7.

[204] Yoshida N. Molecular basis of mammalian cell invasion by Trypanosoma cruzi. An Acad Bras Cienc 2006; 78: 87-111.

[205] Schmunis GA. Epidemiology of Chagas disease in non-endemic countries: the role of international migration. Mem Inst Oswaldo Cruz 2007; 102 (Suppl 1): 75-85.

[206] Bombeiro AL, D'Império Lima MR, Chadi G, Alvarez JM. Neurodegeneration and increased production of nitrotyrosine, nitric oxide synthase, IFN-gamma and S100beta protein in the spinal cord of IL-12p40-deficient mice infected with Trypanosoma cruzi. Neuroimmunomod 2010; 17: 67-78.

[207] Leiguarda R, Roncoroni A, Taratuto AL, et al. Acute CNS infection by Trypanosoma cruzi (Chagas' disease) in immunosuppressed patients. Neurology 1990; 40: 850-1.

[208] Hecht MM, Nitz N, Perla F. Araujo PF, et al. Inheritance of DNA transferred from American trypanosomes to human hosts. Plos One 2010; 5: e9181.

[209] Hotez PJ, Bottazzi ME, Franco-Paredes C, et al. The neglected tropical diseases of Latin America and the Caribbean: a review of disease burden and distribution and a roadmap for control and elimination. PLoS Negl Trop Dis 2008; 2: e300.

[210] WHO 2006. http://www.who.int/mediacentre/factsheets/fs259/en/

[211] Schmunis GA, Yadon ZE. Chagas disease: a Latin American health problem becoming a world health problem. Acta Trop 2010; 115: 14-21.

[212] El-Sayed NM, Myler PJ, Bartholomeu DC, et al. The genome sequence of Trypanosoma cruzi, etiologic agent of Chagas disease. Science 2005; 309: 409-15.

[213] Macedo AM, Pena SD. Genetic variability of Trypanosoma cruzi: implications for the pathogenesis of Chagas' disease. Parasitol Today $1998 ; 14: 119-24$.

[214] Anonymous. Recommendation from an International Symposium to commemorate the 90th anniversary of the discovery of Chagas disease. [Proceedings of the International Symposium on the Advances in Knowledge of Chagas Disease 90 Years After its Discovery. Rio de Janeiro, Brazil,]. Mem Inst Oswaldo Cruz 1999; 94: 429-32.

[215] Zingales B, Stolf BS, Souto RP, Fernandes O, Briones MR. Epidemiology, biochemistry and evolution of Trypanosoma cruzi lineages based on ribosomal RNA sequences. Mem Inst Oswaldo Cruz 1999; 94: 159-64.

[216] Tomazi L, Kawashita SY, Pereira PM, Zingales B, Briones MR. Haplotype distribution of five nuclear genes based on network genealogies and Bayesian inference indicates that Trypanosoma cruzi hybrid strains are polyphyletic. Genet Mol Res 2009; 8: 458-76.

[217] Stuart K, Brun R, Croft S, et al. Kinetoplastids: related protozoan pathogens, different diseases. J Clin Invest 2008; 118: 1301-10.

[218] Monteón VM, Furuzawa-Carballeda J, Alejandre-Aguilar R, et al. American trypanosomosis: in situ and generalized features of parasitism and inflammation kinetics in a murine model. Exp Parasitol 1996; 83: 267-74.

[219] Zhang L, Tarleton RL. Parasite persistence correlates with disease severity and localization in chronic Chagas' disease. J Infect Dis 1999; 180: 480-6.
[220] Manoel-Caetano F da S, Silva AE. Implications of genetic variability of Trypanosoma cruzi for the pathogenesis of Chagas disease. Cad Saude Publica 2007; 3: 2263-74.

[221] Marinho CR, Bucci DZ, Dagli ML, et al. Pathology affects different organs in two mouse strains chronically infected by a Trypanosoma cruzi clone: a model for genetic studies of Chagas' disease. Infect Immun 2004; 72: 2350-7.

[222] Freitas JM, Andrade LO, Pires SF, et al. The MHC gene region of murine hosts influences the differential tissue tropism of infecting Trypanosoma cruzi strains. PLoS One 2009; 4: e5113.

[223] Vago AR, Andrade LO, Leite AA, et al. Genetic characterization of Trypanosoma cruzi directly from tissues of patients with chronic Chagas disease: differential distribution of genetic types into diverse organs. Am J Pathol 2000; 156: 1805-9.

[224] Epting CL, Coates BM, Engman DM. Molecular mechanisms of host cell invasion by Trypanosoma cruzi. Exp Parasitol 2010; 126: 283-91.

[225] Nakayasu ES, Gaynor MR, Sobreira TJ, Ross JA, Almeida IC. Phosphoproteomic analysis of the human pathogen Trypanosoma cruzi $i$ at the epimastigote stage. Proteomics 2009; 9: 3489-506.

[226] Alves MJ, Colli W. Role of the gp85/trans-sialidase superfamily of glycoproteins in the interaction of Trypanosoma cruzi with host structures. Subcell Biochem 2008; 47: 58-69.

[227] Kulkarni MM, Olson CL, Engman DM, McGwire BS. Trypanosoma cruzi GP63 proteins undergo stage-specific differential posttranlational modification and are important for host cell infection. Infect Immun 2009; 77: 2193-200.

[228] Villalta F, Zhang Y, Bibb KE, Burns JM Jr, Lima MF. Signal transduction in human macrophages by gp83 ligand of Trypanosoma cruzi: trypomastigote gp83 ligand up-regulates trypanosome entry through the MAP kinase pathway. Biochem Biophys Res Commun 1998; 249: 247-52.

[229] Gaulton GN, Pratt JC. Glycosylated phosphatidylinositol molecules as second messengers. Semin Immunol 1994; 6: 97-104.

[230] Almeida IC, Gazzinelli RT. Proinflammatory activity of glycosylphosphatidylinositol anchors derived from Trypanosoma cruzi structural and functional analyses. J Leukoc Biol 2001; 70: 467-77.

[231] Gazzinelli RT, Denkers EY. Protozoan encounters with Toll-like receptor signalling pathways: implications for host parasitism. Nat Rev Immunol 2006; 6: 895-906.

[232] Frasch AC. Functional diversity in the trans-sialidase and mucin families in Trypanosoma cruzi. Parasitol Today 2000; 16: 282-6.

[233] Acosta-Serrano A, Almeida IC, Freitas-Junior LH, Yoshida N, Schenkman S. The mucin-like glycoprotein super-family of Trypanosoma cruzi: structure and biological roles. Mol Biochem Parasitol 2001; 114: 143-50.

[234] Buscaglia CA, Campo VA, Frsch ACC, Di Noia JM. Trypanosoma cruzi surface mucins: host-dependent coat diversity. Nature Reviews 2006; 4: 229-36.

[235] Moody T, Ochieng J, Villalta F. Novel mechanism that Trypanosoma cruzi uses to adhere to the extracellular matrix-mediated by human galectin-3. FEBS Lett 2000; 470: 305-8.

[236] Kleshchenko YY, Moody TN, Furtak VA, et al. Human galectin-3 promotes Trypanosoma cruzi adhesion to human coronary artery smooth muscle cells. Infect Immun 2004; 72: 6717-21.

[237] Previato JO, Andrade AF, Pessolani MC, Mendonça-Previato L. Incorporation of sialic acid into Trypanosoma cruzi macromolecules. A proposal for a new metabolic route. Mol Biochem Parasitol 1985; 16: 85-96.

[238] Schenkman S, Jiang MS, Hart GW, Nussenzweig V. A novel cell surface trans-sialidase of Trypanosoma cruzi generates a stagespecific epitope required for invasion of mammalian cells. Cell 1991; 65: 1117-25.

[239] Parodi AJ, Pollevick GD, Mautner M, et al. Identification of the gene(s) coding for the trans-sialidase of Trypanosoma cruzi. EMBO J 1992; 11: 1705-10.

[240] Cremona ML, Sánchez DO, Frasch AC, Campetella O. A single tyrosine differentiates active and inactive Trypanosoma cruzi transsialidases. Gene 1995; 160: 123-8.

[241] Cremona ML, Campetella O, Sánchez DO, Frasch AC. Enzymically inactive members of the trans-sialidase family from Trypanosoma cruzi display beta-galactose binding activity. Glycobiology 1999; 9: 581-7.

[242] Magdesian MH, Giordano R, Ulrich H, et al. Infection by Trypanosoma cruzi. Identification of a parasite ligand and its host cell receptor. J Biol Chem 2001; 276: 19382-9. 
[243] Claser C, Curcio M, de Mello SM, et al. Silencing cytokeratin 18 gene inhibits intracellular replication of Trypanosoma cruzi in HeLa cells but not binding and invasion of trypanosomes. BMC Cell Biol 2008; 9: 68-80.

[244] Bonay P, Fresno M. Caracterization of carbohydrate binding proteins in Trypanosoma cruzi. J Biol Chem 1995; 270: 11062-70.

[245] Beucher M, Meira WS, Zegarra V, et al. Expression and purification of functional, recombinant Trypanosoma cruzi complement regulatory protein. Protein Expr Purif 2003; 27: 19-26.

[246] Beucher M, Norris KA. Sequence diversity of the Trypanosoma cruzi complement regulatory protein family. Infect Immun 2008; 76: 750-8.

[247] García GA, Joensen LG, Búa J, et al. Trypanosoma cruzi: molecular identification and characterization of new members of the Tc13 family. Description of the interaction between the Tc13 antigen from Tulahuén strain and the second extracellular loop of the beta(1)-adrenergic receptor. Exp Parasitol 2003; 103: 112-9.

[248] García GA, Arnaiz MR, Laucella AS, et al. Immunological and pathological responses in BALB/c mice induced by genetic administration of Tc13 Tul antigen of Trypanosoma cruzi. Parasitology 2006; 132: 855-66.

[249] Teixeira MM, Yoshida N. Stage-specific surface antigens of metacyclic trypomastigotes of Trypanosoma cruzi identified by monoclonal antibodies. Mol Biochem Parasitol 1986; 18: 271-82.

[250] Staquicini DI, Martins RM, Macedo S, et al. Role of GP82 in the selective binding to gastric mucin during oral infection with Trypanosoma cruzi. PLoS Negl Trop Dis 2010; 4: e613.

[251] Van Voorhis WC, Schlekewy L, Trong HL. Molecular mimicry by Trypanosoma cruzi: the F1-160 epitope that mimics mammalian nerve can be mapped to a 12-amino acid peptide. Proc Natl Acad Sci USA 1991; 88: 5993-7.

[252] Avila JL. Molecular mimicry between Trypanosoma cruzi and host nervous tissues. Acta Cient Venez 1992; 43: 330-40.

[253] Atwood JA 3rd, Minning T, Ludolf F, et al. Glycoproteomics of Trypanosoma cruzi trypomastigotes using subcellular fractionation, lectin affinity, and stable isotope labeling. J Proteome Res 2006; 5: 3376-84.

[254] Bartholomeu DC, Cerqueira GC, Leão AC, et al. Genomic organization and expression profile of the mucin-associated surface protein (masp) family of the human pathogen Trypanosoma cruzi. Nucleic Acids Res 2009; 37: 3407-17.

[255] Cuevas BD, Abell AN, Witowsky JA, et al. MEKK1 regulates calpain-dependent proteolysis of focal adhesion proteins for rearend detachment of migrating fibroblasts. EMBO J 2003; 22: 334655 .

[256] Scharfstein J, Schmitz V, Svensjö E, Granato A, Monteiro AC. Kininogens coordinate adaptive immunity through the proteolytic release of bradykinin, an endogenous danger signal driving dendritic cell maturation. Scand Immunol 2007; 66: 128-36.

[257] Yao C. Major surface protease of trypanosomatids: One size fits all? Infect Immun 2010; 78: 22-31.

[258] Burleigh BA, Andrews NW. A 120-kDA alkaline peptidase from Trypanosma cruzi is involved in the generation of a novel $\mathrm{Ca}^{2+}$ signaling factor for mammalian cells. J Biol Chem 1995; 270: 5172-80

[259] Burleigh BA, Caler EV, Webster P, Andrews NW. A cytosolic serine endopeptidase from Trypanosoma cruzi is required for the generation of a $\mathrm{Ca}^{2+}$-signaling in mammalian cells. J Cell Biol 1997; 136: 609-20.

[260] Caler EV, de Avalos SV, Haynes PA, Andrews NW, Burleigh BA. Oligopeptidase B-dependent signaling mediates host cell invasion by Trypanosoma cruzi. EMBO J 1998; 17: 4975-86.

[261] Caler EV, Morty RE, Burleigh BA, Andrews NW. Dual Role of Signaling Pathways Leading to Ca21 and CyclicAMP Elevation in Host Cell Invasion by Trypanosoma cruzi. Infect Immun 2000; 68: 6602-10.

[262] Gutierrez FR, Mariano FS, Lalu MM, et al. Increased activities of cardiac matrix metalloproteinases matrix metalloproteinase (MMP)-2 and MMP-9 are associated with mortality during the acute phase of experimental Trypanosoma cruzi infection. J Infect Dis 2008; 197: 1468-76.

[263] Nogueira de Melo AC, Meirelles MNL, Porrozzi R, et al. Reduced activity of matrix metalloproteinase-9 in Trypanosoma cruzi infected mouse embryo hepatocyte cell. Hepatol Res 2004; 28: 4956.
[264] Santana JM, Grellier P, Schrével J, Teixeira AR. A Trypanosoma cruzi-secreted $80 \mathrm{kDa}$ proteinase with specificity for human collagen types I and IV. Biochem J 1997; 325: 129-37.

[265] Grellier P, Vendeville S, Joyeau R, et al. Trypanosoma cruzi prolyl oligopeptidase Tc80 is involved in nonphagocytic mammalian cell invasion by trypomastigotes. J Biol Chem 2001; 276: 47078-86.

[266] Bastos IM, Grellier P, Martins NF, et al. Molecular, functional and structural properties of the prolyl oligopeptidase of Trypanosoma cruzi (POP TC80), which is required for prasite entry into mammalian cells. Biochem J 2005; 388: 29-38.

[267] Fairlamb AH, Blackburn P, Ulrich P, Chait BT, Cerami A. Trypanothione: A novel Bis(glutathionyl)spermidine cofactor for gluthatione reductase in trypanosomatids. Science $1985 ; 227$ : 1485 7.

[268] Irigoin F, Cibils L, Comini MA, et al. Insights into the redox biology of Trypanosoma cruzi: Trypanothione metabolism and oxidant detoxification. Free Radic Biol Med 2008; 45: 733-42.

[269] Meiering S, Inhoff O, Mies J, et al. Inhibitors of Trypanosoma cruzi trypanothione reductase revealed by virtual screening and parallel synthesis. J Med Chem 2005; 48: 4793-802.

[270] Wilkinson SR, Meyer DJ, Taylor MC, et al. The Trypanosoma cruzi enzyme TcGPXI is a glycosomal peroxidase and can be linked to trypanothione reduction by glutathione or tryparedoxin. J Biol Chem 2002; 277: 17062-71.

[271] Wilkinson SR, Taylor MC, Touitha S, et al. TcGPXII, a glutathione-dependent Trypanosoma cruzi peroxidase with substrate specificity restricted to fatty acid and phospholipid hydroperoxides, is localized to the endoplasmic reticulum. Biochem J 2002; 364: 787-94.

[272] Wilkinson SR, Obado SO, Mauricio IL, Kelly JM. Trypanosoma cruzi expresses a plant-like ascorbate-dependent hemoperoxidase localized to the endoplasmic reticulum. Proc Natl Acad Sci USA 2002; 99: 13453-8

[273] Krauth-Siegel RL, Comini MA. Redox control in trypanosomatids, parasitic protozoa with trypanothione-based thiol metabolism. Biochim Biophys Acta 2008; 1780: 1236-48.

[274] Wilkinson SR, Meyer DJ, Kelly JM. Biochemical characterization of a trypanosome enzyme with glutathione-dependent peroxidase activity. Biochem J 2000; 352: 744-61.

[275] Piacenza L, Alvarez MN, Peluffo G, Radi R. Fighting the oxidative assault: the Trypanosoma cruzi journey to infection. Curr Opin Microbiol 2009; 12: 415-21.

[276] Piacenza L, Zago MP, Peluffo G, et al. Enzymes of the antioxidant network as novel determiners of Trypanosoma cruzi virulence. Int J Parasitol 2009; 39: 1455-64.

[277] Piacenza L, Peluffo G, Alvarez MN, et al. Peroxiredoxins play a major role in protecting Trypanosoma cruzi against macrophageand endogenously-derived peroxynitritie. Biochem J 2008; 410 : 359-68.

[278] Piñeyro MD, Parodi-Talice A, Arcari T, Robello C. Peroxiredoxins from Trypanosoma cruzi: Virulence factors and drug targets for treatment of Chagas disease? Gene 2008; 408: 45-50.

[279] Wilkinson SR, Temperton NJ, Mondragon A, Kelly JM. Distinct mitochondrial and cytosolic enzymes mediate trypanothionedependent peroxide metabolism in Trypanosoma cruzi. J Biol Chem 2000; 275: 8220-5.

[280] Piacenza L, Irigoín F, Alvarez MN, et al. Mitochondrial superoxide radicals mediate programmed cell death in Trypanosoma cruzi: cytoprotective action of mitochondrial iron superoxide dismutase overexpression. Biochem J 2007; 403: 323-34.

[281] Temperton NJ, Wilkinson SR, Meyer DJ, Kelly JM. Overexpression of superoxide dismutase in Trypanosoma cruzi results in increased sensitivity to the trypanocidal agents gentian violet and benznidazole. Mol Biochem Parasitol 1998; 96: 167-76.

[282] Engman DM, Kirchhoff LV, Donelson JE. Molecular cloning of mtp70, a mitochondrial member of the hsp70 family. Mol Cell Biol 1989; 9: 5163-8.

[283] Engman DM, Sias SR, Gabe JD, Donelson JE, Dragon EA. Comparison of HSP70 genes from two strains of Trypanosoma cruzi. Mol Biochem Parasitol 1989; 37: 285-7.

[284] Olson CL, Nadeau KC, Sullivan MA, et al. Molecular and biochemical comparison of the $70-\mathrm{kDa}$ heat shock proteins of Trypanosoma cruzi. J Biol Chem 1994; 269: 3868-74.

[285] Marañón C, Planelles L, Alonso C, López MC. HSP70 from Trypanosoma cruzi is endowed with specific cell proliferation potential leading to apoptosis. Int Immunol 2000; 12: 1685-93. 
[286] Cuellar A, Santander SP, Thomas Mdel C, et al. Monocyte-derived dendritic cells from chagasic patients vs healthy donors secrete differential levels of IL-10 and IL-12 when stimulated with a protein fragment of Trypanosoma cruzi heat-shock protein-70. Immunol Cell Biol 2008; 86: 255-60.

[287] Graefe SE, Wiesgigl M, Gaworski I, MacDonald A, Clos J. Inhibition of HSP90 in Trypanosoma cruzi induces a stress response but no stage differentiation. Eukaryot Cell 2002; 1: 936-43.

[288] Tibbetts RS, Jensen JL, Olson CL, Wang FD, Engman DM. The DnaJ family of protein chaperones in Trypanosoma cruzi. Mol Biochem Parasitol 1998; 91: 319-26.

[289] Edkins AL, Ludewig MH, Blatch GL. A Trypanosoma cruzi heat shock protein 40 is able to stimulate the adenosine triphosphate hydrolysis activity of heat shock protein 70 and can substitute for a yeast heat shock protein 40. Int J Biochem Cell Biol 2004; 36: 1585-98.

[290] Salmon D, Montero-Lomeli M, Goldenberg S. A DnaJ-like protein homologous to the yeast co-chaperone Sis1 (TcJ6p) is involved in initiation of translation in Trypanosoma cruzi. J Biol Chem 2001; 276: 43970-9.

[291] Folgueira C, Requena JM. A postgenomic view of the heat shock proteins in kinetoplastids. FEMS Microbiol Rev 2007; 31: 359-77.

[292] Pérez-Morales D, Ostoa-Saloma P, Espinoza B. Trypanosoma cruzi SHSP16: Characterization of an alpha-crystallin small heat shock protein. Exp Parasitol 2009; 123: 182-9.

[293] Serrano AA, Schenkman S, Yoshida N, et al. The lipid structure of the glycosylphosphatidylinositol-anchored mucin-like sialic acid acceptors of Trypanosoma cruzi changes during parasite differentiation from epimastigotes to infective metacyclic trypomastigote forms. J Biol Chem 1995; 270: 27244-53.

[294] Pereira-Chioccola VL, Acosta-Serrano A, Correia de Almeida I et al. Mucin-like molecules form a negatively charged coat that protects Trypanosoma cruzi trypomastigotes from killing by human anti-alpha-galactosyl antibodies. J Cell Sci 2000; 113: 1299-307.

[295] Todeschini AR, de Almeida EG, Agrellos AO, et al. Alpha-Nacetylglucosamine-linked O-glycans of sialoglycoproteins (Tcmucins) from Trypanosoma cruzi Colombiana strain. Mem Inst Oswaldo Cruz 2009; 104 Suppl 1: 270-4.

[296] Chamond N, Grégoire C, Coatnoan N, et al. Biochemical characterization of proline racemases from the human protozoan parasite Trypanosoma cruzi and definition of putative protein signatures. J Biol Chem 2003; 278: 15484-94.

[297] Chamond N, Goytia M, Coatnoan N, et al. Trypanosoma cruzi proline racemases are involved in parasite differentiation and infectivity. Mol Microbiol 2005; 58: 46-60.

[298] Reina-San-Martín B, Degrave W, Rougeot C, et al. A B-cell mitogen from a pathogenic trypanosome is a eukaryotic proline racemase. Nat Med 2000; 6: 890-7.

[299] Andrews NW, Abrams CK, Slatin SL, Griffiths G. A T. cruzisecreted protein immunologically related to the complement component C9: evidence for membrane pore-forming activity at low pH. Cell 1990; 61: 1277-87.

[300] Schenkman S, Kurosaki T, Ravetch J, Nussenzweig V. Evidence of the participation of the Ssp-3 antigen in the invasion of nonphagocytic mammalian cells by Trypanosoma cruzi. J Exp Med 1992; 175: 1635-41.

[301] Da Silva CV, Luquetti AO, Rassi A, Mortara RA. Involvement of Ssp4-related carbohydrate epitopes in mammalian cells invasion by Trypanosoma cruzi amastigotes. Microbes Infect 2006; 8: 2120-9.

[302] Teixeira SM, Russell DG, Kirchhoff LV, Donelson JE. A differentially expressed gene family encoding "amastin," a surface protein of Trypanosoma cruzi amastigotes. J Biol Chem 1994; 269: 2050916.

[303] Jackson AP. The evolution of amastin surface glycoproteins in trypanosomatid parasites. Mol Biol Evol 2010; 27: 33-45.

[304] Nozaki T, Toh-e A, Fujii M, et al. Cloning and characterization of a gene encoding phosphatidyl inositol-specific phospholipase C from Trypanosoma cruzi. Mol Biochem Parasitol 1999; 102: 28395.

[305] Furuya T, Kashuba C, Docampo R, Moreno SN. A novel phosphatidylinositol-phospholipase $\mathrm{C}$ of Trypanosoma cruzi that is lipid modified and activated during trypomastigote to amastigote differentiation. J Biol Chem 2000; 275: 6428-38

[306] Okura M, Fang J, Salto ML, et al. A lipid-modified phosphoinositide-specific phospholipase C (TcPI-PLC) is involved in differen- tiation of trypomastigotes to amastigotes of Trypanosoma cruzi. J Biol Chem 2005; 280: 16235-43.

[307] Martins VD, Okura M, Maric D, et al. Acylation-dependent export of Trypanosoma cruzi phosphoinositide-specific phospholipase C to the outer surface of amastigotes. J Biol Chem 2010; 285: 3090617.

[308] Quanquin NM, Galaviz C, Fouts DL, Wrightsman RA, Manning JE. Immunization of mice with a TolA-like surface protein of Trypanosoma cruzi generates CD4(+) T-cell-dependent parasiticidal activity. Infect Immun 1999; 67: 4603-12.

[309] Villalta F, Zhang Y, Bibb KE, et al. Signal transduction in human macrophages by gp83 ligand of Trypanosoma cruzi: trypomastigote gp83 ligand up-regulates trypanosome entry through protein kinase C activation. Mol Cell Biol Res Commun 1999; 2: 64-70.

[310] Nde PN, Simmons KJ, Kleshchenko YY, et al. Silencing of the laminin gamma-1 gene blocks Trypanosoma cruzi infection. Infect Immun 2006; 74: 1643-8.

[311] Nde PN, Johnson CA, Pratap S, et al. Gene network analysis during early infection of human coronary artery smooth muscle cells by Trypanosoma cruzi and its gp83 ligand. Chem Biodivers 2010; 7: 1051-64.

[312] Ortega-Barria E, Pereira ME. A novel T. cruzi heparin-binding protein promotes fibroblast adhesion and penetration of engineered bacteria and trypanosomes into mammalian cells. Cell 1991; 67: 411-21.

[313] Herrera EM, Ming M, Ortega-Barria E, Pereira ME. Mediation of Trypanosoma cruzi invasion by heparan sulfate receptors on host cells and penetrin counter-receptor on the trypanosomes. Mol Biochem Parasitol 1994; 65: 73-83.

[314] Augustine SA, Kleshchenko YY, Nde PN, et al. Molecular cloning of a Trypanosma cruzi cell surface casein kinase II substrate, Tc-1, involved in cellular infection. Infect Immun 2006; 74: 3922-9.

[315] Marcipar IS, Welchen E, Roodveldt C, Marcipar AJ, Silber AM. Purification of the 67-kDa lectin-like glycoprotein of Trypanosoma cruzi, LLGP-67, and its evaluation as a relevant antigen for the diagnosis of human infection. FEMS Microbiol Lett 2003; 220: 14954.

[316] Manning-Cela R, Cortés A, González-Rey E, et al. LYT1 protein is required for efficient in vitro infection by Trypanosoma cruzi. Infect Immun 2001; 69: 3916-23.

[317] Moro A, Ruiz-Cabello F, Fernández-Cano A, Stock RP, González A. Secretion by Trypanosoma cruzi of a peptidyl-prolyl cis-trans isomerase involved in cell infection. EMBO J 1995; 14: 2483-90.

[318] Bisaggio DF, Peres-Sampaio CE, Meyer-Fernandes JR, SoutoPadrón T. Ecto-ATPase activity on the surface of Trypanosoma cruzi and its possible role in the parasite-host cell interaction. Parasitol Res 2003; 91: 273-82.

[319] Meyer-Fernandes JR, Saad-Nehme J, Peres-Sampaio CE, et al. A $\mathrm{Mg}$-dependent ecto-ATPase is increased in the infective stages of Trypanosoma cruzi. Parasitol Res 2004; 93: 41-50.

[320] Torres C, Pérez-Victoria FJ, Parodi-Talice A, Castanys S, Gamarro F. Characterization of an ABCA-like transporter involved in vesicular trafficking in the protozoan parasite Trypanosoma cruzi. Mol Microbiol 2004; 54: 632-46.

[321] Hasne MP, Coppens I, Soysa R, Ullman B. A high-affinity putrescine-cadaverine transporter from Trypanosoma cruzi. Mol Microbiol 2010; 76: 78-91

[322] Ashton AW, Mukherjee S, Nagajyothi FN, et al. Thromboxane A2 is a key regulator of pathogenesis during Trypanosoma cruzi infection. J Exp Med 2007; 204: 929-40.

[323] Gomes MT, Monteiro RQ, Grillo LA, et al. Platelet-activating factor-like activity isolated from Trypanosoma cruzi. Int J Parasitol 2006; 36: 165-73.

[324] Mauel J. In vitro induction of intracellular killing of parasitic protozoa by macrophages. Immunobiology 1982; 161: 392-400.

[325] Thorne KJ, Blackwell JM. Cell-mediated killing of protozoa. Adv Parasitol 1983; 22: 43-151.

[326] De Araujo-Jorge TC, Barbosa HS, Meirelles MN. Trypanosoma cruzi recognition by macrophages and muscle cells: perspectives after a 15-year study. Mem Inst Oswaldo Cruz 1992; 87 (Suppl 5): 43-56.

[327] Kuhn RE. Macrophages in experimental Chagas' disease. Immunol Ser 1994; 60: 495-502.

[328] Muñoz-Fernández MA, Fernández MA, Fresno M. Synergism between tumor necrosis factor-alpha and interferon-gamma on macrophage activation for the killing of intracellular Trypanosoma 
cruzi through a nitric oxide-dependent mechanism. Eur J Immunol 1992; 22: 301-7.

[329] Muñoz-Fernández MA, Fernández MA, Fresno M. Activation of human macrophages for the killing of intracellular Trypanosoma cruzi by TNF-alpha and IFN-gamma through a nitric oxidedependent mechanism. Immunol Lett 1992; 33: 35-40.

[330] Burleigh BA. Host cell signaling and Trypanosoma cruzi invasion: do all roads lead to lysosomes? Sci STKE 2005; 2005 (293): pe36.

[331] Tardieux I, Webster P, Ravesloot J, et al. Lysosome recruitment and fusion are early events required for trypanosome invasion of mammalian cells. Cell 1992; 71: 1117-30.

[332] Tardieux I, Nathanson MH, Andrews NW. Role in host cell invasion of Trypanosoma cruzi-induced cytosolic-free $\mathrm{Ca}^{2+}$ transients. J Exp Med 1994; 179: 1017-22.

[333] Woolsey AM, Sunwoo L, Petersen CA, et al. Novel PI 3-kinasedependent mechanisms of trypanosome invasion and vacuole maturation. J Cell Sci 2003; 116: 3611-22.

[334] Andrade LO, Andrews NW. The Trypanosoma cruzi-host-cell interplay: location, invasion, retention. Nat Rev Microbiol 2005; 3 : 819-23.

[335] Maganto-Garcia E, Punzon C, Terhorst C, Fresno M. Rab5 activation by Toll-like receptor 2 is required for Trypanosoma cruzi internalization and replication in macrophages. Traffic 2008; 9: 1299-315.

[336] De Diego J, Punzon C, Duarte M, Fresno M. Alteration of macrophage function by a Trypanosoma cruzi membrane mucin. J Immunol 1997; 159: 4983-9.

[337] Ropert C, Ferreira LR, Campos MA, et al. Macrophage signaling by glycosylphosphatidylinositol-anchored mucin-like glycoproteins derived from Trypanosoma cruzi trypomastigotes. Microbes Infect 2002; 4: 1015-25.

[338] Kahn S, Wleklinski M, Aruffo A, et al. Trypanosoma cruzi amastigote adhesion to macrophages is facilitated by the mannose receptor. J Exp Med 1995; 182: 1243-58.

[339] Bafica A, Santiago HC, Goldszmid R, et al. Cutting edge: TLR9 and TLR2 signaling together account for MyD88-dependent control of parasitemia in Trypanosoma cruzi infection. J Immunol 2006; 177: 3515-19.

[340] Campos MA, Almeida IC, Takeuchi O, et al. Activation of Tolllike receptor- 2 by glycosylphosphatidylinositol anchors from a protozoan parasite. J Immunol 2001; 167: 416-23.

[341] Campos MA, Gazzinelli RT. Trypanosoma cruzi and its components as exogenous mediators of inflammation recognized through Toll-like receptors. Mediators Inflamm 2004; 13: 139-43.

[342] Novick P, Zerial M. The diversity of Rab proteins in vesicle transport. Curr Opin Cell Biol 1997; 9: 496-504.

[343] Simpson JC, Jones AT. Early endocytic Rabs: functional prediction to functional characterization. Biochem Soc Symp 2005; 72: 99108.

[344] Grosshans BL, Ortiz D, Novick P. Rabs and their effectors: achieving specificity in membrane traffic. Proc Natl Acad Sci USA 2006; 103: 11821-7.

[345] Duclos S, Diez R, Garin J, et al. Rab5 regulates the kiss and run fusion between phagosomes and endosomes and the acquisition of phagosome leishmanicidal properties in RAW 264.7 macrophages. J Cell Sci 2000; 113: 3531-41.

[346] McBride HM, Rybin V, Murphy C, et al. Oligomeric complexes link Rab5 effectors with NSF and drive membrane fusion via interactions between EEA1 and syntaxin 13. Cell 1999; 98: 377-86.

[347] Roberts RL, Barbieri MA, Ullrich J, Stahl PD. Dynamics of rab5 activation in endocytosis and phagocytosis. J Leukoc Biol 2000; 68: 627-32.

[348] Vieira OV, Bucci C, Harrison RE, et al. Modulation of Rab5 and Rab7 recruitment to phagosomes by phosphatidylinositol 3-kinase. Mol Cell Biol 2003; 23: 2501-14.

[349] Ley V, Robbins ES, Nussenzweig V, Andrews NW. The exit of Trypanosoma cruzi from the phagosome is inhibited by raising the pH of acidic compartments. J Exp Med 1990; 171: 401-13.

[350] Sacks D, Sher A. Evasion of innate immunity by parasitic protozoa. Nat Immunol 2002; 3: 1041-7.

[351] De Souza W, Ulisses de Carvalho TM, Barria ES. Review on Trypanosoma cruzi: host cell interaction. Int J Cell Biol 2010; 2010; pii: 295394

[352] Andrews NW, Whitlow MB. Secretion by Trypanosoma cruzi of a hemolysin active at low pH. Mol Biochem Parasitol 1989; 33: 24956.
[353] Rubin-de-Celis SS, Uemura H, Yoshida N, Schenkman S. Expression of trypomastigote trans-sialidase in metacyclic forms of Trypanosoma cruzi increases parasite escape from its parasitophorous vacuole. Cell Microbiol 2006; 8: 1888-98.

[354] Albertti LA, Macedo AM, Chiari E, Andrews NW, Andrade LO. Role of host lysosomal associated membrane protein (LAMP) in Trypanosoma cruzi invasion and intracellular development. Microbes Infect 2010; 12: 784-9.

[355] Howe C, Granger BL, Hull M, et al. Derived protein sequence, oligosacharides, and membrane insertion of the $120 \mathrm{kDa}$ lysosomal membrane glyocprotein (lgp120): identification of a highly conserved family of lysosomal membrane glycoproteins. Proc Natl Acad Sci USA 1988; 85: 7577-581.

[356] Eskelinen EL, Tanaka Y, Saftig P. At the acidic edge: emerging functions for lysosomal membrane proteins. Trends Cell Biol 2003; 13: $137-45$.

[357] Hall BF, Webster P, Ma AK, Joiner KA, Andrews NW. Desialylation of lysosomal membrane glycoproteins by Trypanosoma cruzi: a role for the surface neuraminidase in facilitating parasite entry into the host cell cytoplasm. J Exp Med 1992; 176: 313-25.

[358] Tanowitz H, Wittner M, Kress Y, Bloom B. Studies of in vitro infection by Trypanosoma cruzi. I. Ultrastructural studies on the invasion of macrophages and L-cells. Am J Trop Med Hyg 1975; 24: 25-33.

[359] McCabe RE, Remington JS, Araujo FG. Mechanisms of invasion and replication of the intracellular stage in Trypanosoma cruzi. Infect Immun 1984; 46: 372-6.

[360] McCabe RE, Remington JS, Araujo FG. Ketoconazole inhibition of intracellular multiplication of Trypanosoma cruzi and protection of mice against lethal infection with the organism. J Infect Dis 1984; 150: 594-601.

[361] Bogdan C, Röllinghoff M. How do protozoan parasites survive inside macrophages? Parasitol Today 1999; 15: 22-8.

[362] Russo DM, Barral-Netto M, Barral A, Reed SG. Human T cell responses in Leishmania infections. Prog Clin Parasitol 1993; 3: 119-144.

[363] Souza PE, Rocha MO, Menezes CA, et al. Trypanosoma cruzi infection induces differential modulation of costimulatory molecules and cytokines by monocytes and $\mathrm{T}$ cells from patients with indeterminate and cardiac Chagas' disease. Infect Immun 2007; 75: 1886-94.

[364] Faria DR, Gollob KJ, Barbosa J, et al. Decreased in situ expression of interleukin-10 receptor is correlated with the exacerbated inflammatory and cytotoxic responses observed in mucosal leishmaniasis. Infect Immun 2005; 73: 7853-9.

[365] Tarleton RL. Immune system recognition of Trypanosoma cruzi. Curr Opin Immunol 2007; 19:430-4.

[366] Martin DL, Postan M, Lucas P, Gress R, Tarleton RL. TGF-beta regulates pathology but not tissue $\mathrm{CD}^{+8} \mathrm{~T}$ cell dysfunction during experimental Trypanosoma cruzi infection. Eur J Immunol 2007; 37: 2764-71.

[367] Torrecilhas AC, Tonelli RR, Pavanelli WR, et al. Trypanosoma cruzi: parasite shed vesicles increase heart parasitism and generate an intense inflammatory response. Microbes Infect 2009; 11: 2939.

[368] Monteiro AC, Schmitz V, Svensjo E, et al. Cooperative activation of TLR2 and bradykinin B2 receptor is required for induction of type 1 immunity in a mouse model of subcutaneous infection by Trypanosoma cruzi. J Immunol 2006; 177: 6325-35.

[369] Alcaide P, Fresno M. The Trypanosoma cruzi membrane mucin AgC10 inhibits T cell activation and IL-2 transcription through Lselectin. Int Immunol 2004; 16: 1365-75.

[370] Rodrigues MM, Alencar BC, Carla Claser C, et al. Swimming against the current: genetic vaccination against Trypanosoma cruzi infection in mice. Mem Inst Oswaldo Cruz 2009; 104: 281-7.

[371] Soares MB, Lima RS, Rocha LL, et al. Transplanted bone marrow cells repair heart tissue and reduce myocarditis in chagasic mice. Am J Pathol 2004; 164: 441-7.

[372] Soares MBP, Santos RR. Current status and perpectives of cell therapy in Chagas disease. Mem Inst Oswaldo Cruz 2009; 104: 325-32.

[373] Pinazo MJ, Espinosa G, Gállego M, et al. Successful treatment with posaconazole of a patient with chronic Chagas disease and systemic lupus erythematosus. Am J Trop Med Hyg 2010; 82: 5837 . 
[374] Coura JR, De Castro SL. A critical review on Chagas disease chemotherapy. Mem Inst Oswaldo Cruz 2002; 97: 3-24.

[375] Maya JD, Cassels BK, Iturriga-Vásquez P, et al. Mode of action of natural and synthetic drugs against Trypanosoma cruzi and their interation with the mammalian host. Comp Biochem Physiol 2007; 146: 601-20.

[376] McKerrow JH, Doyle PS, Engle JC, et al. Two approaches to discovering and developing new drugs for Chagas disease. Mem Inst Oswaldo Cruz 2009; 104: 263-9.

[377] Schofield CJ, Jannin J, Salvatella R. The future of Chagas disese control. Trends Parasitol 2006; 22: 583-8.

[378] Zerba EN. Susceptibility and resistance to insecticides of Chagas disease vectors. Medicina (B Aires) 1999; 59 (Suppl 2): 41-6.

[379] Sonoda IV, Pessoa GC, Cortez MR, et al. Susceptibility of Triatoma infestans to deltamethrin in Rio Grande do Sul, Brazil. Mem Inst Oswaldo Cruz 2009; 104: 668-70.

[380] Germano MD, Vassena CV, Picollo MI. Autosomal inheritance of deltamethrin resistance in field populations of Triatoma infestans (Heteroptera: Reduviidae) from Argentina. Pest Manag Sci 2010; 66: 705-8.

[381] Cecchi G, Courtin F, Paone M, et al. Mapping sleeping sickness in Western Africa in a context of demographic transition and climate change. Parasite 2009; 16: 99-106.

[382] Raper J, Portela MP, Lugli E, Frevert U, Tomlinson S. Trypanosome lytic factors: novel mediators of human innate immunity. Curr Opin Microbiol 2001; 4: 402-8.

[383] Lai DH, Hashimi H, Lun ZR, Ayala FJ, Lukes J. Adaptations of Trypanosoma brucei to gradual loss of kinetoplast DNA: Trypanosoma equiperdum and Trypanosoma evansi are petite mutants of $T$. brucei. Proc Natl Acad Sci 2008; 105: 1999-2004.

[384] Cox FE. History of sleeping sickness (African trypanosomiasis). Infect Dis Clin N Am 2004; 2: 231-45.

[385] Kennedy PG. Diagnostic and neuropathogenesis issues in human African trypanosomiasis. Int J Parasitol 2006; 36: 505-12.

[386] Barrett MP, Burchmore RJ, Stich A, et al. The trypanosomiases. Lancet 2003; 362: 1469-80.

[387] Sternberg JM. Human African trypanosomiasis: clinical presentation and immune response. Parasite Immunol 2004; 26: 469-76.

[388] Simarro PP, Cecchi G, Paone M, et al. Towards the Atlas of human African trypanosomiasis. Int J Health Geogr 2009; 8: 15.

[389] Ferrante A, Allison AC. Alternative pathway activation of complement by African trypanosomes lacking a glycoprotein coat. Parasite Immunol 1983; 5: 491-8.

[390] Magez S, Stijlemans B, Baral T, De Baetselier P. VSG-GPI anchors of African trypanosomes: Their role in macrophage activation and induction of infection-associated immunopathology. Microb Infect 2002; 4: 999-1006.

[391] Pays E, Laurent M, Delinte K, Van Meirvenne N, Steinert M. Differential size variations between transcriptionally active and inactive telomeres of Trypanosoma brucei. Nucleic Acids Res 1983; 11: $8137-47$

[392] Taylor JE, Rudenko G. Switching trypanosome coats: what's in the wardrobe? Trends Genet 2006; 22: 614-20.

[393] Donelson JE. Antigenic variation and the African trypanosome genome. Acta Trop 2003; 85: 391-404.

[394] Morrison LJ, Marcello L, McCulloch R. Antigenic variation in the African trypanosome: molecular mechanisms and phenotypic complexity. Cell Microbiol 2009; 11: 1724-34.

[395] Mansfield JM. T-cell responses to the trypanosome variant surface glycoprotein: a new paradigm? Parasitol Today 1994; 10: 267-70.

[396] Sternberg JM, Maclean L. A spectrum of disease in Human African trypanosomiasis: the host and parasite genetics of virulence. Parasitol 2010; 21: 1-9.

[397] Baral TN. Immunobiology of African Trypanosomes: need of alternative interventions. J Biomed Biotechnol 2010; 2010: 389153

[398] Coller SP, Mansfield JM, Paulnock DM. Glycosylinositolphosphate soluble variant surface glycoprotein inhibits IFN- $\gamma$-induced nitric oxide production via reduction in STAT1 phosphorylation in African trypanosomiasis. J Immunol 2003; 171: 1466-72.

[399] Tachado SD, Schofield L. Glycosylphosphatidylinositol toxin of Trypanosoma brucei regulates IL- $1 \alpha$ and TNF- $\alpha$ expression in macrophages by protein tyrosine kinase mediated signal transduction. Biochem Biophys Res Commun 1994; 205: 984-91.

[400] Magez S, Radwanska M, Beschin A, Sekikawa K, De Baetselier P. Tumor necrosis factor alpha is a key mediator in the regulation of experimental Trypanosoma brucei infections. Infect Immun 1999; 67: 3128-32.

[401] Hertz CJ, Filutowicz H, Mansfield JM. Resistance to the African trypanosomes is IFN- $\gamma$ dependent. J Immunol 1998; 161: 6775-83.

[402] Uzonna JE, Kaushik RS, Gordon JR, Tabel H. Cytokines and antibody responses during Trypanosoma congolense infections in two inbred mouse strains that differ in resistance. Parasite Immunol 1999; 21: 57-71.

[403] Inoue N, Inoue M, Kuriki K, et al. Interleukin 4 is a crucial cytokine in controlling Trypanosoma brucei gambiense infection in mice. Vet Parasitol 1999; 86: 173-84.

[404] Mertens B, Taylor K, Muriuki C, Rocchi M. Cytokine mRNA profiles in trypanotolerant and trypanosusceptible cattle infected with the protozoan parasite Trypanosoma congolense: protective role for interleukin-4? J Interf Cytok Res 1999; 19: 59-65.

[405] Taylor KA. Immune responses of cattle to African trypanosomes: protective or pathogenic? Internat J Parasitol 1998; 28: 219-40.

[406] Darji A, Lucas R, Magez S, et al. Mechanisms underlying trypanosome-elicited immunosuppression. Annal Soc Belge Med Trop 1992; 72 (Suppl 1): 27-38.

[407] Flynn JN, Sileghem M. The role of the macrophage in induction of immunosuppression in Trypanosoma congolense-infected cattle. Immunology 1991; 74: 310-6.

[408] Sileghem M, Darji A, De Baetselier P. In vitro simulation of immunosuppresion caused by Trypanosoma brucei. Immunology 1991; 73: 246-8.

[409] D'Ieteren GD, Authie E, Wissocq N, Murray M. Trypanotolerance, an option for sustainable livestock production in areas at risk from trypanosomosis. OIE Revue Scientif Tech 1998; 17: 154-75.

[410] Vincendeau P, Bouteille B. Immunology and immunopathology of African trypanosomiasis. Ann Braz Acad Sci 2006; 78: 645-65.

[411] Reinitz DM, Mansfield JM. T-cell-independent and T-celldependent B-cell responses to exposed variant surface glycoprotein epitopes in trypanosome-infected mice. Infec Immun 1990; 58: 2337-42.

[412] Hudson KM, Terry RJ. Immunodepression and the course of infection of a chronic Trypanosoma brucei infection in mice. Paras Immunol 1979; 1: 317-26.

[413] Lambert PH, Berney M, Kazyumba G. Immune complexes in serum and in cerebrospinal fluid in African trypanosomiasis. Correlation with polyclonal B cell activation and with intracerebral immunoglobulin synthesis. J Clin Invest 1981; 67: 77-85.

[414] Lejon V, Buscher P, Magnus E, et al. A semi-quantitative ELISA for detection of Trypanosoma brucei gambiense specific antibodies in serum and cerebrospinal fluid of sleeping sickness patients. Acta Trop 1998; 69: 151-64.

[415] Radwanska M, Guirnalda P, De Trez C, et al. Trypanosomiasisinduced B cell apoptosis results in loss of protective anti-parasite antibody responses and abolishment of vaccine-induced memory responses. PLoS Pathog 2008; 4: e1000078.

[416] Bacchi CJ. Chemotherapy of human African trypanosomiasis. Interdiscip Perspect Infect Dis 2009; 2009: 195040.

[417] Gehrig S, Efferth T. Arsenicals (melarsoprol), pentamidine and suramin in the treatment of human African trypanosomiasis. Parasitol Res 2003; 90: 71-9.

[418] Barrett MP, Boykin DW, Brun R, Tidwel RR. Human African trypanosomiasis: pharmacological re-engagement with a neglected disease. Br J Pharmacol 2007; 152: 1155-71.

[419] Gehrig S, Efferth T. Development of drug resistance in Trypanosoma brucei rhodesiense and Trypanosoma brucei gambiense. Treatment of human African trypanosomiasis with natural products. Int J Mol Med 2008; 22: 411-9.

[420] Koning HP, Lüscher A, Mäser P. Chemotherapeutic strategies against Trypanosoma brucei: drug targets vs. drug targeting. Curr Pharm Des 2007; 13: 555-67.

[421] Priotto G, Kasparian S, Mutombo W, et al. Nifurtimox-efl ornithine combination therapy for second-stage African Trypanosoma brucei gambiense trypanosomiasis: a multicentre, randomised, phase III, non-inferiority trial. Lancet 2009; 374: 56-64.

[422] Berriman M, Ghedin E, Hertz-Fowler C, et al. The genome of the African trypanosome Trypanosoma brucei. Science 2005; 309: 416-22.

[423] Lança AS, de Sousa KP, Atouguia J, et al. Trypanosoma brucei: Immunisation with plasmid DNA encoding invariant surface glycoprotein gene is able to induce partial protection in experimental African trypanosomiasis. Exp Parasitol 2010; in press. 
[424] Silva MS, Prazeres DM, Lança A, et al. Trans-sialidase from Trypanosoma brucei as a potential target for DNA vaccine development against African trypanosomiasis. Parasitol Res 2009; 105: 1223-9.

[425] Lainson R, Shaw JJ. Epidemiology and ecology of leishmaniasis in Latin-America. Nature 1978; 273: 595-600.

[426] El-On J. Current status and perspectives of the immunotherapy of leishmaniasis. Isr Med Assoc J 2009; 11: 623-8.

[427] Lainson R, Shaw J. Evolution, classification and geographical distribution. In The Leishmaniasis in Biology and Medicine, Biology and Epidemiology. Peters W, Killick-Kendrick R. Eds. London: Academic Press 1987; 1: 1-120.

[428] Beverley SM, Ismach R, McMahon-Pratt D. Proc. Evolution of the genus Leishmania as revealed by comparisons of nuclear DNA restriction fragment patterns Proc Natl Acad Sci USA 1987; 84: 4848.

[429] Wortmann G, Hochberg L, Houng H, et al. Rapid Identification of Leishmania complexes by a real-time PCR assay. Am J Trop Med Hyg 2005; 73: 999-1004.

[430] Lukes J, Mauricio IL, Schonian G, et al. Evolutionary and geographical history of the Leishmania donovani complex with a revision of current taxonomy. Proc Natl Acad Sci USA 2007; 104: 9375-80.

[431] Luis L, Ramirez AH, Ramirez R, Velez ID, Mendoza-Leon A. Nuclear DNA sequence specific to Leishmania (Viannia) subgenus: a molecular marker for species identification. Parasitol 2001; 122: 405-14.

[432] Berman JD. Human leishmaniasis: clinical, diagnostic and therapeutic developments in the last 10 years. Clin Infect Dis 1997; 24: 684-703.

[433] Besteiro S, Williams RA, Coombs GH, Mottram JC. Protein turnover and differentiation in Leishmania. Int J Parasitol 2007; 37:1063-75.

[434] McConville MJ, Blackwell JM. Developmental changes in the glycosylated phosphatidylinositols of Leishmania donovani. Characterization of the promastigote and amastigote glycolipids. J Biol Chem 1991; 266: 15170-9.

[435] Capul AA, Hickerson S, Barron T, et al. Comparisons of mutants lacking the Golgi UDP-galactose or GDP-mannose transporters establish that phosphoglycans are important for promastigote but not amastigote virulence in Leishmania major. Infect Immun 2007; 75: 4629-37.

[436] Devault A, Bañuls AL. The promastigote surface antigen gene family of the Leishmania parasite: differential evolution by positive selection and recombination. BMC Evol Biol 2008; 8: 292.

[437] Guimarães-Costa AB, Nascimento MT, Froment GS, et al. Leishmania amazonensis promastigotes induce and are killed by neutrophil extracellular traps. Proc Natl Acad Sci USA 2009; 106: 6748-53.

[438] Brinkmann V, Zychlinsky A. Beneficial suicide: why neutrophils die to make NETs. Nat Rev Microbiol 2007; 5: 577-82.

[439] Vouldoukis I, Riveros-Moreno V, Dugas B, et al. The killing of Leishmania major by human macrophages is mediated by nitric oxide induced after ligation of the Fc epsilon RII/CD23 surface antigen. Proc Natl Acad Sci USA 1995; 92: 7804-8.

[440] Kropf P, Freudenberg MA, Modolell M, et al. 2004. Toll-like receptor 4 contributes to efficient control of infection with the protozoan parasite Leishmania major. Infect Immun 2004; 72: 1920-8.

[441] Whitaker SM, Colmenares M, Pestana KG, McMahon-Pratt D. Leishmania pifanoi proteoglycolipid complex P8 induces macrophage cytokine production through Toll-like receptor 4 . Infect Immun 2008; 76: 2149-56.

[442] Dondji B, Pérez-Jimenez E, Goldsmith-Pestana K, Esteban M, McMahon-Pratt D. Heterologous prime-boost vaccination using LACK antigen protects against murine visceral leishmaniasis. Infect Immun 2005; 73: 5286-9.

[443] Borja-Cabrera GP, Correia Pontes NN, da Silva VO, et al. Long lasting protectionagainst canine kala-azar using the FML-QuilA saponin vaccine in anendemic area of Brazil (São Gonçalo do Amarante). Vaccine 2002; 20: 3277-84

[444] Palatnik-de-Sousa CB. Vaccines for leishmaniasis in the fore coming 25 years. Vaccine 2008; 26: 1709-24.

[445] Borja-Cabrera GP, Santos FN, Santos FB, et al. Immunotherapy with the saponin enriched-Leishmune vaccine versus immunochemotherapy in dogs with natural canine visceral leishmaniasis. Vaccine 2010; 28: 597-603.
[446] Seifert K, Lemke A, Croft SL, Kayser O. Antileishmanial structure-activity relationships of synthetic phospholipids: in vitro and in vivo activities of selected derivatives. Antimicrob Agents Chemother 2007; 51: 4525-8.

[447] Croft SL, Seifert K, Yardley V. Current scenario of drug development for leishmaniasis. Indian J Med Res 2006; 123: 399-410.

[448] Jankevicius JV, Jankevicius SI, Campaner M, et al. Life cycle and culturing of Phytomonas serpens (Gibbs), a trypanosomatid parasite of tomatoes. J Protozool 1989; 36: 265-71.

[449] Camargo EP, Wallace FG. Vectors of plant parasites of the genus Phytomonas (Protozoa, Zoomastigophorea, Kinetoplastida) In: Advances in disease vector research. New York: Springer-Verlag Inc. 1994; Vol. X: pp. 333-59.

[450] Jankevicius JV, Itow-Jankevicius S, Maeda LA, et al. Biological cycle of Phytomonas. Mem Inst Oswaldo Cruz 1988; 83 Suppl 1: 601-10.

[451] Schaub GA, Jensen C. Developmental time and mortality of the reduviid bug Triatoma infestans with differential exposure to coprophagic infections with Blastocrithidia triatomae (Trypanosomatidae). J Invertebr Pathol 1990; 55: 17-27.

[452] França C. La flagellose des euphorbes. Annales de l'Institut Pasteur 1920; 34: 432-65.

[453] Dollet M, Cambrony D, Gargani D. Culture axenique in vitro de Phytomonas sp. (Trypanosomatidae) d'Euphorbe transmis par Stenocephalus agilis Scop. (Coreidae). C R Acad Sci D Ser III Paris 1982; 295: 547-50.

[454] McCoy RE. Mycoplasmas and yellow diseases. In The Mycoplasmas. Plant and Insect Mycoplasmas. Whitcomb RF, Tully JG. Eds. 3:229-264. New York/San Francisco/London: Academic. 1979; 351.

[455] Serrano MG, Camargo EP, Teixeira MM. Phytomonas: analysis of polymorphism and genetic relatedness between isolates from plants and phytophagous insects from different geographic regions by RAPD fingerprints and synapomorphic markers. J Eukaryot Microbiol 1999; 46: 618-25.

[456] Sturm NR, Dollet M, Lukes J, Campbell DA. Meaningful subdivision of plant trypanosomes (Phytomonas spp.) based on minicircle conserved region analysis. Infect Genet Evol 2007; 7: 570-6.

[457] Dollet M, Sturm NR, Sánchez-Moreno M, Campbell DA. 5S ribosomal RNA gene repeat sequences define at least eight groups of plant trypanosomatids (Phytomonas spp.): phloem-restricted pathogens form a distinct section. J Eukaryot Microbiol 2000; 47: 56974 .

[458] Votypka J, Maslov DA, Yurchenko V, et al. Probing into the diversity of trypanosomatid flagellates parasitizing insect hosts in SouthWest China reveals both endemism and global distribution. Mol Phyl Evol 2010; 54: 243-53.

[459] Vickerman K, Preston TM. Comparative cell biology of the kinetoplastid flagelltes. In: Biology of Kinetoplastid. New York: Academic Press 1976.

[460] Lafont A. Sur la presénce d'un parasite de la classe des Flagellés dans le latex de l'Euphorbia pilulifera. C R Soc Biol 1909; 66: 1011-3.

[461] Lafont A. Sur la presence d'un Leptomonas, parasite de la classe des Flagellés, dans le latex de trois Euphorbiacées. Annales de l'Institut Pasteur Paris 1910; 24: 205-19.

[462] Attias M, Teixeira MM, Camargo EP, De Souza W. Immunocytochemical localization of antigenic sites in some Phytomonas isolates using monoclonal antibodies to Phytomonas serpens. Biocell 1993; 17: 89-93.

[463] Camargo EP. Phytomonas and other trypanosomatid parasites of plants and fruit. Adv Parasitol 1999; 42: 29-112.

[464] Chaumont F, Schanck AN, Blum JJ, Opperdoes FR. Aerobic and anaerobic glucose metabolism of Phytomonas sp. isolated from Euphorbia characias. Mol Biochem Parasitol 1994; 67: 321-31.

[465] Nawathean P, Maslov DA. The absence of genes for cytochrome c oxidase and reductase subunits in maxicircle kinetoplast DNA of the respiration-deficient plant trypanosomatid Phytomonas serpens. Curr Genet 2000; 38: 95-103.

[466] Nebohacova M, Kim CE, Simpson L, Maslov DA. RNA editing and mitochondrial activity in promastigotes and amastigotes of Leishmania donovani. Int J Parasitol 2009; 39: 635-44.

[467] Maslov DA, Nawathean P, Scheel J. Partial kinetoplastmitochondrial gene organization and expression in the respiratory 
deficient plant trypanosomatid Phytomonas serpens. Mol Biochem Parasitol 1999; 99: 207-21.

[468] D'Avila-Levy CM, Santos LO, Marinho FA, et al. gp63-like molecules in Phytomonas serpens: possible role in the insect interaction. Curr Microbiol 2006; 52: 439-44.

[469] D'Avila-Levy CM, de Almeida Dias F, Nogueira de Melo AC, et al. Insights into the role of gp63-like proteins in lower trypanosomatids. FEMS Microbiol Lett 2006; 254: 149-56.

[470] Elias CG, Pereira FM, Dias FA, et al. Cysteine peptidases in the tomato trypanosomatid Phytomonas serpens: influence of growth conditions, similarities with cruzipain and secretion to the extracellular environment. Exp Parasitol 2008; 120: 343-52.

[471] Elias CG, Aor AC, Valle RS, et al. Cysteine peptidases from Phytomonas serpens: biochemical and immunological approaches. FEMS Immunol Med Microbiol 2009; 57: 247-56.

[472] Santos AL, D'Avila-Levy CM, Dias FA, et al. Phytomonas serpens: cysteine peptidase inhibitors interfere with growth, ultrastructure and host adhesion. Int J Parasitol 2006; 36: 47-56.

[473] Pinge-Filho P, Peron JP, de Moura TR, et al. Protective immunity against Trypanosoma cruzi provided by oral immunization with
Phytomonas serpens: role of nitric oxide. Immunol Lett 2005; 96: 283-90.

[474] Camargo EP, Sbravate C, Teixeira MM, et al. Ribosomal DNA restriction analysis and synthetic oligonucleotide probing in the identification of genera of lower trypanosomatids. J Parasitol 1992; 78: 40-8.

[475] Hollar L, Maslov DA. A phylogenetic view on the genus Phytomonas. Mol Biochem Parasitol 1997; 89: 295-9.

[476] Dollet M. Phloem-restricted trypanosomatids form a clearly characterised monophyletic group among trypanosomatids isolated from plants. Int J Parasitol 2001; 31: 459-67.

[477] Marín C, Alberge B, Dollet M, Pagès M, Bastien P. First complete chromosomal organization of a protozoan plant parasite (Phytomonas spp.). Genomics 2008; 91: 88-93.

[478] Marín C, Dollet M, Pagès M, Bastien P. Large differences in the genome organization of different plant Trypanosomatid parasites (Phytomonas spp.) reveal wide evolutionary divergences between taxa. Infect Genet Evol 2009; 9: 235-40.

Received: November 15, 2009

(C) Lopes et al.; Licensee Bentham Open.

This is an open access article licensed under the terms of the Creative Commons Attribution Non-Commercial License (http://creativecommons.org/licenses/by-nc/3.0/) which permits unrestricted, non-commercial use, distribution and reproduction in any medium, provided the work is properly cited. 